\title{
CONF-9009267-.1
}

\section{RADIATION INTERACTIONS IN HIGH-PRESSURE GASES 1}

\author{
Loucas G. Christophorou \\ Atomic, Molecular, and High Voltage Physics Group \\ Health and Safety Research Division \\ Oak Ridge National Laboratory \\ Oak Ridge, Tennessee 37831 USA
}

CONF-9009267--1

DE9 1000732

and

Department of Physics

The University of Tennessee

Knoxville, Tennessee 37996 USA

\section{INTRODUCTION}

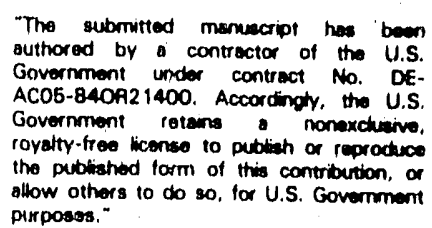

The understanding of radiobiological effects and mechanisms necessitates knowledge on (i) the basic phenomena and processes involved in the interaction of ionizing radiation with matter, and (ii) the effects of the density, nature, and state of matter on these basic phenomena and processes. Our knowledge in this area- -especially on gases at or below atmospheric pressures - - advanced phenomenally in the last two decades, and has illuminated the fields of radiobiological science and impacted broadly on pure science, applied science and engineering. The previous chapters concentrated on (i) and we shall now focus on aspects of (ii).

The effects of the nature, density, and state of the medium are generally small for low-lying valence states, but they are profound for quasi-charge separated states (e.g., high $\mathrm{n}$-Rydberg states), charge-separated states (electrons; positive and negative ions) transient negative ion states, and the physical quantities which describe their behavior and reactions. Thus, for example, the electron energy $\epsilon$, the quasi-free (excess) electron "ground state" energy $V_{0}$, the electron drift velocity $w$, the electron mobility $\mu$, the cross se',tions for electron scattering $\sigma_{\mathrm{sc}^{\prime}}$, electron attachment $\sigma_{\mathrm{a}}$, dissociative attachment $\sigma_{\mathrm{da}}$ '

1Research sponsored by the Office of Health and Environmental Research, U.S. Department of Energy, under Contract No. DE-AC05-84OR.21400 with Martin Marietta Energy Systems, Inc. 
autodetachment $\sigma_{a d}$, ionization $\sigma_{i}$, and the associated physical quantities [e.g., the electron affinity $\mathrm{EA}$, the vertical attachment energy $\mathrm{VAE}$, the vertical detachment energy VDE, the ionization threshold energy I, and the polatization energy of the positive $\left(\mathrm{P}^{+}\right)$and the negative $\left(\mathrm{P}^{-}\right)$ions] are all strong functions of the nature and density of the medium in which these elementary physical processes occur. While these physical quantities have well-defined values at low-gas number densities, they assume a spectrum of values in dense media. Understanding these effects is a prerequisite for the successful use of physicochemical knowledge in establishing mechanisms of radiobiological action and in developing novel radiobiological instrumentation.

This article is on basic radiation interaction processes in dense fluids and on interphase studies aiming a.t the interfacing of knowledge on radiation interaction processes in the gaseous and the liquid state of matter. It is specifically focused on the effect of the density and nature of the medium on electron production in irradiated fluids and on the state, energy, transport, and attachment of slow excess electrons in dense fluids especially dielectric liquids which possess excess-electron conduction bands ( $V_{0}<0$ eV) [1-4]. Studies over the past two decades have shown that the interactions of low-energy electrons with molecules embedded in dense media depend not only on the molecules themselves [1-7] and their internal state of excitation [8-10], but also on the electron state and energy in - - and the nature and density of - - the medium in which the interactions occur $[3,4,11,12]$.

\section{ELECTRON PRODUCTION IN DENSE FLUIDS}

\section{A. Total and Free Electron Yields}

The processes by which isolated atoms and molecules are ionized by radiation, and the corresponding cross sections, have been well studied and are reasonably well understood $[1,2,5-7]$. Measurements of electron impact ionization cross sections $\sigma_{i}(\varepsilon)$ in gases are, for example, abundant. This, however, can not be said of dense fluids. In these, there exist measurements of only the density, $N$, normalized ionization coeffacieni $\alpha / N$ ás a füntitioñ of 
the density-reduced electric field $\mathrm{E} / \mathrm{N}$ (Fig. 1) at relatively low pressures $\left(\lesssim 5 \times 10^{10}\right.$ molecules $\mathrm{cm}^{-3}$ ): In this gas density range, $\alpha / \mathrm{N}$ is generally independent of $\mathrm{N}$. This, however, is expected not to be the case for dense gases $\left(\mathrm{N} \gtrsim 10^{20}\right.$ molecules $\mathrm{cm}^{-3}$ ) and liquids. An indirect measurement [15] of $\alpha(\mathrm{E} / \mathrm{N})$ for liquid Xe, for example, has indicated that it does not scale from the gaseous value by considering the density difference between the gas and the liquid.

While the effect of $N$ on $\sigma_{i}(\varepsilon)$ and $\alpha / \mathrm{I}(\mathrm{E} / \mathrm{N})$ is largely unknown, many studies (e.g., $2-4,16$ ) have shown that the total, $G_{t e}$, and especially the free, $G_{f e}$, electron yield are strong functions of the density and state - gaseous (G), liquid (L) or solid (S)- $\multimap$ of matter. At least for the heavier rare gases ( $\mathrm{Ar}, \mathrm{Kr}, \mathrm{Xe}$ )

$$
\left(G_{t e}\right)_{L}>\left(G_{t e}\right)_{G}
$$

and for all liquids

$$
\left(\mathrm{G}_{\mathrm{fe}}\right)_{\mathrm{L}}<<\left(\mathrm{G}_{\mathrm{fe}}\right)_{\mathrm{G}}
$$

The inequality (2) is especially profound for densely ionizing (high LET) particles (Table 1). The primary reason for (1) is the lowering of the isolated atom's minimum ionization energy $I_{G}$ when the atcm is embedded in the dense medium. The primary reason for (2) is the profound effect of geminate recombination on $\left(\mathrm{G}_{\mathrm{fe}}\right)_{\mathrm{L}}$, especially for high LET particles. Understanding electron production in dense fluids, then, requires an understanding of the density dependence of the ionization cross sections and energetics and electron-positive ion recombination.

\section{DISCLAIMER}

\footnotetext{
This report was prepared as an account of work sponsored by an agency of the United States Government. Neither the United States Government nor any agency thereof, nor any of their employees, makes any warranty, express or implied, or assumes any legal liability or responsibility for the accuracy, completeness, or usefulness of any information, apparatus, product, or process discinsed, or represents that its use would not infringe private!y owned rights. Reference herein to any specific commercial product, process, or service by trade name, trademark, manufacturer, or otherwise does rot necessarily constitute or imply its endorsement, recommendation, or favoring by the United States Government or any agency thereof. The views and opinions of authors expressed herein do not necessarily state or reflect those of the United States Government or any agency thereof.
} 
Table 1: Electron Yields in Dielectric Liquids with Excess Electron Conduction Bands $\left(\mathrm{V}_{0}<0 \mathrm{eV}\right)$

Electron Yield (Electrons/100 eV Fnergy Absorbed)

\begin{tabular}{|c|c|c|c|c|c|}
\hline Liquid & $G_{\text {te }}(e, \gamma, x)^{a}$ & \multicolumn{2}{|c|}{$\mathrm{G}_{\mathrm{fe}}(\mathrm{e}, \gamma, \mathrm{x})^{\mathrm{a}}$} & $\mathrm{G}_{f \mathrm{e}^{\mathrm{E}}}^{(\alpha)^{\mathrm{b}}}$ & Gas: $G_{t e} \simeq G_{f e}{ }^{c}$. \\
\hline & & $\mathrm{E}^{\mathrm{d}}=0$ & $\mathrm{E}>0$ & $E>0$ & \\
\hline $\operatorname{Ar}(87 \mathrm{~K})$ & $4.2 \mathrm{e}$ & $\begin{array}{l}2.3^{\mathrm{f}} \\
2.7^{\mathrm{h}}\end{array}$ & $\begin{array}{l}4.4^{\mathrm{f}, \mathrm{g}} \\
4.15^{\mathrm{f}, \mathrm{g}}\end{array}$ & $\begin{array}{l}0.45^{f}, g \\
0.46^{f}, g \\
0.38^{f}, g\end{array}$ & 3.8 \\
\hline $\mathrm{Kr}(129 \mathrm{~K})$ & $\begin{array}{l}6.0^{\mathrm{h}} \\
4.9^{\mathrm{i}}\end{array}$ & $4.0^{\mathrm{h}}$ & $\therefore$ & - & 4.2 \\
\hline $\mathrm{Xe}(155 \mathrm{~K})$ & $6.4 \mathrm{e}$ & $4.4^{\mathrm{h}}$ & - & - & 4.6 \\
\hline $\mathrm{C}\left(\mathrm{CH}_{3}\right)_{4}(\sim 296 \mathrm{~K})$ & $4.3^{j}$ & $\begin{array}{l}1.1^{\mathrm{f}} \\
1.0^{\mathrm{k}}\end{array}$ & $1.18^{f, g}$ & $0.036^{f}, \mathrm{~g}$ & - \\
\hline $\mathrm{S}_{\mathrm{i}}\left(\mathrm{CH}_{3}\right)_{4}(\sim 296 \mathrm{~K})$ & - & $0.74^{\mathrm{f}}, 1$ & $\begin{array}{l}1.19^{f}, g \\
0.98^{m}, g\end{array}$ & $\begin{array}{l}0.029^{\mathrm{f}, \mathrm{g}} \\
0.075^{\mathrm{n}}\end{array}$ & $\begin{array}{c}4.20 \\
-\end{array}$ \\
\hline $\mathrm{G}_{\mathrm{e}}\left(\mathrm{CH}_{3}\right)_{4}(\sim 296 \mathrm{~K})$ & - & - & $0.95^{\mathrm{m}, \mathrm{g}}$ & - & - \\
\hline $\mathrm{S}_{\mathrm{n}}\left(\mathrm{CH}_{3}\right)_{4}(\sim 296 \mathrm{~K})$ & - & $0.62^{1}$ & $1.15 \mathrm{~m}, \mathrm{~g}$ & - & - \\
\hline$\left(\mathrm{CH}_{3}\right)_{3} \mathrm{CCH}_{2} \mathrm{C}\left(\mathrm{CH}_{3}\right)_{3}$ & - & $\begin{array}{l}0.73^{f}, g \\
0.83 p^{2}\end{array}$ & $\begin{array}{l}1.1^{\mathrm{f}}, \mathrm{g} \\
1.14^{\mathrm{m}, \mathrm{g}}\end{array}$ & $0.025^{f}, g$ & - \\
\hline
\end{tabular}

aFor low-ionization density radiation [electrons $(e), \gamma$-rays $(\gamma), x$-rays $(x)$ ].

bFor high-ionization density radiation $[\alpha$-particles $(\alpha)]$.

cValue for low-pressure gas determined frnm the W-data (eV per ion pair) in Ref. 1 unless otherwise noted.

dApplied electric field.

$\mathrm{e}[11] ; \mathrm{f}[17] ; \mathrm{g}\left[\mathrm{E}=10^{4} \mathrm{~V} \mathrm{~cm}-1\right] ; \mathrm{h}[19] ; \mathrm{i}[20] ; \mathrm{j}[16] ; \mathrm{k}[21] ; 1[22] ; \mathrm{m}[23] ; \mathrm{n}[24] ; \mathrm{o}[25] ; \mathrm{p}[26]$. 


\section{B. Ionization Threshold Energy and Its Dependence on the Nature and Density of the Medium}

In contrast to the almost complete absence of studies on electron-impact jonization of atoms and molecules in dense fluids, there exist a number of investigations on the photoionization processes and energetics of molecules in dense media [e.g., 11,27--34]. In Table 2 are listed the ionization threshold energies $\mathrm{I}_{\mathrm{L}}$ of a number of dielectric liquids, and of two organic molecules in dielectric liquids for which $\mathrm{V}_{0}$ is known. The data on pure liquids were obtained using UV photoconductivity techniques and assumed photoionization threshold laws. The dita for the two organic molecules in dielectric liquids were obtained using a laser multiphoton ionization conductivity method and carefully monitoring the order of the multiphoton ioniz ation process(es). Figure 2 shows this for the case of azulene in 2,2,4,4-tetramethylpentane (TMP). When the two-photon energy lies well above $\mathrm{I}_{\mathrm{L}}$ [at $5.70 \mathrm{eV}$; (Fig. 2b)], the probability of electron escape is large and two-photon ionization is the predominant multiphoton ionization mechanism. When, however, the two-photon energy approaches $I_{L}$, the geminate electron-ion pair recombines, and ionization occurs predominantly via three-photon ionization. This latter process (Fig. 2b) occurs via two-photon absorption to a high-lying state at energies $\lesssim \mathrm{I}_{\mathrm{L}}$ which converts internally to a lower-lying long-lived state (second excited $x$-singlet state $S_{2}$ for azulene) from which a third photon leads to the ionization continuum high above $\mathrm{I}_{\mathrm{L}}$. The two-photon ionization onset $I_{L}$ was taken to be at that laser wavelength where the two- and three-photon ionization processes contribute, respectively, 10 and $90 \%$ of the total photoionization signal, i.e., when the overall order of multiphoton ionization $S=2.9$. This method is accurate, but requires proper identification of the ionization mechanisms which often become complicated depending on the characteristics of the laser pulse and those of the excited electronic states involved, especially their lifetimes, and intramolecular relaxation pathways [33]. The transition to the continuum by absorption of a photon by 
the excited molecule is both a function of the energy of the absorbed photon and of the particular electronic/vibrational state involved in the process.

The data in Table 2 (and other similar measurements $[11,28,42]$ ) show that $\mathrm{I}_{\mathrm{L}}$ ' is related to $\mathrm{I}_{\mathrm{G}}$ by $[43]^{\mathrm{a}}$

$$
\mathrm{I}_{\mathrm{L}}=\mathrm{I}_{\mathrm{G}}+\mathrm{V}_{\mathrm{O}}+\mathrm{P}^{+}
$$

The polarization energy of the positive ion in the medium $\mathrm{P}^{+}$is a negative quantity which is usually approximated by the Born charging energy [44] (see, however, $[33,45]$ )

aBy analogy, the electron affinity of a molecule in the liquid, $(E A)_{L}$, is related to that, $(\mathrm{EA})_{\mathrm{G}}$, in the low-pressure gas by $(\mathrm{EA})_{\mathrm{L}}=(\mathrm{EA})_{\mathrm{G}}+\mathrm{V}_{\mathrm{O}}-\mathrm{P}^{-}$where $\mathrm{P}^{-}$is the difference in the solvation energies of the neutral molecule and its anion in the liquid. Since $\mathrm{P}^{-}$is always a negative quaritity and, as a rule, much larger in absolute magnitude than $\mathrm{V}_{0^{\prime}}$ $(\mathrm{EA})_{\mathrm{L}}>(\mathrm{EA})_{\mathrm{G}}$. Photodetachment $\left(\mathrm{M}_{\mathrm{L}}-\mathrm{h} \nu \longrightarrow \mathrm{M}_{\mathrm{L}}+\mathrm{e}_{\mathrm{L}}\right)$ studies in dense fluids are scarce and must be undertaken. 
Table 2: Ionization threshold energies $\mathrm{I}_{\mathrm{L}}$ for a number of dielectric liquids and corresponding low-pressure gas values $I_{G}$ along with the $V_{0}$ values of these liquids. $I_{G}$ values for azulene and fluoranthene and the $\mathrm{I}_{\mathrm{L}}$ values for these two molecules in various dielectric liquids.

\begin{tabular}{|c|c|c|c|}
\hline Liquid & $\mathrm{I}_{\mathrm{L}}(\mathrm{eV})^{\mathrm{a}}$ & $\mathrm{I}_{\mathrm{G}}(\mathrm{eV})^{\mathrm{b}}$ & $V_{0}(e V) c$ \\
\hline 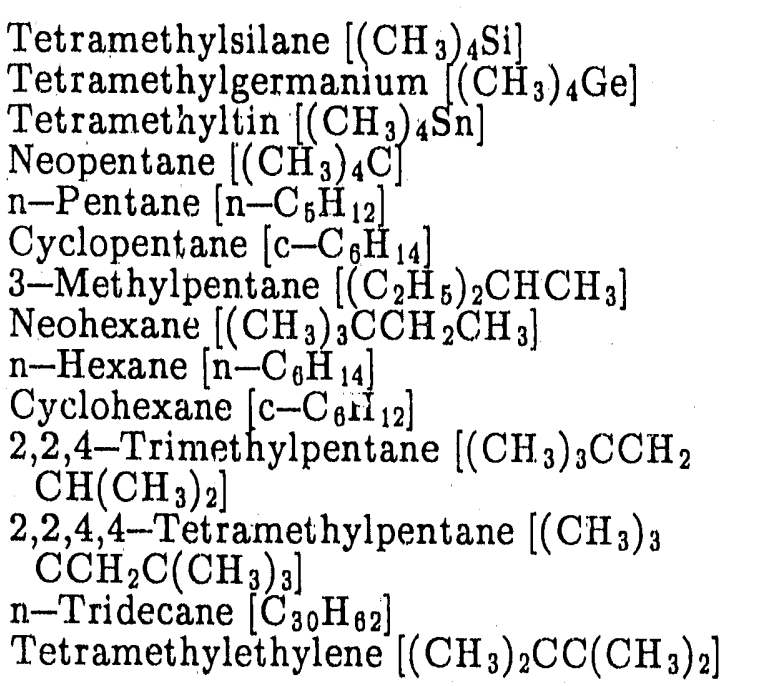 & $\begin{array}{l}8.1 \mathrm{~d} ; 8.05^{\mathrm{e}} \\
7.6 \mathrm{~d} \\
6.9 \mathrm{~d} \\
8.55^{\mathrm{d}}, \mathrm{e} \\
9.15^{\mathrm{d}} ; 8.86 \mathrm{e} \\
8.82^{\mathrm{e}} \\
8.85^{\mathrm{d}} \\
8.73^{\mathrm{d}} ; 8.49 \mathrm{e} \\
8.70^{\mathrm{e}} \\
8.75^{\mathrm{d}} ; 8.43^{\mathrm{e}} \\
8.38^{\mathrm{e}} \\
8.2^{\mathrm{f}} \\
9.25^{\mathrm{d}} \\
6.80^{\mathrm{d}}\end{array}$ & $\begin{array}{c}9.65 \\
9.35 \\
8.89 \\
10.23 \\
10.28 \\
10.53 \\
10.08 \\
10.06 \\
10.22 \\
9.87 \\
9.86 \\
9.5 \\
\\
10.03 \\
8.30\end{array}$ & $\begin{array}{l}-0.55 \\
-0.64 \\
-0.75 \\
-0.43 \\
+0.01 \\
-0.22 \\
+0.01 \\
-0.22 \\
+0.07 \\
+0.01 \\
-0.17 \\
-0.36 \\
+0.21 \\
-0.24\end{array}$ \\
\hline $\begin{array}{l}\text { Azulene in } \\
\text { Tetramethyltin } \\
\text { Tetramethylsilane } \\
2,2,4,4-\text { Tetramethylpentane } \\
\text { n-Pentane } \\
\text { n-Tridecane } \\
\text { Fluoranthene in } \\
\text { Tetramethylsilane }\end{array}$ & $\begin{array}{l}5.33 \mathrm{~g} \\
5.45 \mathrm{~g} \\
5.70 \mathrm{~g} \\
6.12 \mathrm{~g} \\
6.28 \mathrm{~g} \\
5.70 \mathrm{~h}\end{array}$ & $7.42 \mathrm{~g}$ & \\
\hline $\begin{array}{l}\mathrm{Ar} \\
\mathrm{Kr} \\
\mathrm{Xe}\end{array}$ & $\begin{array}{l}\sim 14.1[87 \mathrm{~K}]^{\mathrm{i}} \\
11.55[121 \mathrm{~K}]^{1} \\
9.2[165 \mathrm{~K}]^{1} \\
8.9^{\mathrm{m}}\end{array}$ & $\begin{array}{l}15.755 \mathrm{j} \\
13.996 \mathrm{j} \\
12.127 \mathrm{j}\end{array}$ & $\begin{array}{l}-0.20 k \\
k \\
-0.61 k\end{array}$ \\
\hline
\end{tabular}

$\mathrm{a} T \simeq 295 \mathrm{~K}$ inless otherwise indicated.

$\checkmark$ A verage of photoionization and photoelectron values given in Ref. 35 .

cUnless otherwise indicated, from Refs. 11, 36 and 37.

d[32,38]; e[31]; f[39]; g[33]; h[40]; i[11]; j[1]; k[see Fig. 5]; 1[30]: m[41]. 


$$
\mathrm{P}^{+}=-\frac{\mathrm{e}^{2}}{2 \mathrm{R}}\left(1-\frac{1}{\epsilon}\right)
$$

where $\epsilon$ is the optical dielectric constant of the medium. The fact that the measurements follow (3) shows that in the dense fluid the polarization dynamics are very fast $(<\mathrm{ps})$. For the systems in Table 2, the average values of $\mathrm{P}^{+}$and $\epsilon$ are $-1.273 \pm 0.156 \mathrm{eV}$ and $\sim 1.94$, respectively, which give a mean value for the effective radius $\mathrm{R}$ of the positive ion cavity of $\sim 2.74 \AA$.

The energy difference $I_{L}-I_{G}(\sim-1$ to $-3 \mathrm{eV}$ for organic molecules in nonpolar liquids) is, then, given by $\mathrm{P}^{+}+\mathrm{V}_{\mathrm{O}}$ and the effect of the medium and its density on $\mathrm{I}_{\mathrm{L}}$ is a manifestation of that on $\mathrm{P}^{+}$and $\mathrm{V}_{0}$.

The gradual lowering of $\mathrm{I}_{\mathrm{G}}$ to its $\mathrm{I}_{\mathrm{L}}$ value in going from the low-pressure gas to the liquid can be seen from Fig. 3 (see, also [29], [30], [34]). Here the ionization onset energy $\mathrm{I}_{\mathrm{F}}$ of the molecule TMPD ( $\mathrm{N}, \mathrm{N}, \mathrm{N}^{\prime}, \mathrm{N}^{\prime}$--tetramethyl-p-phenylenediamine) mixed with $\mathrm{C}_{2} \mathrm{H}_{6}$ was measured [34] as a function of the density of the latter from the low-pressure gas to the liquid and in the liquid itself. The $\mathrm{I}_{\mathrm{F}}$ decreases with increasing gas density and temperatureb. The dependence of $\mathrm{I}_{\mathrm{F}}$ on $\mathrm{N}$ has been shownc to be due to the $\mathrm{N}$-dependence of $\mathrm{P}^{+}$and $\mathrm{V}_{\mathrm{O}}$, viz.,

$$
\mathrm{I}_{\mathrm{F}}(\mathrm{N})=\mathrm{I}_{\mathrm{G}}+\mathrm{P}^{+}(\mathrm{N})+\mathrm{V}_{\mathrm{O}}(\mathrm{N})
$$

bAt a given medium density the observed decrease in $\mathrm{I}_{\mathrm{F}}$ with increasing $\mathrm{T}$ (Fig. 3) was understood from the $\mathrm{T}$-dependence of $\mathrm{V}_{0}[34]$.

cIn Eq. (5) the broadening of the valence levels of the isolated atom (molecule) in the dense gas or the liquid has been neglected. 
The density dependence of $\mathrm{P}^{+}$is dominated by the $\mathrm{N}$-dependence of $\epsilon$, and can be calculated [34] or be experimentally determined $([3,11,29-34,37,38,42])$ via Eq. (3) when the other quantities are known or assumed. The $V_{0}(N)$ function is more complicated; it has been calculated for a few cases $[34,46,47]$ using the Springett-Jortner-Cohen (SJC) model [46] or has been estimated via Eq. (5) when the other quantities are known or assumed $[29,30,48]$. In Fig. 4 are shown values of $\mathrm{P}^{+}$for TMPD in $\mathrm{C}_{2} \mathrm{H}_{6}$ calculated [34] as a function of the $\mathrm{C}_{2} \mathrm{H}_{6}$ density; they clearly show that $\mathrm{P}^{+}$is a monotonically decreasing function of the fluid density $\rho$. This decrease of $\mathrm{P}^{+}$with increasing $\rho$ is primarily due to the increase of $\epsilon$ with $\rho$ and to a lesser extent due to changes in $R$ with increasing $\rho$ [34]. Also plotied in Fig. 4 is $\mathrm{V}_{0}(\rho)$ for $\mathrm{C}_{2} \mathrm{H}_{\theta}$ calculated' [34] by using the SJC model or by relaxing sume of the model's basic assumptions [34]. The $\mathrm{V}_{0}(\rho)$ values determined by the modified SJC model [34] agree rather well with the experimental measurements [48].

To understand the function $\mathrm{V}_{0}(\mathrm{~N})$ let us refer briefly to the SJC model. In this model each molecule occupies a sphere whose radius ("the Wigner-Seitz (WS)" radius) $\mathrm{r}_{\mathrm{ws}}$ is equal to $\left(\frac{4}{3} \pi N\right)^{-1 / 3}$; each molecule, also, has a hard-core radius $\bar{a}$ such that the surn of the Hartree-Fock atomic potentials $U_{H F}(r)=\infty$ for $r<\bar{a}$ and $U_{H F}(r)=0$ for $r>\bar{a}$ $[34,46,47]$. The calculated values of $V_{0}(N)$ (Fig. 4) are rather strong functions of these quantities. For TMPD in $\mathrm{C}_{2} \mathrm{H}_{0}$ both theory and experiment $[34,48]$ suggest a value of 1.45 to $1.50 \AA$ for $\bar{a}$. The data in Fig. 4 show that $V_{0}(N)$ goes through a minimum; this is more dramatically exemplified in the case of the rare gases $\mathrm{Ar}, \mathrm{Kr}$, and $\mathrm{Xe}$ whose scattering length is negatived as can be seen for the data in Fig. 5. This is understood by noting that $V_{O}$ is a sum of two terms: the polarization energy $U_{p}$ and the kinetic energy $K$. That is,

dFor He whose scattering length is positive, $V_{0}$ increases with increasing $N$ [49]. 


$$
\mathrm{V}_{\mathrm{O}}=\mathrm{U}_{\mathrm{p}}+\mathrm{K}
$$

where

$$
\begin{aligned}
& U_{p}=U_{p}(r)+\left\langle\Sigma U_{p}\left(r-r_{i}\right)\right\rangle \\
& =-\left[\frac{3}{2} \frac{\alpha e^{2}}{r^{4}{ }_{w s}}\right] \times\left[\frac{8}{7}+\left[1+\frac{8}{3} \pi a N\right]^{-1}\right]
\end{aligned}
$$

and

$$
\mathrm{K}=\frac{\hbar^{2} \mathrm{k}^{2}}{2 \mathrm{~m}}
$$

when $\alpha$ is the molecular polarizability, a $(\simeq \bar{a})$ is the scattering length, and $k_{0}$ is the electron wave number determined by

$$
\tan k_{0}\left(r_{w s}-\bar{a}\right)=k_{0} r_{w s}
$$

Since $U_{p}$ is negative ind decreases with $\rho$, and $K$ is positive and increases with $\rho$, the $V_{0}$ has a minimum whose value and position depends mainly on the hard core radius $\bar{a}$. The functions $\mathrm{P}^{+}(\mathrm{N})$ and $\mathrm{V}_{0}(\mathrm{~N})$ in Fig. 4 were used by Faidas et al: [34] along with the value, $5.9 \mathrm{eV}$, they measured for $\mathrm{I}_{\mathrm{G}}(\mathrm{TMPD})$ to estimate the $\mathrm{I}_{\mathrm{F}}(\mathrm{N})$ of TMPD in $\mathrm{C}_{2} \mathrm{H}_{6}$ using Eq. (5). Their results for three values of $\bar{a}$ are represented by the solid lines in Fig. 3. They obtained the best fit to their measurements at $373 \mathrm{~K}$ with $\overline{\mathrm{a}}=1.4 \AA$. This understanding, gratifying as is, has not as yet been extended to polar media. 
As $\mathrm{I}_{\mathrm{F}}(\mathrm{N})$ is lowered from its low-pressure value $\mathrm{I}_{\mathrm{G}}$, excited states lying in the range $I_{G}-I_{F}(N)$ become autoionizing. The effect of the medium density on such high-lying excited electronic states has been investigated especially for high-n Rydberg states. For example, high $\mathrm{n}$-states of $\mathrm{CH}_{3} \mathrm{I}$ and $\mathrm{C}_{6} \mathrm{H}_{6}$ in $\mathrm{H}_{2}$ or $\mathrm{Ar}$ were found [50] to shift linearly with the number density of atomic $\operatorname{Ar}\left(0.6\right.$ to $\left.7.5 \times 10^{20} \mathrm{atoms}^{-3}\right)$ and molecular $\mathrm{H}_{2}\left(0.9\right.$ to $10.5 \times 10^{20}$ molecules $\left.\mathrm{cm}^{-3}\right)$. The density-induced energy shift $\Delta(\mathrm{N})$ of atomic or molecular high--n Rydberg states was reported [50] to decrease linearly with the density of the medium to $\mathrm{N} \simeq 1 \times 10^{21}$ molecules $\mathrm{cm}^{-3}$ and to agree with the modified Fermi model [51,52]. This model expresses $\Delta(\mathrm{N})$ as

$$
\Delta(\mathrm{N})= \pm\left(2 \pi \hbar^{2} / \mathrm{m}\right) \mathrm{aN}-9.87\left(\alpha \mathrm{e}^{2} / 2\right)^{2 / 3}(\mathrm{hv})^{1 / 3} \mathrm{~N}
$$

where $\mathrm{a}$ is the scattering length and $\mathrm{v}$ is the relative thermal velocity of the colliding partners. In Eq. (10) the first term is due to scattering and the second due to polarization.

C. Recombination

Geminate recombination. While in low-pressure gases $G_{f e} \simeq G_{t e}$, in liquids $G_{f e}<$ $\mathrm{G}_{\mathrm{te}}$. The two quantities are related to each other and to the applied electric field $\mathrm{E}$ by

$$
\begin{aligned}
& G_{f e}^{0}=p_{e s c}^{o} G_{t e} \\
& G_{f e}^{E}=p_{e s c}^{E} G_{t e}
\end{aligned}
$$

In Eqs. (11) and (12), $\mathrm{p}_{\mathrm{esc}}^{\mathrm{o}}$ and $\mathrm{p}_{\mathrm{esc}}^{\mathrm{E}}$ are, respectively, the escape probabilities (i.e., the probabilities that an electron at an initial separation distance $r$ would escape recombination with its sibling cation) in the absence $(E=0)$ and in the presence $(E>0)$ of an applied electric field. For isolated ionizations (low LET particles) $\mathrm{p}_{\mathrm{esc}}^{\mathrm{O}}$ and $\mathrm{p}_{\mathrm{esc}}^{\mathrm{E}}$ are normally expressed as $[3,53]$ 


$$
\begin{aligned}
& \mathrm{p}_{\mathrm{esc}}^{\mathrm{O}}=\exp \left(-\mathrm{r}_{\mathrm{c}} / \mathrm{r}\right) \\
& \mathrm{p}_{\mathrm{esc}}^{\mathrm{E}}=\exp \left(-\mathrm{r}_{\mathrm{c}} / \mathrm{r}\right)\left[1+\frac{\mathrm{er} \mathrm{c}}{2 \mathrm{kT}} \mathrm{E}\right]
\end{aligned}
$$

The quantity $r_{c}-$-the "Onsager length" - -is the distance at which the Coulomb energy of the electron-cation pair equals $\mathrm{kT}$, viz.

$$
r_{c}=\frac{e^{2}}{\epsilon k T}
$$

where $\epsilon$ is the dielectric constant of the medium. Actually, since there is a distribution of electron-cation thermalization distances $r$ the fraction of the electrons that escape (for $\mathrm{E}=$ $0)$ is

$$
\int d^{3} r g(r) \exp (-r / r)
$$

where $g(r)$ is the probability density of the electron thermalization distances. ${ }^{\theta}$

In low-pressure gases $\mathrm{r}$ is very large and $\mathrm{p}_{\mathrm{esc}} \longrightarrow 1$. In liquids, however, $\mathrm{r}$ is short $\left(100-200 \AA\right.$ for dielectric liquids [3] and $\sim 11 \AA$ for water [54]) and thus $\mathrm{p}_{\mathrm{esc}}<<1$. Of the parameters which govern the process of free electron production in liquids $\epsilon$ appears to be of primary significance; $G_{f e}$ increases with increasing $\epsilon[3,55]$.

Geminate recombination can, of course, involve the whole spectrum of incompletely relaxed to completely relaxed states. 
In Eq. (12), $\mathrm{G}_{f \mathrm{e}}^{\mathrm{E}}$ is the free electron yield when an electric field $\mathrm{E}$ is applied across the volume in which the electrons are generated; $G_{f e}^{E}$ exceeds $G_{f e}^{O}$ by an amount which depends on $E$ and the liquid $[3,53]$. This is especially the case for densely ionizing particles (e.g., $\alpha$-particles, Table 1 ) due to the low, value of $\mathrm{p}_{\mathrm{esc}}$ in sich instances. The $\mathrm{p}_{\mathrm{esc}}$ increases with increasing drift velocity $w$; the $w$ - -as well as the electron thermalization length - -increases with decreasing electron scattering cross section of the liquid. For pure liquids $\left(\mathrm{V}_{0}<\mathrm{CeV}\right)$, then, a low $\mathrm{I}_{\mathrm{L}}$ and a large $w$ and $\mathrm{E}$ are desirable for a large $\mathrm{G}_{\mathrm{fe}}^{\mathrm{E}}$.

In Fig. 6 the $\mathrm{G}_{\mathrm{fe}}^{0}$ and the density-normalized thermalization distance b $\rho$ are plotted as a function of the medium density $\rho$ (from 0.01 to $0.6 \mathrm{~g} \mathrm{~cm}^{-3}$ along the vapor/liquid coexistence curve) for $n$-pentane $(-\bar{r} \dot{i})$ and neopentane (neo-Pt) [16]. The $G_{f e}^{O}$ decreases continuowsly with increasing $\rho$ in $\mathrm{Pt}$, but it goes through a maximum in neo-Pt (and other "spherical"-molecule liquids) with conduction bands $\left(\mathrm{V}_{0}<0 \mathrm{eV}\right)$. The b $\rho$ also goes through a maximum in neo-Pt (and other "spherical"-molecule liquids) but remains relatively constant for $\mathrm{n}-\mathrm{Pt}$. The maximum in $\mathrm{G}_{\mathrm{fe}}^{\mathrm{o}}$ and $\mathrm{b} \rho$ for "spherical"-molecule liquids correlates with that of the density-normalized thermal electron mobility $\mu \mathrm{N}$.

Finally, attention is drawn to recent femptosecond studies of the kinetics and dynamics of geminate recombination of electron-cation pairs formed in liquids (water [54], alkanes [54]) by photoionization. In the case of water it was reported [54] that within $\sim 60$ ps of electron solvation, $\sim 50$ to $60 \%$ of the solvated electrons undergo geminate recombination.

Volume or Bulk In low-pressure gases, volume electron-cation recombination is normally an overall three-body process with a recombination rate constant $\mathrm{k}_{\mathrm{r}}$ that can be expressed as [57]

$$
k_{\overline{1}}=k_{2}+k_{3} N
$$


where $k_{2}$ and $k_{3}$ are the two- and three-body coefficients and $N$ is the medium number density. At high gas pressures and in nonpolar liquids (at least in those with electron mobilities $\mu$ in the range 0.09 to $\left.300 \mathrm{~cm}^{2} \mathrm{~V}^{-1} \mathrm{~s}^{-1}[58]\right)$, recombination occurs on a time scale many orders of magnitude longer than geminate recombination and $k_{r}$ assumes diffusion-controlled values

$$
\mathrm{k}_{\mathrm{D}}=4 \pi \mathrm{e} \mu / \epsilon
$$

that is, $\mathrm{k}_{\mathrm{r}}$ is limited by the rate at which the electrons diffuse toward the ions.

In Fig. 7 is shown [58] the variation of the $\mathrm{k}_{\mathrm{r}}$ for $\mathrm{CH}_{4}$ in the density range $2 \times 10^{20}$ to $1: 9 \times 10^{22}$ molecules $\mathrm{cm}^{-3}$ including the critical region and the liquid-solid phase change. The N--dependence of $\mathrm{k}_{\mathrm{r}}$ follows closely that of $\mu(\mathrm{N})$ (Fig. 7b). The abrupt increase in $\mathrm{k}_{\mathrm{r}}$ and $\mu$ on the phase transition from liquid to solid is common to other liquids with $\mathrm{V}_{0}<0$ $\mathrm{eV}$ and may be due to the decrease of the isothermal compressibility on phase change [58].

III. THE ELECTRON STATE AND ENERGIES (UNDER STEADY-STATE CONDITIONS) IN LOW PRESSURE GASES, DENSE GASES, AND DIELECTRIC LIQUIDS

In low-pressure gases the electron mean free path $\ell\left(\approx\left[\mathrm{N} \sigma_{\mathrm{sc}}\right]^{-1} ; \sigma_{\mathrm{sc}}=\right.$ total electron scattering cross section) is much longer than the electron de Broglie wavelength $\lambda(=2 \pi \lambda)$ and the electrons in such media are free interacting with single atoms and single molecules. Their electron transport properties have been, in many instances, successfully treated using the Boltzmann transport equation. The electron kinetic energies have been found to be well in excess of thermal by a 7 amount that depends on the gas and the value of $E / N[1,2]$. In Fig. 8 the mean electron energy $\langle\epsilon\rangle$ is plotted as a function of $E / N$ for a number of low-pressure gases to illustrate the gas properties which determine their ability to slow-down subexcitation electrons: negative ion states for $\mathrm{N}_{2}$ and $\mathrm{CO}_{2}$ (the low-lying $[1,2]$ negative ion states of $\mathrm{CO}_{2}$ are responsible for its exceptional slowing-down properties, 
while the $2.3 \mathrm{eV}$ negative ion state of $\mathrm{N}_{2}$ explains the flat portion of the $\langle\epsilon\rangle$ vs $\mathrm{E} / \mathrm{N}$ function for this gas), dipole scattering for $\mathrm{NH}_{3}$, multiple-bonds for $\mathrm{C}_{2} \mathrm{H}_{2}$; the lower-lying vibrational thresholds of $\mathrm{CF}_{4}$ compared to $\mathrm{CH}_{4}$ explain the superior thermalizing ability of $\mathrm{CF}_{4}$ at low energies. The steady-state electron energy distribution functions $\mathrm{f}(\epsilon, \mathrm{E} / \mathrm{N})$ are non-Maxwellian (except at very low E/N) and--depending on the gas, E/N and T-they peak at energies ranging from $1.5 \mathrm{kT}$ to $\lesssim 10 \mathrm{eV}$ ([1.2]; Fig. 9).

In dense gases and liquids, $\ell<\lambda$, the electrons interact with more than one species simultaneously and they are not free but quasi-free $\left(\mathrm{e}_{\mathrm{qf}}\right)$ and/or localized $\left(\mathrm{e}_{\ell}\right)$ depending on the medium, $\mathrm{N}$ and $\mathrm{T}$. Excess electrons are generally localized-- -upon thermalization-in dense media whose $\mathrm{V}_{0}>0 \mathrm{eV}$ and they are quasi-free in those with $\mathrm{V}_{0}<0 \mathrm{eV}$. The $\mathrm{V}_{\mathrm{o}}$ itself can be a function of N(Figs. 4 and 5). Quasi-free electrons have much higher mobilities than localized electrons (see Section IV; $[3,11,12,64])$. The energies of the excess electrons are generally thermal in dense media. However, in dense media with $\mathrm{V}_{0}<0 \mathrm{eV}$, the excess electrons can- - especially at high $\mathrm{E} / \mathrm{N}$ - -attain energies well above thermal. This can be seen from the data shown in Figs. 10 to 12 for liquid $\mathrm{Ar}$ and liquid Xe. Evidence for steady-state excess-electron energy distributions energetically lying above thermal has been obtained also for "spherical"-molecule liquids with $\mathrm{V}_{0}<0 \mathrm{eV}[72,73]$. While the accuracy and the quality of such knowledge is still very limitedf, it clearly shows the existence of energetic excess electrons in dense fluids with conduction bands $\left(\mathrm{V}_{0}<0\right.$ $\mathrm{eV}$ ). The state of the electron and its energy crucially depend on the medium and profoundly affect the magnitude of the interaction cross sections of excess electrons in dense media.

fThe $\mathrm{E} / \mathrm{N}$ dependence of the $\mathrm{D}_{\mathrm{T}} / \mu$ measurements for liquid Ar and liquid Xe in Fig. 10 lends support to the $\langle\epsilon>$ vs $\mathrm{E} / \mathrm{N}$ data of Ref. 65 (Figs. 11 and 12). 


\section{ELFCTRON DRIFT AND SCATTERING IN LOW-PRESSURE GASES, DENSE GASES, AND DIELECTRIC LIQUIDS}

The electron transport coefficients- -electron drift velocity $w$ and transverse $\left(D_{T}\right)$ and longitudinal $\left(\mathrm{D}_{\mathrm{L}}\right)$ diffusion coefficient- -are functions of the gaseous medium, $\mathrm{E} / \mathrm{N}$, and $\mathrm{T}[1,2,74,75]$. For sufficiently low $\mathrm{N}$ where $\ell>>\lambda$, w and $\mathrm{D}_{\mathrm{T}}\left(\mathrm{D}_{\mathrm{L}}\right)$ are independent of $N$. Under these cond: ons well-developed expressions relate $w$ and $D_{T}\left(D_{L}\right)$ to $f(\epsilon, E / N)$ and the cross sections $\sigma_{\mathrm{Sc}}(\epsilon)$ of the various collision processes $[1,2,74]$. Thus, the low-dersity low-field value, $(\mu \mathrm{N})_{0}$, of the density-normalized electron mobility $\mu \mathrm{N}$ is expressed as

$$
(\mu \mathrm{N})_{\mathrm{O}}=\frac{4}{3} \frac{\mathrm{e}}{(2 \pi \mathrm{mkT})^{1 / 2}} \frac{1}{\left\langle\sigma_{\mathrm{sc}}>\right.}
$$

where $\left\langle\sigma_{\mathrm{sc}}\right\rangle$ is an average of the scattering cross section at thermal energies. Accurate measurements of $\mathrm{w}(\mathrm{E} / \mathrm{N})$ and $\mathrm{D}_{\mathrm{T}} / \mu(\mathrm{E} / \mathrm{N})[1,2,74,75]$, along with the development of the Boltzmann transport and Monte Carlo computational code analyses in the past two decades, have provided a substantial body of information on- -and an improved understanding of- -electron motion in gases and the cross sections for the various energy-loss processes $[2,63,74-79]$. In Fig. 13 an example of the collision cross sections obtained from such analyses [83] is shown. As the density of the medium is increased, howeve:, wg decreases or increases depending on the medium and the type and cross sestivins of the electron-interaction processes involved. Thus, in the density range over

gThe author is not aware of any experimental observations on the dependence of $D_{T}$ on $N$, although they have been hypothesized [84]. 
which $\mathrm{N} \sigma_{\mathrm{Sc}}{ }^{\dagger} \lesssim 0.5$, w (or $\mu$ or $\left.\mu \mathrm{N}\right)$ decreases slowly with increasing $\mathrm{N}$ for nonpolar gases with small $\sigma_{\text {Sc }}$ (e.g., $\mathrm{H}_{2}, \mathrm{~N}_{2}, \mathrm{C}_{2} \mathrm{H}_{6}$ ). An understanding of these dependences of $\mathrm{w}$ on $\mathrm{N}$ was attempted $[2,71,85-88]$ by considering the effects of multiple scattering on $w$ and by introducing phenomenological density corrections to the low $-\mathrm{N}$ expiessions for drift velocity $\mathrm{w}$ [or mobility $\mu, \mathrm{Eq}$. (19)]. The dependence of $\mathrm{w}$ on $\mathrm{N}$ seems to be energy dependent. For example, it was found [89] that the maximum change in w with pressure occurs at thermal energies $(\sim 0.038 \mathrm{eV})$ for $\mathrm{H}_{2}$ and $\mathrm{C}_{3} \mathrm{H}_{8}$ but at $\sim 0.06 \mathrm{eV}$ for $\mathrm{CH}_{4}$ and at $\sim 0.07 \mathrm{eV}$ for $\mathrm{C}_{2} \mathrm{H}_{6}$.

The electron drift velocity (or the electron mobility) has been shown $[2,12]$ to decrease substantially with increasing medium density in systems (e.g., $\mathrm{He}, \mathrm{CO}_{2}, 1-\mathrm{C}_{3} \mathrm{~F}_{6}$ ) where transient or permanent anions are increasingly formed as the medium density is increased, and for polar media where, in addition, the electron scattering cross section is large (due to the long-range electron-electric dipole interaction). Thus the $\mathrm{w}$ in $\mathrm{CO}_{2}$ decreases by $\sim 3$ orders of magnitude when $\mathrm{N}$ is increased to $\sim 10^{21}$ molecules $\mathrm{cm}^{-3}$ [90]; large decreases in $\mathrm{w}$ at even lower number densities $\left(\lesssim 5 \times 10^{18}\right.$ molecules $\left.\mathrm{cm}^{-3}\right)$ were reported for $1-\mathrm{C}_{3} \mathrm{~F}_{6}$ [91]. In polar media $\mathrm{N} \sigma_{\mathrm{SC}} \lambda>1$ at relatively low $\mathrm{N}$ and the delay in electron drift begins at relatively low values of $\mathrm{N}\left(\sim 2 \times 10^{19}\right.$ molecules $\left.\mathrm{cm}^{-3}\right)$. This can seen from Figs. 14a,b where the dependence of $v_{i}(\mathrm{E} / \mathrm{N})$ on $\mathrm{N}(\mathrm{T}=300 \mathrm{~K})$ and $(\mu \mathrm{N}) /(\mu / \mathrm{N})_{0}$ on $\mathrm{N}$ (at various $\mathrm{T}$ ) are given for the polar molecule $\mathrm{NH}_{3}$. For $\mathrm{NH}_{3}$ the $\left\langle\sigma_{\mathrm{Sc}}\right\rangle$ at thermal $(\mathrm{T}=300 \mathrm{~K})$ energies is $\sim 1.2 \times 10^{-13} \mathrm{~cm}^{2}[92]$ and $\ell \simeq \lambda$ at $\sim 5.5 \times 10^{19}$ molecules $\mathrm{cm}^{-3}$. As $\mathrm{N}$ increases beyond the range of values in Fig. 14, permanent or transient electron trapping occurs and causes a rather sharp decrease in w or $\mu$ as can be seen from the data in Fig. 15. These latter processes are, cbviously, a function of $\mathrm{T}$; their effect decreases with increasing $\mathrm{T}$.

On the other hand, $\mathrm{w}(\mu$ or $\mu \mathrm{N})$ was found to increase with increasing $\mathrm{N}$ for the heavier rare gases and the "spherical"-molecule hydrocarbon dielectric fluids for which $V_{0}$ $<0 \mathrm{eV}$. An example of this type of behavior is shown in Fig. 16 for Xe. The increase in w 
up to $\sim 3 \times 10^{21}$ atoms $\mathrm{cm}^{-3}$ is associated with a reduced contribution to electron scattering from ine polarization component of the interaction potential by overlapping of the fields of adjacent atoms. The evolution of the $\mathrm{N}$-dependence of the low-field (thermal) electron mobility for $\mathrm{Xe}$ in the density range from the low pressure regime to the liquid is shown in Fig. 17. Below $\sim 3 \times 10^{20}$ atoms $\mathrm{cm}^{-3}$ (Fig. 17) $\mu \mathrm{N}$ is independent of $\mathrm{N}$ since in this range $\mathrm{N} \sigma$ sc is low enough for single-atom scattering to prevail. Beyond this value, $\mu \mathrm{N}$ decreases, passes through a minimum, increases to a maximum and falls again. The decrease in the density range from $\sim 3$ to $\sim 40 \times 10^{20}$ atoms $\mathrm{cm}^{-3}$ was attributed (see discussion in Ref. 11) to enhanced electron scattering due to multibody interactions and the large subsequent increase due to interference effects. Certainly the structure of the medium and its effect on electron transport needs to be considered at these high densities. Multiple scattering theories [85-88] atternpted to acccunt for these changes for gases with negative scattering lengths by considering the attenuation of the electron scattering by density effects due to the screening of the long-range polarization interaction potential. In general, however, the theoretical treatments of $w(N)$ fail at high $\mathrm{N}$ especially in the transition region. Part of the difficulty lies in the fact that the theory often retains the atomic scattering picture and introduces corrections to the low-density scattering as the $\mathrm{N}$ is increased. Another serious problem is the inability to properly describe the electron scattering potential and its screening by the medium, and to account for the effects on $w$ of temporary electron trapping.

In the liquid, $\mathrm{N} \sigma_{\mathrm{sc}}{ }^{\lambda}>>1$ and the electron is strongly influenced by the structure of the medium. The thermal electron mobility $\left(\mu_{\mathrm{L}}\right)_{\mathrm{th}}$ in the liquid has been expressed by

$$
\left(\mu_{\mathrm{L}}\right)_{\mathrm{th}}=\frac{2}{3} \frac{1}{\mathrm{~N}}\left[\frac{2}{\pi \mathrm{mkT}}\right)^{1 / 2} \frac{\mathrm{e}}{4 \pi \mathrm{a}_{\mathrm{ef}}^{2} \mathrm{~S}(0)}
$$


where $a_{\text {ef }}(N)$ is the effective scattering length at a density $N, S(0)=N k T \chi$ is the structure factor at thermal energies $(K \rightarrow 0)$, and $\chi$ is the isothermal compressibility, $[S(0) \simeq 0.03-$ 0.05 near the triple point of simple fluids; $S(K) \rightarrow 1$ for $\epsilon \geq 4 \mathrm{eV}$.] It is emphasized that the success of any theoretical treatment of electron motion in liquids depends on the assumed form of the scattering potential and the proper correction for its screening by the medium.

That the electron scattering processes at low energies are strongly affected by the liquid structure, can be seen from Figs. 18 and 19 where w(E/N) for gaseous (low-pressure) and liquid $\mathrm{Ar}$ and Xe [Fig. 18] and gaseous (low pressure) and liquid tetramethylsilane (TMS), neo-pentane (TMC) and 2,2,4,4-tetramethylpentane (TMP) [Fig. 19] are shown. The polyatomic molecules of TMS, TMC, and TMP are "spherical" and their liquids- -as those of $\mathrm{Ar}$ and $\mathrm{Xe}-$-have excess electron conduction bands (Table 2). It is clearly seen (Figs. 18 and 19) that at a given value of $\mathrm{E} / \mathrm{N}$, the $w$ is very much larger in the liquid than in the corresponding gas, indicating that $\sigma_{\mathrm{SC}}(\epsilon)$ is much smaller at low energies $\epsilon$ in the liquid. Indeed, the $w(E / N)$ measurements for liquid $\mathrm{Ar}$ and Xe in Fig. 18 were used [99]-in a manner analogous to that for gases [83]- -in a Boltzmann transport equation analysis to determine a set of scattering cross sections and an electron energy distribution function $\mathrm{f}(\epsilon, \mathrm{E} / \mathrm{N})$ consistent with the $\mathrm{w}(\mathrm{E} / \mathrm{N})$ measurements. The cross section for elastic energy loss $\sigma_{0}(\epsilon)$, elastic momentum transfer $\sigma_{\Lambda}(\epsilon)$, and inelastic electron scattering for liquid Ar and Xe obtained this way [99] are shown in Fig. 20. Clearly $\sigma_{0}(\epsilon)$ and $\sigma_{1}(\epsilon)$ are lower than $\sigma_{\mathrm{m}}(\epsilon)$ below $\sim 0.2 \mathrm{eV}$, and exhibit a shallower Ramsauer-Townsend minimum which is shifted to lower $\epsilon$ compared to that of $\sigma_{\mathrm{m}}(\epsilon)$. (See also [89] and [100]). At $\epsilon \gtrsim 4$ $\mathrm{eV}, \sigma_{\mathrm{o}}$ and $\sigma_{1} \rightarrow \sigma_{\mathrm{m}}$ ' A quantitative calculation of $\sigma_{\mathrm{sC}}$ in any liquid is still lacking. Finally, it is interesting to observe that for the molecular liquids in Fig. 19, w increases linearly with $\mathrm{E}$ up to a "critical" electric field $\mathrm{E}_{\mathrm{c}}$ beyond which the $\mathrm{E} / \mathrm{N}$ dependence of $\mathrm{w}$ becomes sublinear indicating that at $\mathrm{E}>\mathrm{E}_{\mathrm{C}}$ the excess electrons have mean kinetic energies $\langle\epsilon\rangle_{\mathrm{L}}>1.5 \mathrm{kT}$. Such media have potential applications in radiation detectors [17,101-104] pulsed power switches [105] and other technologies [4]. In Table 3 
are listed values of $\mathrm{E}_{\mathrm{c}^{\prime}} \mu_{\mathrm{th}}$, maximum, $\mathrm{w}_{\max }$, electron drift velocity measured and the corresponding, $\mathrm{E}_{\mathrm{max}}$, applied,for dielectric liquids with excess electron conduction bands. 
Table 3: $\quad \mathrm{E}_{\mathrm{c}}, \mu_{\text {th. }}, \mathrm{w}_{\max }$ and $\mathrm{E}_{\max }$ for a number of dielectric liquids with $\mathrm{V}_{\mathrm{O}}<0 \mathrm{eV}$

\begin{tabular}{|c|c|c|c|c|}
\hline Liquida & $\begin{array}{c}\mathrm{E}_{\mathrm{c}} \\
\left(10^{3} \mathrm{Vcm}^{-1}\right)\end{array}$ & $\mu_{\left(\mathrm{cm}^{2} \mathrm{~s}^{-1} \mathrm{~V}-1\right)}$ & $\underset{\left(10^{8} \mathrm{cms}^{-1}\right)}{w_{\max }}$ & $\frac{\mathrm{E}_{\max }}{\left(10^{3} \mathrm{Vcm}^{-1}\right)}$ \\
\hline $\begin{array}{l}\mathrm{Ar}(87 \mathrm{~K}) \\
\mathrm{Xe}(165 \mathrm{~K}) \\
\mathrm{C}\left(\mathrm{CH}_{3}\right)_{4} \mathrm{~d} \\
\mathrm{Si}\left(\mathrm{CH}_{3}\right)_{4} \mathrm{~d} \\
\mathrm{Ge}\left(\mathrm{CH}_{3}\right)_{4} \mathrm{~d} \\
\mathrm{Sr}\left(\mathrm{CH}_{3}\right)_{4}{ }_{4}^{\mathrm{d}} \\
\left(\mathrm{CH}_{3}\right)_{3} \mathrm{CCH}_{2} \mathrm{C}\left(\mathrm{CH}_{3}\right)_{3} \mathrm{~d}\end{array}$ & $\begin{array}{l}0.3^{b} \\
0.05^{b} \\
3.5^{\circ} \\
7^{\circ} \\
15^{\circ} \\
30^{\circ} \\
15^{\circ}\end{array}$ & $\begin{array}{c}400^{\mathrm{b}} \\
2000^{\mathrm{b}} \\
71.5^{\mathrm{e}} \\
119.3^{\mathrm{e}} \\
114.7^{\mathrm{e}} \\
85.7^{\mathrm{e}} \\
31.8^{\mathrm{e}}\end{array}$ & $\begin{array}{l}0.65 \mathrm{~b}, \mathrm{o} \\
0.26 \mathrm{~b}, \mathrm{c} \\
3.3 \mathrm{e}, \mathrm{f} \\
7.2 \mathrm{e}, \mathrm{f} \\
7.4 \mathrm{e} \\
6.0 \mathrm{\theta} \\
2.6 \mathrm{e}, \mathrm{f}\end{array}$ & $\begin{array}{c}- \\
\overline{116^{\mathrm{e}}} \\
125^{\mathrm{e}} \\
109^{\mathrm{e}} \\
75^{\mathrm{e}} \\
115^{\mathrm{e}}\end{array}$ \\
\hline
\end{tabular}

aSee Table 2 for values of $\mathrm{I}_{\mathrm{L}}, \mathrm{I}_{\mathrm{G}}$, and $\mathrm{V}_{\mathrm{O}}$ for these liquids.

bRef. [101].

'See Fig. 18.

d $296 \mathrm{~K}$.

eRefs. [102,73].

fSee Fig. 19. 


\section{EFFECT OF THE MEDIUM ON NEGATIVE ION STATES (TRANSIENT ANIONS)}

Studies of negative ion states (NISs) of isolated molecules are abundant $[1,2]$. None, however, exists to the author's knowledge on liquids. Notable changes are expected, however, in the resonance energy, cross section, and lifetime of the NISs of atoms and molecules embedded in dense fluids as the fludd density is increased $[2,11,12,65,69]$. Figure 21 shows schematically the increase in the vertical attachment energy (VAE) and the electron affinity (EA) in going from a low-pressure gas to the liquid and Fig. 22 shows how the position of the $\mathrm{NO}_{2}{ }^{-{ }^{*}}$ resonance responsible for the reaction

$$
\mathrm{e}+\mathrm{N}_{2} \mathrm{O} \longrightarrow \mathrm{N}_{2} \mathrm{O}^{-*} \longrightarrow \mathrm{O}^{-}+\mathrm{N}_{2}
$$

shifts from $\sim 2.3 \mathrm{eV}$ when the reaction occurs in a low-pressure gas of Ar to $\sim 0.3 \mathrm{eV}$ when the reaction occurs in liquid Ar [69]. Similar downward shifts in the energies of the NISs of isolated molecules have been observed for solid films of molecules such as $\mathrm{H}_{2}, \mathrm{~N}_{2}, \mathrm{O}_{2}, \mathrm{C}_{6} . \mathrm{H}_{6}$ [106]. In general, these downward shifts in the resonance energies of transient anions can be accounted for by considering the polarization of the dense medium (fluid or solid) by the temporarily localized electron. The gradual downward shift in the energy position of a NIS (and the associated changes in the electron attachment cross section) with increasing $\mathrm{N}$ of a dense gas, have first been observed for the case of $\mathrm{O}_{2}^{--}$in a buffer gas of $\mathrm{N}_{2}$ whose density was increased from $\sim 1 \times 10^{10}$ to $1 \times 10^{21}$ molecules $\mathrm{cm}^{-3}$ [107-109]. Later work on the EA of cluster negative ions as a function of their size [110] is consistent with these early findings.

Under isolated-molecule (single-collision) conditions the autodetachment lifetimes $\tau_{\mathrm{a}}$ of transient anions vary from $\sim 10^{-10}$ to $>10^{-4} \mathrm{~s}[1,2,111]$. Similarly, in low-pressure gases (multiple-collision conditions) the attachment cross sections $\sigma_{\mathrm{a}}$ for negative-ion 
formation vary from molecule to molecule (and the position of the negative lon states) by over 11 orders of magnitude $[1,2,111]$. 'The transition from a low-pressure gas to the liquid can result in changes of both $\tau_{\mathrm{a}}$ and $\sigma_{\mathrm{a}}$. In general such changes would depend on whether the electron affinity of the molecule in the gas $(\mathrm{EA})_{\mathrm{G}}$ is negative $(<0 \mathrm{eV})$ or positive $(>0$ $\mathrm{eV}$ ) and on whether a negative $(\mathrm{EA})_{\mathrm{G}}$ becomes positive in the condensed phase.

In connection with the changes in $\tau_{a}$, studies of the lowest $((\mathrm{EA})<0 \mathrm{eV})$ NISs of $\mathrm{N}_{2}, \mathrm{CO}$, and $\mathrm{H}_{2}$ in solid films have shown [106] that the $\tau_{a}$ of the NIS in the solid is decreased from its value, $\left(r_{a}\right)_{G}$, in the low-pressure gas; in the condensed phase the centrifugal barrier is greatly distorted due to symmetry changes which are effected by the medium. One might, thus, expect $\left(\tau_{a}\right)_{G}$ to be longer than the lifetime $\left(\tau_{a}\right)_{L}$ of the NIS in the liquid. When $(\mathrm{EA})_{\mathrm{G}}>0 \mathrm{eV}$ (or when the EA of a molecule is negative in the gas but positive in the liquid), $\left(\tau_{a}\right)_{G}<\left(\tau_{a}\right)_{L}$ due to the faster energy relaxation in the liquid.

In connection with the changes in $\sigma_{a}$, the electron state in the liquid (or the dense gas) crucially determines both the magnitude of $\left(\sigma_{a}\right)_{L}$ and the relation of $\left(\sigma_{a}\right)_{L}$ to the corresponding value $\left(\sigma_{a}\right)_{G}$ in the gas. As will be shown in the next section $\left(\sigma_{a}\right)_{L}\left(e_{q f}\right)>>$ $\left(\sigma_{a}\right)_{L}\left(e_{\ell}\right)$. It is only for liquids for which the electron is in the quasi-free state that a comparison with gaseous data is meaningful. When, however, (EA) ${ }_{\mathrm{G}}>0 \mathrm{eV}$ the electron attachment cross section in the liquid $\left(\sigma_{a}\right)_{L}$ is maximum when the captured electron is quasi-free $\left(e_{\mathrm{qf}}\right)$ and $\left(\sigma_{\mathrm{a}}\right)_{\mathrm{L}}$ is close to its diffusion-controlled value when the captured electron is localized $\left(e_{\ell}\right)$.

In connection with the decomposition of the NIS via dissociative attachment, it is clear that since $\left(\tau_{a}\right)_{\mathrm{L}}<\left(\tau_{\mathrm{a}}\right)_{\mathrm{G}}$ for molecules such as $\mathrm{O}_{2}\left(\mathrm{O}_{2}+\mathrm{e} \rightarrow \mathrm{O}_{2}{ }^{*} \rightarrow \mathrm{O}^{-}+\mathrm{O}^{\text {; }}\right.$ resonance peak at $6.7 \mathrm{eV}$ in the gas) the cross section for dissociation attachment o da would be smaller in the liquid than in the low-pressure gas due to the decrease in the survival probability $[1,2]$. It should, however, be noted that since the position of the resonance is lower in the liquid than in the gas and since the magnitude of the dissociative attachment cross section is larger the lower the energy position of the resonance $[1,2]$, the 
cross section for a dissociative attachment process may actually be much larger in the liquid than in the gas. This is certainly the case for reaction (21) (see Fig. 22). Fast energy relaxation in derise flulds may reduce $\left(\sigma_{\mathrm{da}}\right)_{\mathrm{L}}$ when the dissociative attachment process is exoerglc.

\section{ELECTRON ATTACHMENT IN DENSE GASES AND LIQUIDS}

Studies of electron-molecule attaching collisions in dense gases are the domain of electron swarm methods $[1,2,5,112,113]$. The last two decades have seen the "maturity" of swarm methods and their unique contributions to the understanding of electron interactions in fluids. A most distinct advancement in this area has been the development of experimental methods to study electro's attachment to molecules embedded in dense buffer gases for which the electron energy distribution function $f(\epsilon, E / N)$ can be calculated over a wide range of $\mathrm{E} / \mathrm{N}$ values (Fig. $\theta ;[1,2]$ ). These methods allowed measurement of the absolute (total) electron attachment rate constant $\mathrm{k}_{\mathrm{a}}$ as a function of $\mathrm{E} / \mathrm{N}$ or as a function of the mean electron energy $\langle\epsilon\rangle$ since $\langle\epsilon\rangle(E / N)$ can be computed once $f(\epsilon, E / N)$ is known. Furthermore, the measured $k_{a}(\langle\epsilon\rangle)$ have been used to determine the absolute total electron attachment cross section $\sigma_{a}(\epsilon)$ from

$$
\mathrm{k}_{\mathrm{a}}(\langle\epsilon\rangle)=(2 / \mathrm{m})^{\frac{1}{2}} \int_{0}^{\infty} \sigma_{\mathrm{a}}(\epsilon) \epsilon^{\frac{1}{2}} \mathrm{f}(\epsilon, \mathrm{E} / \mathrm{N}) \mathrm{d} \epsilon
$$

In iilg. 23, is shown the $\mathrm{k}_{\mathrm{a}}(\langle\epsilon\rangle)$ and $\sigma_{a}(\epsilon)$ obtained [61] by these methods for the perfluoroalkanes $n-C_{N} H_{2 N+2}(N=1$ to 6$)$. The attachment cross sections increase with decreasing resonance energy, $\epsilon_{\text {res }}$, approaching $\pi \lambda^{2}$ as $\epsilon_{\text {res }} \rightarrow \mathrm{k}^{\prime} \mathrm{T}[1,8]$. The wealth of knowledge that has been obtained from such studies has had a profound impact on the basic understanding of slow electron-molecule interactions (especially indirect electron scattering and molecular fragmentation by electron capture), and on the development of energy and pollutant-monitoring technologies (e.g., lasers [114], radiation and chemical 
detection devices [114-116], gaseous dielectrics $(114,117]$, pulsed power switches $[114,117,118])$.

The nature and number density of a gaseous medium in which electron attachment reactions occur can have a profound effect on such reactions. The effect is a function of the medium and its density, the mode (dissuciative or nondissialative) of electron attachment, and the anionic state involved in the electron attachment process especially its lifetime and resonance energy. For dissoclative electron attachment processes the effect of the medium is insignificant at low $\mathrm{N}$ because fragment anions do not normally require collisional stabilization. For nondissociative electron attachment, however, the effect of the medium-even at low $\mathrm{N}-$-can be profound.

Quite generally, at low gas number densities ( $\lesssim 5 \times 10^{10}$ molecules $\mathrm{cm}^{-3}$ ) electron attachment to a molecule $\mathrm{AX}$ in a gas $\mathrm{M}$ can be represented by the reaction scheme.

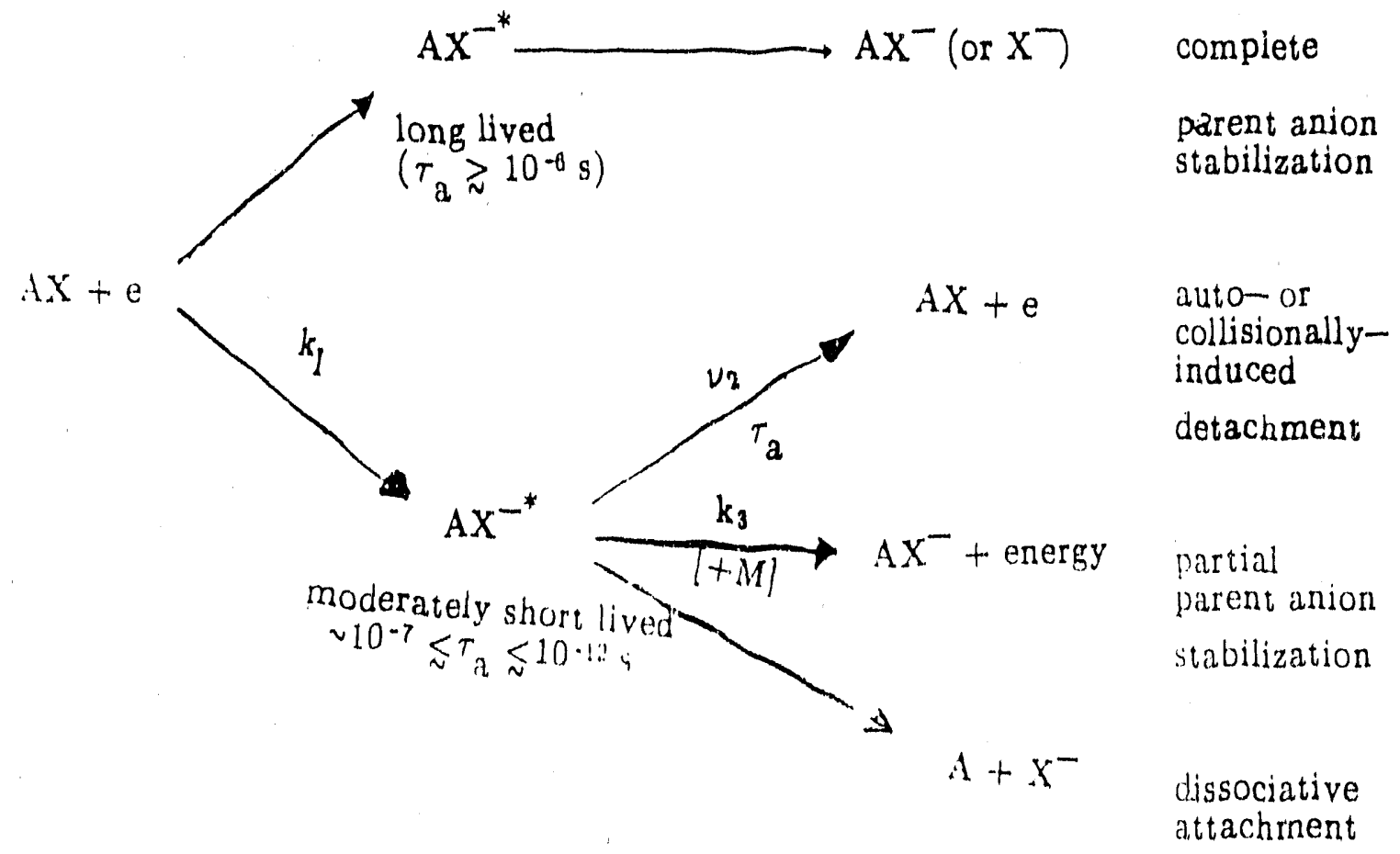

When only long-lived $\left(\tau_{\mathrm{a}} \gtrsim 10^{-\theta} \mathrm{s}\right)$ anions [process (23); e.g., SF ${ }^{-{ }^{*}}$ at near-zero energy] and/or dissociative attachment fragment anions (process (26); e.g., fragment anions of $\mathrm{C}_{3} \mathrm{~F}_{8}$ 
and $\mathrm{n}-\mathrm{C}_{4} \mathrm{~F}_{10}$ (Fig, 23)] are formed by electron capture, $\mathrm{k}_{\mathrm{a}}$ is independent of $\mathrm{N}$. In the absence of processes (23) and (26) competition between auto- or collisionally-induced detachment (process (24)) and stabilization of $\mathrm{AX}^{-{ }^{*}}$ by collision with $\mathrm{M}$ (process (25j) can result in a pressure-dependent $k_{a}$. For the above reaction scherne

$$
\mathrm{k}_{\mathrm{a}}=\mathrm{k}_{1}\left[\frac{\mathrm{k}_{3} \mathrm{~N}}{\nu_{2}+\mathrm{k}_{3} \mathrm{~N}}\right] \text {. }
$$

At low $\mathrm{N}$ or short $\tau_{\mathrm{a}}$ such that $\nu_{2}=\tau_{\mathrm{a}}{ }^{-1}>>\mathrm{k}_{3} \mathrm{~N}, \mathrm{k}_{\mathrm{a}} \alpha \mathrm{N}$ if dissociative attachment and other processes are absent. Alternatively, if the $\tau_{\mathrm{a}}$ is long or $\mathrm{N}$ is large (i.e., $\tau_{\mathrm{a}}{ }^{-1}<<\mathrm{k}_{3} \mathrm{~N}$ ), then $k_{a}=k_{1}$ and is independent of $N$ or the nature of $M$. Considerable variations in the ability of the molecules $M$ to collisionally stabilize $\mathrm{AX}^{-*}$ have been reported [107,109,119-121] and showed that $k_{3}$ increases with increasing complexity of the stabilizing third body M. A.t relatively low $\mathrm{N}\left(\lesssim 5 \times 10^{19}\right.$ molecules $\left.\mathrm{cm}^{-3}\right)$ a number of molecules (e.g., $\mathrm{O}_{2}, \mathrm{SO}_{2}, \mathrm{~N}_{2} \mathrm{O}[1,8,107,109,119-122]$ have been found to attach electrons by a three-body process which is well-represented by (24) and (25). At higher $\mathrm{N}$, however, the $k_{a}(N)$ of a number of molecules (e.g., $\left.\mathrm{O}_{2}, 1-\mathrm{C}_{3} \mathrm{~F}_{6}[107,109,120-123]\right)$ does not follow that predicted by a three-body process. This is exemplified by the $\mathrm{k}_{\mathrm{a}}(\mathrm{N})$ data in Fig. 24 for the formation of $\mathrm{O}_{2}^{-}$in the buffer gases $\mathrm{N}_{2}$ and $\mathrm{C}_{2} \mathrm{H}_{6}$, which show the involvement of more than one buffer gas molecules in the electron attachment process $[107,109]$. Other studies $[121,122]$ contented that electron attachment to Van der Waals dimers is a major electron capture process; for example, electron attachment to $\mathrm{O}_{2}$ forming $\mathrm{O}_{2}^{-}$in a dense buffer gaseous medium $M$ was suggested to be principally due to electron capture by Van der Waals molecules of the form $\left[\mathrm{O}_{2} \cdot \mathrm{M}\right]$.

When, over a given energy range reactions (25) to (26) occur concomitantly, the $\mathrm{k}_{\mathrm{a}}(\langle\epsilon\rangle)$ has both a density independent [due to processes (26) and/or (23)] and a density-dependent component [due to (25)]; the latter is a function of $\mathrm{M}$ and $\tau_{\mathrm{a}}$. This can be seen from the data in Fig. 25 where the $k_{a}(\langle\varepsilon\rangle)$ are shown for $\mathrm{C}_{3} \mathrm{~F}_{8}$ and $n-\mathrm{C}_{4} \mathrm{~F}_{10}$ for 
several buffer gas pressures. The increase in $\mathrm{k}_{\mathrm{a}}$ with $\mathrm{N}^{\prime}$ is due to process (25) and the $\mathrm{N}$-independent comporent due to process (26). For these molecules as the size of the transient anion increases its $\tau_{\mathrm{a}}$ increases [61] and hence, the effect of $N$ on $\mathrm{k}_{\mathrm{a}}(\langle\epsilon\rangle)$ is less for $\mathrm{n}-\mathrm{C}_{4} \mathrm{~F}_{10}$ compared to $\mathrm{C}_{3} \mathrm{~F}_{8}$.

To illustrate the effect of the state of matter on electron attachment and the relevance of electron attachment to molecules in low-pressure gases to those in liquids, we focus on the simple case where the electron attaching molecule $\left(\mathrm{SF}_{6}\right)$ in low-pressure gases captures thermal and epithermal energy electrons forming predominantly long-lived $\left(\tau_{a}>\right.$ $10^{-5} \mathrm{~s}$ ) parent anions $\left(\mathrm{SF}_{6}{ }^{-*}\right.$ ) and the liquid medium (liquefied Ar) has a conduction band $\left(\mathrm{V}_{\mathrm{o}}<0 \mathrm{eV} ; \mathrm{e}_{\mathrm{qf}}\right)$. In Fig. 26 the rate constant $\left(\mathrm{k}_{\mathrm{a}}\right)_{\mathrm{G}}$ for electron attachment to $\mathrm{SF}_{6}$ in low-pressure $(\lesssim 3 \mathrm{~atm})$ gaseous $\mathrm{Ar}(\mathrm{T} \simeq 300 \mathrm{~K})$ as a function of $\mathrm{E} / \mathrm{N}$ or $\langle\epsilon\rangle_{\mathrm{G}}$ (the mean electron energy in the gas) is compared with that, $\left(k_{a}\right)_{L}(E / N)$ in liquefied $\operatorname{Ar}(T \sim 87 K)$. The thermal value of $\left(\mathrm{k}_{\mathrm{a}}\right)_{\mathrm{G}}$ at $298 \mathrm{~K}$ and at $87 \mathrm{~K}$ (extrapolated) agree well with the liquid $\left(k_{a}\right)_{L}$ data for the lowest $E / N$, showing that $\left(k_{a}\right)_{G} \simeq\left(k_{a}\right)_{L}$ when the electron energy distribution is thermal. Indeed, in liquefied rare gases the attachment of slow electrons to $\mathrm{SF}_{6}$ forming $\mathrm{SF}_{6}{ }^{-}$is similar to that in gases both in magnitude and energy dependence (see discussion in [65]). This is actually the case for other molecules as can be seen from Fig. 27 where the $\mathrm{k}_{2}$ for $\mathrm{SF}_{6}, \mathrm{O}_{2}$, and $\mathrm{N}_{2} \mathrm{O}$ measured [124] as a function of the electric field strength $E$ is platted as a function of $\langle\epsilon\rangle_{L}$ (as determined in [65]).

In general $[11,12,65,69,109]$ for high mobility dielectric liquids $\left(\mu>>1 \mathrm{~cm}^{2} \mathrm{~V}^{-1} \mathrm{~s}^{-1}\right.$; $\mathrm{V}_{\mathrm{O}}<0 \mathrm{eV}$ ) the electron is quasi-free and its attachment to a molecule $\mathrm{AX}$ embedded in the liquid can be viewed - as in gases - as a vertical transition between the initial ( $\mathrm{e}+$ $\mathrm{AX})_{\mathrm{L}}$ and the final $\left(\mathrm{AX}^{-*}\right)_{\mathrm{L}}$ state; the attachment process depends on the properties of $\mathrm{AX}$ and the medium (especially $\mathrm{V}_{\mathrm{o}}$ ) and a comparison of $\left(\mathrm{k}_{\mathrm{a}}\right)_{\mathrm{L}}$ with $\left(\mathrm{k}_{\mathrm{a}}\right)_{\mathrm{G}}$ is possible. However, in liquids in which the electron is initially in a localized state, the rate determining step is the diffusive motion of the electron, and $\left(k_{a}\right)_{L}$ depends only weakly on the medium and varies little with $\mathrm{AX}$. In such cases $\left(\mathrm{k}_{\mathrm{a}}\right)_{\mathrm{L}}$ can attain diffusion-controlled 
values as long as a negative ion state of $\mathrm{AX}$ exists at thermal energies; this condition seems to be satisfied for most liquids when $\left(\epsilon_{\max }\right)_{\mathrm{G}} \lesssim 1 \mathrm{eV}[109]$. In these cases $\left(\mathrm{k}_{\mathrm{a}}\right)_{\mathrm{L}}$ can be expressed as

$$
\left(\mathrm{k}_{\mathrm{a}}\right)_{\mathrm{L}} \simeq 4 \pi \mathrm{R} \mathrm{D}_{\mathrm{e}}
$$

where $R$ is the encounter radius, and $D_{e}$ is the electron diffusion coefficient. Since, morfover, $\mathrm{D}_{\mathrm{e}}=(\mathrm{kT} / \mathrm{e}) \mu,\left(\mathrm{k}_{\mathrm{a}}\right)_{\mathrm{L}}$ is predicted to increase linearly with $\mu$, a behavior observed experimentally in some instances $[124,125]$. Finally, when the electron drifts part of the time as quasi-free and part of the time as localized, $\left(\mathrm{k}_{\mathrm{a}}\right)_{\mathrm{L}}$ can be expressed as

$$
\left(k_{a}\right)_{L}=\left(k_{a}\right)_{\ell} p+\left(k_{a}\right)_{f}(1-p)
$$

where $\left(k_{a}\right)_{\ell}$ and $\left(k_{a}\right)_{f}$ are, respectively, the attachment rate constants involving $e_{\ell}$ and $e_{q f}$ and $p$ is the probability of finding the electron in the localized state (see further discussion in [11]).

\section{ELECTRON-EXCITED MOLECULE INTERACTIONS}

The interactions of slow electrons with molecules depend not only on the electron energy, but also on the internal-energy content of the molecules themselves. While the study of electron-ground state molecule interactions traces back many decades, the study of electron-excited molecule interactions is just beginning. Indeed, little is known about the scattering of electrons from excited molecules in spite of their implicit significance in radiation and life sciences- -especially the initial stages of radiation action on matter-and in many applied areas such as lasers and plasmas.

Electron transport in "hot" (vibrationally-/rotationally-excited) gases has been shown to be influenced by the internal vibrational/rotational states $[1,2,74,126]$ and a number of recent studies $[8,9,112,113,127-133]$ have unraveled delicate and often large 
effects of the internal energy of molecules (e.g., freons, halocarbons, perfluorocarbons) on the decomposition of their transient anions by dissociative electron attachment and autodetachment. Dissociative electron attachment to molecules has been shown [ $[8,9,112,113,127-131$.$] to increase with increasing internal energy of molecules (Fig. 28a).$ On the other hand, nondissociative electron attachment to many molecules which form long-lived parent negative ions at ambient temperature (e.g., the perfluorocarbons $\mathrm{C}_{6} \mathrm{~F}_{0}$, $\left.\mathrm{n}-\mathrm{C}_{4} \mathrm{~F}_{10}, \mathrm{c}-\mathrm{C}_{4} \mathrm{~F}_{8}\right)$ has been shown $[8,9,129,131-133]$ to decrease when the gas temperature is increased above ambient (Fig. 28b). While the preponderance of the observations on the effect of internal energy of molecules on their dissociative electron attachment cross sections involved electron attachment to thermally-excited vibrational/rotational states of the ground electronic states of rnolecules, similar observations have been reported for vibrationally-excited molecules produced by laser irradiation [134].

Electron scattering from electronically-excited atoms and molecules is very limited indeed. The little information that exists on electronic excitation from metastable states suggests that the cross sections are substantially higher than those for the ground states. Thus, the scattering cross section for the reaction

$$
\mathrm{O}_{2}\left(\mathrm{a} \cdot_{\Delta_{\mathrm{g}}}+\mathrm{e}(4.5 \mathrm{eV}) \frac{}{2.3 \times 10^{-17} \mathrm{~cm}^{2}} \mathrm{O}_{2}^{*}\left(\mathrm{~b}^{1} \Sigma_{\mathrm{g}}^{+}\right)+\mathrm{e}^{\prime}\right.
$$

has been reported [135] to be $\sim 10$ times larger than that for the ground state, viz.,

$$
\mathrm{O}_{2}\left(\mathrm{X}^{3} \Sigma_{\mathrm{g}}^{-}\right)+\mathrm{e}(4.5 \mathrm{eV}) \frac{}{2.1 \times 10^{-18} \mathrm{~cm}^{2}} \mathrm{O}_{2}^{*}\left(\mathrm{~b}^{\mathrm{L}} \mathrm{g}_{\mathrm{g}}^{+}\right)+\mathrm{e}^{\prime}
$$

In keeping with this trend, the low-lying (excitation energy $\sim 0.98 \mathrm{eV}$ ) electronically-excited state $\mathrm{O}_{2}\left(\mathrm{~A}^{1} \Delta_{\mathrm{g}}\right)$ produced in a microwave discharge was shown to have 3 to 4 times iarger cross section for dissociative ejectron attachment compared to the $\mathrm{O}_{2}\left(\mathrm{X}^{3} \Sigma_{\mathrm{g}}^{-}\right)$ground-electronic state [136]. 
Recently a number of novel techniques have been developed $[10,137-139]$ for the study of electron attachment to electronically-excited molecules using lasers. The first observation of optically-enhanced electron attachment to electronically excited molecules was reported [137] in 1987. Thiophenol $\left(\mathrm{C}_{6} \mathrm{H}_{6} \mathrm{SH}\right)$ molecules were indirectly excited (via laser light absorption to high-lying optically-allowed states which undergo rapid internal conversion and efficient intersystem crossing) to their long-lived (lifetime $\sim 8 \mathrm{~ms}$ ) first-excited triplet states; at near-zero electron energies $\sim 5$ to 6 orders of magnitude larger electron attachment coefficients (due to dissociative attachment via these triplet states) were measured compared to the ground electronic states of these molecules (Fig. 29; $[10,137])$. Quite similar to the case of thiophenol, 5 to 7 orders of magnitude enhancement in electron attachment has been reported for the first-excited triplet states of p-benzoquinone and its methylated derivatives [140].

Very recently, Pinnaduwage et al. $[138,139]$ used a newly-developed technique for the study of electron attachment to short-lived $\left(<10^{-8} \mathrm{~s}\right)$ species. In this technique the same laser pulse that produces (via multiphoton absorption) the electronically-excited species also produces in their vicinity concomitantly (via multiphoton ionization of the same gas or of an additive gas) the attaching electrons. They claim to have observed electron attachment to superexcited states of molecules occurring with enormous $\left(>10^{-11}\right.$ $\mathrm{cm}^{2}$ ) cross sections which (for the triethylamine molecules investigated) are $\sim 10^{7}$ times larger than those for the ground state molecule. These incredibly large cross sections may involve high-lying Rydberg states (See discussion in [139]).

It is, therefore, clear that slow electrons colliding with electronically-excited molecules have electron attachment cross sections many (has high as 107) times larger than those for the ground state (unexcited) molecules. The optical control of the electron-molecule collision cross sections opens up new frontiers and new possibilities of ontically controlling the impedance characteristics of (gasenus) mat ter at times in the ls to 
ns range. The excited species are very reactive toward slow electrons. Slow electrons by transferring their energy to molecules, make the molecules and themselves more reactive. VIII. CONCLUDING REMARKS

Our understanding of the basic processes of radiation interaction with dense gaseous matter has advanced considerably over the last two decades. Progress has also been made in our efforts to link knowlerlge on radiation interactions in low-pressure gases with knowledge on such processes in dense fluids. The basic knowledge acquired illuminated broad areas of pure and applied science, led to new radiobiological and environmental-monitoring instrumsntation, and aided the development of many energy technologies.

In spite of the impressive progress, our knowledge still remains incomplete in a number of important areas (see a partial list in Table 4). Foremost among these are the interfacing of the gaseous and condensed phases of matter and the interactions of radiation (especially slow electrons and photons) with energy-rich (excited) atoms and molecules. The understanding of radiobiological effects and mechanisms from basic knowledge remains a challenge.

The long-range programs of the Office of the Health and Envirownental Research of the Department of Energy contributed fundamentally to these developments. 
Table 4: Radiation Interaction with Dense Fluids (Quasi-Liquids and Liquids): Some Future Research Areas

- Electron interactions with electronically-excited species.

- Electron diffusion and energies in dense fludds with conduction bands.

- Electron-impact ionization and excitation cross sections.

- Electron dynamics and fast (sub-picosecond) medium responses.

- Theoretical understanding of electron scattering and dynamics.

- Photon absorption by electronically-excited species.

- (Multi) photon ionization and energetics especially in polar media.

- Transient photoionization mechanisms.

- Ionic and neutral decomposition mechanisms.

- Relation of microscopic to macroscopic properties.

- $\quad$ Structured fluids.

- Fast pulse conductivity techniques.

- Liquici state electron and mass spectrometry. 


\section{REFERENCES}

1. L. G. Christophorou, Atomic and Molecular Radiation Physics, Wiley-Interscience New York, 1971.

2. L. G. Christophorou (Ed.), Electron-Molecule Interactions and Their Applications, Academic Press, Volumes 1 and 2, New York, 1984.

3. G. R. Freeman (Ed.), Kinetics of Nonhomogeneous Processes, Wiley-Interscience, New York, 1987.

4. E. E. Kunhardt, L. G. Christophorou, and L. H. Luessen (Eds.), The Liquild State and Its Electrical Properties, NATO ASI Series B: Physics, Vol. 193, Plenum Press, New York, 1987.

5. H.S.W. Massey, Electronic and Ionic Impact Phenomena, Oxford Press, Volumes I-IV, 1969.

6. M. Inokuti, in Applied Atomic Collision Physics, H.S.W. Massey, E. W. McDaniel and B. Bederson (Eds.), Vol. 4, Chapt. 3, 1983; I. Shimamura and K. Takayanagi (Eds.), Electron-Molecule Collisions, Plenum Press, New York, 1984.

7. E. W. McDaniel, Atomic Collisions, John Wiley \& Sons, New York, 1989.

8. L. G. Christophorou, D. L. McCorkle, and A. A. Christodoulides, Ref. 2, Vol 1, Chapt. 6.

9. L. G. Christophorou, Electron Attachment and Detachment Processes in Electronegative Gases, Pla.sma Physics, 27:237-281 (1987).

10. L. A. Pinnaduwage, L. G. Christophorou, and S. R. Hunter, Optically Enhanced Electron Attachment to Thiophenol, J' Chem. Phys. 90:6275-6289 (1989).

11. L. G. Christophorou and K. Siomos, Ref, 2, Vol, 2, Chapt. 4.

12. L. G. Christophorou, Ref. 4, pp. 283-316.

13. S. R. Hunter, J. G. Carter, and L. G. Christophorou, Electron Attachment and Ionization Processes in $\mathrm{CF}_{4}, \mathrm{C}_{2} \mathrm{~F}_{\theta}, \mathrm{C}_{3} \mathrm{~F}_{8}$, and $\mathrm{n}-\mathrm{C}_{4} \mathrm{~F}_{10}$, J. Chem. Phys. 86:693-703 (1987). 
14. S. R, Hunter, J, G. Carter, and L, G. Christophorou, Electron Transport Measurements in Methane Using an Improved Pulsed Townsend Technique, J. Appl. Phys, 60:24-35 (1986).

15. S. E. Derenzo, T. S. Mast, H. Zaklad, and R. A. Muller, Electron Avalanche in Liquid Xenon, Phys. Rev. A 9:2582-2591 (1074).

16. I. György and G. R. Freeman, Ionlzation and Electron Thermalization Distances in Isomeric Pentanes: Effects of Molecular Shape and Density, J. Chem. Phys. 86:681-687 (1987).

17. R. A. Holroyd and D. F. Anderson, The Physics and Chemistry of Room-Temperature Liquid-Filled Ionization Chambers, Nucl. Instr. Meth. Phys. Res. A236:294-299 (1985).

18. T. G, Ryan and G, R. Freeman, Electron Mobilities and Ranges in MethylSubstituted Pentanes Through the Liquid and Critical Regions, J. Chem. Phys. 86:5144-5150 (1978).

19. S.S.-S. Huang and G. R. Freeman, Effect of Density on the Total Ionization Yilelds in X-Irradiated Argon, Krypton, and Xenon, Can. J. Chem. 55:1838-1845 (1977).

20. T. Takahashi, S. Konno, and T. Doke, The Average Energies, W, Required to Form an Ion Pair in Liquefied Rare Gases, J. Phys. C7:230-240 (1974).

21. P. G. Fuochi and G. R. Freeman, Molecular Structure Effects on the Free-Ion Yields and Reaction Kinetics in the Radiolysis of the Methyl-Substituted Propanes and Liquid Argon: Electron and Ion Mobilities, J. Chem. Phys. 56:2333-2341 (1972).

22. W. F, Schmidt and A, O. Allen, Free--Ion Yields in Sundry Irradiated Liquids, $J$. Chem. Phys. 52:2345-2351 (1970).

23. S. Geer, R. A. Holroyd and F. Ptohos, Field Dependent Free Ion Yiclds of Room Temperature Tetramethyl Liquids and Their. Mixtures, Nucl. Instr. Meth. Phys. Res. A287:4.47-451 (1990). 
24. $E=4 \times 10^{4} \mathrm{~V} \mathrm{~cm}{ }^{4} ;$ R. C. Munoz, J, B. Cumming, and R. A. Holroyd, Ionization of Tetramethylsilane by Alpha Particles, Chem. Phys. Lett, 115:477-480 (1985).

25. I. Lopes, H. Hilmert, and W. F. Schmidt, Lonization of Some Molecular Gases by ${ }^{00}$ Co- - Radiation: W-Values, Radiat. Phys, Chem. 29:93-95 (1987).

28. J.-P. Dodelet and G. R. Freeman, Mobilities and Ranges of Electrons in Liquids: Effect of Molecular Structure in $\mathrm{C}_{6}-\mathrm{C}_{12}$ Alkanes, Can. J. Chem. 50:2667-2679 (1972).

27. B. S. Yakovlev and L. V. Lukin, in Photodissociation and Photolonization, K. P. Lawrey (Ed.), John Wiley \& Sons, New York, p. 99, 1985.

28. R. A. Holroyd and R. L. Russell, Solvent and Temperature Effects in the Photoionization of Tetramethyl-p phenylenediamine, J. Phys. Chem. 78:2128-2135 (1974).

29. R. Reininger, V. Saile, P. Laporte, and I. T. Steinberger, Photoconduction in Rare Gas Flulds Doped With Small Organic Molecules, Chem. Phys. 89:473-479 (1981).

30. R. Reininger, V. Saile, G. L. Findley, P. Laporte, and I. T. Steinberger, in Photophysics and Photochemistry Above $6 \mathrm{eV}, \mathrm{F}$. Lahmani (Ed.), Elsevier Science Publishers, Amsterdam, 253; U. Asaf and I. T. Steinberger, Photoconductivity and Electron Transport Parameters in Liquid and Solid Xenon, Phys. Rev. B 10:4464-4468 (1974).

31. J. Casanovas, R. Grob, D. Delacroix, J. P. Guelfucci, and D. Blanc, Photoconducitivity Studies in Some Nonpolar Liquids, J. Chem. Phys. 75:4661-4668 (1981).

32. E.-H. Böttcher and W. F. Schmidt, Photoconductivity of Nonpolar Liquids Induced by Vacuum-.Ultraviolet Light, J. Chem. Phys. 80:1353-1359 (1984).

33. H, Faidas and L, G. Christophorou, Determination of the Ionization Threshold of Azulene in Hydrocarbon Liquids by Multiphoton Ionization, J. Chem. Phys. 
88:8010-8011. (1988); Laser Multiphoton Ionization of Aromatic Moleculen in Nonpolar Liquids, Radiat. Phys, Chem. 32:433-438 (1988),

34. H. Faidas, L. G. Christophorou, P. G. Datskos, and D, L. McCorkle, The Ionization Threshold of $\mathrm{N}, \mathrm{N}, \mathrm{N}^{\prime}, \mathrm{N}^{\prime}-$ Tetramethyl-p-phenylenediamine, J. Chem. Phys. 90:6618-6628 (1089),

35. R. D. Lovin and S. G. Lias, Ionization Potential and Appearance Potential Measurements 1071-1081, Department of Commerce NSRDS-NBS-71, NBS October 1982.

36. A. O. Allen, Drift Mobilities and Conduction Band Energies of Excess Electrons in Dielectric Liquids, NSRDS-NBS 58, May 1076.

37. H. A. Holroyd, S. Tames, and A. Kennedy, Effect of Temperature on Conduction Bind Energies of Electrons in Nonpolar Liquids, J. Phys. Chem. 70:2857-2861 (1.875).

38. L.-H, Böttcher, Experimentelle Untersuchung der phutoulektrischen Leitung reiner und mit aromatischen Molektlen dotierter organischer Flidssingkeiten, $G m b H$ HMI-B406, Berlin, 1084.

39. K. Buschick and W. F. Schmidt, Vacuum Ultraviolet Photoconductivity of 2,2,4,4-T'etramethylpentane and Bis (Trimethylsilyl) Ethane, IEEE Trans. Electr. Insul. 24:353-356 (1980).

40. H. Faidas and L. G. Christophorou, Multiphoton Ionization of Fluoranthene in Tetramethylsilane, J. Chem. Phys. 86:2505-2509 (1087).

4!. I. Roberts and E. G. Wilson, The Intrinsic Photoconductivity of Liquid Xenon, $J$. Phys. C 0:2169-2183 (1073).

42. R. A. Holroyd, J. M. Preses, and N. Zevos, Single-Photon Induced Conductivity of Solutes in Nonpolar Solvents, J. Chem. Phy/g, 79:483-487 (1983).

43. B. Raz and J. Jortner, Energy of the Quasi-Free Electron State in Liquid and Solid Rare Gases, Chem. Phys. Lett. 4:155-158 (1969). 
44. M. Born, Volumen und Hydratationswärme der Ionen, Z. Phys. 1:45-48 (1920).

45. I. Messing and J, Jortner, Adiabatic Polarization Energy in a Slmple Dense Flud, Chem. Phys. 21:183-189 (1977).

46. B. E. Springett, J. Jortner, anc M. H. Cohen, St billty Criterion for the Localization of an Excess Electron in a Nonpolar Fludd, J. Chem. Phys. 48:2720-2731 (1968).

47. S. Noda, L, Kevan, and K. Fueki, Conduction State Energy of Excess Electrons in Condensed Media: Lilquid Mothane, Ethane, and Argon and Glassy Matrices, J. Phys. Chem. 79:2866-2874 (1975).

48. Y. Yamaguchi, T. Nakajima, and M. Nishkawa, Conduction Band Lnergy in Dense Ethane Fluid, J. Chem. Phys. 71:550-551 (1079).

49. U. Asaf and I. T. Steinberger, The Energies of Excess Electrons in Hellum, Chem. Phys, Lett, 128:91-84 (1986); R. Reininger, U. Asaf, I. T. Steinberger and S. Basak, Relationship Between the Fnergy $\mathrm{V}_{0}$ of the Quasi-Free Electron and Its Mobility in Fluid Argon, Krypton, and Xenon, Phys. Rev, B 28:4426-4432 (1083); U. Asaf, R. Reininger, and I. T', Steinberger, The Energy $\mathrm{V}_{0}$ of the Quasi-Firee Electron in Gaseous, Lidquid, and Solid Methane, Chem. Phys. Lett, 100:363-360 (1083); J. T. Steinberger, in Ref. [4], p. 235.

50. U. Asaf, W. S. Felps, K. Pupnik, S. P. McGlynn and G. Ascarelli, Density Effocts of High-n-Molecular R.ydberg States: $\mathrm{CH}_{3} \mathrm{I}$ and $\mathrm{C}_{4} \mathrm{H}_{0}$ in $\mathrm{H}_{2}$ and $\mathrm{Ar}, J$. Chem. Phys, 01:5170-5174 (1080).

51. L. Fermi, Sopra lo spostamento per pressione delle righe elevate delle serie spettrali, Nuovo Cimento 11:157-166 (1.934).

52. V. A. Alekseev and I. I. Sobel'man, JETP 22, 882 (1066).

53. L. Onsager, Initial Recombination of Ions, Phys. Rev. 54:554-557 (1038). 
54. H. Lu, F, H. Long, R. M. Bowman, and K. B. Elsenthal, Iemptosecond Studies of Glectron-Cation Geminate Rocombination in Wator, J. Phys. Chem. 03:27-28 (1989).

55. C. Ferradini a.ıd J,-P. Jay-Gerin, Radiolysis of Liquids With High Static Dielactric Constant: An Estimate of the Total Ionization Yleld, Electron Thermalization Distance, and Contribution of Heterogeneolis Reactions, J. Cherr. Phys. 89:0710-0722 (1088); J.-P. Jay-Gorin, and C. Ferradini, On the Variation of the Free-Ion Yield With the Static Dielectric Constant in the Radiolysis of Liquids, Radiat. Phys, Chem, 33:251-253 (1980),

50. R. M. Bowmen, H, Lu, and K. B. Eisonthal, Femptosecond Study of Geminate Electron-Hole Recombination in Neat Alkanes, J. Chern. Phys. 80:606-608 (1988).

57. J. M. Warman, E. S. Sennhausor, and D. A. Armstrong, Three-Body Electron-Ion Recombination in Molocular Gases, J. Chem. Phys. 70:095-999 (1079); E. S. Sennhauser, D. A. A mstrong, and J. M. Warman, The Temperature Dependence of 'Three-Body Electron Ion Recombination in Gaseous $\mathrm{H}_{2} \mathrm{O}, \mathrm{NH}_{3}$, and $\mathrm{CO}_{2}$, Radiat. Phyg. Chem, 15:479-483 (1080).

58. Y. Nakamura, K. Shinsaka, and Y. Hatano, Electron Mobilities and Electron-Ion Recombination Rate Constants in Solid, Liquid, and Gaseous Methane, J. Chem. Phys. 78:5820-5824 (1083).

50. N. Gee and G, R, Froeman, Density and Temperature Lffects on Electron Mobility In Filuid Methane, Phys. Rev. A20:1152-1161 (1979).

60. N. E. Cipollini, R. A. Holroyd, and M. Nishikawa, Zero-Field Mobility of Excess Eilectrons in Dense Methane, J. Chem. Phys. 07:4636-4039 (1077).

61. S. R. Hunter and L. G. Chrlstophorou, Electron Attachment to the Perfluoroalkanes ${ }_{n-C_{N}} F_{2 N+2}(N=1$ to 6) Using High-Pressure Swarm Techniques, J. Chem. Phys. 80:6150-6164 (1084).

62. I. G. Christophorou, P. G. Datskos, and J. G. Carter (to be published). 
63. M. Hayash, in Swarm Studies and Inelastic Electron-Molecule Cullisionis, pp. 167-18\%, L. C, Pitchford, B. V. McKoy, A. Chutjlan, and S. Trajmar (Eds.) Springer-Verlag, New York, 1987.

64. W. F. Schmidt, Electron Conduction Processes in Dielectric Liquids, IEEE Trans. Electr. Insul. EI-19:389-418 (1984).

65. L. G. Christophorou, S. R. Hunter, and J. G. Carter, Electron Attachment to $\mathrm{SF}_{\theta}$ in Gaseous Ar and $\mathrm{Xe}$; Comparison to Results in Liquid Ar and Xe and Energy of Excess Electrons, Radiat. Phys. Chem. 34:819-827 (1989).

66. E. Shibamura, T. Takahash, S. Kubota, and T. Doke, Ratio of Diffusion Coefficient to Mobility for Electrons in Liquid Argon, Phys. Rev. A20:2547-2554 (1979).

67. S. Kubota, T. Takahashi, and J. Ruangen, Hot Electron Relaxation in Solid and Liquid Argon, Krypton and Xenon, J. Phys. Soc. Japan 51:3274-3277 (1982).

68. S. Nakamura, Y. Sakal, and H. Tagashira, Effective Momentum Transfer Cross Section for Excess Electrons in Liquid Argon, Chern. Phys. Lett. 130:551-554 (1986).

69. L. G. Christophorou, Mean Energy of Excess Electrons in Liquid Ar as a Function of $\mathrm{E} / \mathrm{N} ;$ Electron Attachment to $\mathrm{N}_{2} \mathrm{O}$ in Gaseous and Liquid Ar, Chem. Phys. Lett. $121: 408-411(1985)$.

70. E. M. Gushchin, A. A. Kruglov, and I. M. Obodovskii, Electron Dynamics in Condensed Argon and Xenon, Sov. Phys. JETP 55:650-655 (1982).

71. J. Lekner, Motion of Electrons in Liquicl Argon, Phys. Rev. 158:130--137 (1967).

72. G. Bakale and G. Beck, Field-Dependent Electron Attachment in Liquid Tetramethylsilane, J. Chem. Phys. 84:5344-5350 (1086).

73. H. Faddas, L. G. Christophorou, D. L. McCorkle, and J. G. Carter, Electron Drift Velocities and Electron Mobilities in Fast Room Temperature Dielectric Liquids and Their Corresponding Vapors, Nuch. Instr. Meth. Phys. Res. (in press). 
74. L.G.H. Huxley and R. W. Crompton, The Diffusion and Drift of Electrons in Gases, Wiley-Interscience, Now York, 1074.

75. W. L. Morgan, A Bibliography of Electron Swarm Data 1978-1989, JILA Data Center Report No. 33, NIST, Boulder, Colorado, July 1990.

70. L. C. Pitchford and A. V. Phelps, Comparative Calculations of Electron Swarm Properties in $\mathrm{N}_{2}$ at Moderate E/N Values, Phys, Rev. A25:540-554 (1982).

77. G. L. Braglia, L. Romano, and M. Diligenti, Comment on "Comparative Calculations of Electron Swarm Properties in $\mathrm{N}_{2}$ at Moderate E/N Values," Phys. Rev. A26:3680-3694 (1982).

78. M. Yousfi, P. Ségur, and T. Vassiliadis, Solution of the Boltzmann Equation With Ionization and Attachment: Application to $\mathrm{SF}_{0}$, J. Phys. D 18:359-375 (1985).

79. S. Yachi, Y. Kitamura, K. Kitamori, and H. Tagashira, A Multi-Term Boltzmann Equation Analysis of Electron Swarms in Gases, J. Phys. D 21:914-921 (1988).

80. J. J. Lowke, A. V. Phelps, and B. W. Irwin, Predicted Electron Transport Coefficients and Operating Characteristics of $\mathrm{CO}_{2}-\mathrm{N}_{2}-\mathrm{He}$ Laser Mixtures, J. Appl. Phys. 44:4664-4671 (1973).

81. B. R. Bulos and A. V. Phelps, Excitation of the $4.3 \mu \mathrm{m}$ Bands of $\mathrm{CO}_{2}$ by Low-inergy Electrons, Phys. Rev. A14:615-629 (1976).

82. D. Rapp and P. Englander-Golden, Total Cross Sections for Ionization and Attachment in Gases by Electron Impact: I Positive Ionization, J. Chem. Phys. 43:1464-1479 (1965).

83. S. R. Hunter and L. G. Christophorou, Ref. 2, Vol. 2, p. 202.

84. T, F, O'Malley, Electron Diffusion and the Einstein Relation in High-Density Gases, Phys. Lett. 95 A:32-34 (1983).

85. V. M. Atrazhev and I. T. Yakubov, The Electron Drift Velocity in Dense Gases, $J$. Phys. D 10:2155-21.63 (1977); Electron Mobility in Liquids and Dense Gases, High Temp. 18:966-985 (1980). 
86. G. L. Braglia and V. Dallacasa, Theory of the Density Dependence of Electron Drift Velocity in Gases, Phys. Rev. A 18:711-717 (1978); Theory of Electron Mobility in Dense Gases, Phys. Rev. A 26:902-914 (1982).

87. M. H. Cohen and J. Lekner, Theory of Hot Electrons in Gases, Liquids, and Solids, Phys. Rev. 158:305-309 (1967); J. Lekner, Mobility Maxima in the Rare-Gas Liquids, Phys. Liett. A27:341-348 (1968); S. Basak and M. H. Cohen, Deformation-Potential Theory for the Mobility of Excess Electrons in Liquid Argon, Phys. Rev. B 20:3404-3414 (1979); H. T. Davis, L. D. Schmidt, and R. M. Minday, Kinetic Theory of Excess Electrons in Polyatomic Gases, Liquids, and Solids, Phys. Rev. A 3:1027-1037 (1971).

88. T. F. O'Malley, Multiple Scattering Effect on Electron Mobilities in Dense Gases, J. Phys. B 13:1491-1504 (1980).

89. L. G. Christophorou, Mobilities of Slow Electrons in Low- and High-Pressure Gases and Liquids, Intern. J. Radiat. Phys. Chem. 7:205-221 (1975).

90. H. Lehning, Resonance Capture of Very Slow Electrons in $\mathrm{CO}_{2}$, Phys. Lett. 28A:103-104 (1968).

91. Th. Aschwanden, in Gaseous Dielectric III, L. G. Christophorou, (Ed.), Pergamon, New York, 1982, p. 32.

92. L. G. Christophorou, J. G. Carter, and D. V. Maxey, Electron Motion in High-Pressure Polar Gases: $\mathrm{NH}_{3}, J$. Chem. Phys. 76:2653-2661 (1982).

93. P. Krebs and M. Heintze, Migration of Excess Electrons in High Density Supercritical Ammonia, J. Chem. Phys. 76:5484-5492 (1982); P. Krebs, Localization of Excess Electrons in Dense Polar Vapors, J. Phys. Chem. 88:3702-3709 (1984).

94. V. V. Dmitrenko, A. S. Romanyuk, S. I. Suchkov, and Z. M. Uteshev, Electron Mobility in Dense Xenon Gas, Sov. Phys. Tech. Phys. 28:1440-1444 (1983).

9̄5. G. K. Freeman, in Electron and Ion Swarms, L. G. Christophorou (Ed.), Pergamon, New York, (1981), p. 93.. 
96. A. G. Robertson, Drift Velocities of Low-Energy Electrons in Argon at 293 and 90 K, Aust. J. Phys. 30:39-49 (1977).

97. S. R. Hunter, J. G. Carter, and L. G. Christophorou, Low-Energy Electron Drift and Scattering in Krypton and Xenon, Phys. Rev. A38:5539-5551 (1988).

98. L. S. Miller, S. Howe, and W. E. Spear, Charge Transport in Solid and Liquid Ar, $\mathrm{Kr}$, and Xe, Phys. Rev. 166:871-878 (1968).

99. Y. Sakai, S. Nakamura, and H. Tagashira, Drift Velocity of Hot Electrons in Liquid $\mathrm{Ar}, \mathrm{Kr}$, and Xe, IEEE Trans. Electr. Insul. EI--20:133-137 (1985).

100. L. G. Christophorou and D. L. McCorkle, Experimental Evidence for the Existence of a Ramsauer-Townsend Minimum in Liquid $\mathrm{CH}_{4}$ and Liquid $\mathrm{Ar}$ ( $\mathrm{Kr}$ and $\mathrm{Xe}$ ), Chem. Phys. Lett. 42:533-539 (1976).

101. W. F. Schmidt, in [4], p. 273.

102. H. Faidas, L. G. Christophorou, and D. L. McCorkle, Electron Transport in Fast Dielectric Liquids at High Applied Electric Fields, Proceedings 10th Intern. Conf. on Conduction and Breakdown in Dielectric Liquids, Grenoble, France, September 10-14, 1990, p. ; Drift Velocities of Excess Electrons in 2,2,4,4Tetramethylpentane and Tetramethylsilane: A Fast Drift Technique, Chem. Phys. Lett. 163:495-498 (1989).

103. C. Brassard, Liquid Ionization Detectors, Nucl. Instr. Meth. 162:29-47 (1979); J. Engler and H. Keim, A Liquid Ionization Chamber Using Tetramethylsilane, Nucl. Instr. Meth. Phys. Res. 223:47-51 (1984).

104. M. G. Albrow et al. Performance of a Uranium/Tetramethylpentane Electromagnetic Calorimeter, Nucl. Instr. Meth. A265:303-318 (1988).

105. L. G. Christophorou and H. Faidas, Dielectric Liquids for Possible Use in Pulsed Power Switches, Appl. Phys. Lett. 55:948-950 (1989).

106. J. E. Demüth, D. Schimeisser, and Fon. Ávouris, Resonance Scattering of Electrons From $\mathrm{N}_{2} . \mathrm{CO}, \mathrm{O}_{2}$, and $\mathrm{H}_{2}$. Adsorbed on a Silver Surface, Phys. Rev. Lett. 
47:1166-1169 (1981); L. Sanche and M. Michaud, Resonance-Enhanced Vibrational Excitation in Electron Scattering From $\mathrm{O}_{2}$ Multilayer Films, Phys. Rev. Lett. 47:1008-1011 (1981); Vibrational Excitation Via Shape Resonances in Electron Scattering From $\mathrm{N}_{2}$ Multilayer Films, Chem. Phys. Lett. 84:497-500 (1981); L. Sanche, Investigation of Ultra-Fast Events in Radiation Chemistry With Low-Energy Electrons, Radiat. Phys. Chem. 34:15-33 (1989); Low-Energy Electron Scattering From Molecules on Surfaces, J. Phys. B 23:1597-1624 (1990).

107. R. E. Goans and L. G. Christophorou, Attachment of Slow $(<1 \mathrm{eV})$ Electrons to $\mathrm{O}_{2}$ in Very High Pressures of Nitrogen, Ethylene, and Ethane, J. Chem. Phys. 60:1036-1045 (1974).

108. D. L. McCorkle, L. G. Christophorou, and V. E. Anderson, Low-Energy $(<1 \mathrm{eV})$ Electron Attachment to Molecules at Very High Gas Densities: $\mathrm{O}_{2}, J$. Phys. $B$ 5:1211-1220 (1972).

109. L. G. Christophorou, Intermediate Phase Studies for Understanding Radiation Interaction in Condensed Media: The Electron Attachment Process, J. Phys. Chem. 76:3730-3734 (1972); Electron Attachment to Molecules in Dense Gases ("Quasi-Liquids"), Chem. Rev. 76:409-423 (1976).

110. T. D. Märk and A. W. Castleman, Jr., in Advances in Atomic and Molecular Physics, Academic Press, Orlando, Florida, D. R. Bates and B. Bederson (Eds.), Vol. 20, 1985, p. 65-172; A. W. Castleman, Jr. and R. G. Keesee, Gas-Phase Clusters: Spanning the States of Matter, Science 241:36-42 (1988); R. G. Keesee and A. W. Castleman, Jr., in Atomic and Molecular Clusters, E. R. Bernstein, (Ed.), Elsevier, Armsterdam, 1990, pp. 507-550; R. N. Compton and J. N. Bardsley, in Electron-Molecule Collisions, I. Shimamura and K. Takayanagi, (Eds.), Plenum, New York, 1984, pp. 275-349.

11i. L. G. Chrisistophôtôu, The Lifetimes of Metastable Negative Ions, $A d v$. Elentron. Electron Phys. 46:55-129 (1978). 
112. H.S.W. Massey, Negative Ions, Cambridge University Press, Cambridge, 1976.

113. B. M. Smirnov, Negative Ions, McGraw-Hill, New York, 1982.

114. L. G. Christophorou and S. R. Hunter, Ref. 2, Vol. 2, Chapt. 5.

115. L. G. Christophorou, D. L. McCorkle, D. V. Maxey, and J. G. Carter, Fast Gas Mixtures for Gas-Filled Particle Detectors, Nucl. Instr. Meth. 163:141-149 (1979); M. K. Kopp, K. H. Valentine, L. G. Christophorou, and J. G. Carter, New Gas Mixture Improves Performance of ${ }^{3} \mathrm{H}$ Neutron Counters, Nucl. Instr. Meth. 201:395-401 (1982); L. G. Christophorou, H. Faidas and D. L. McCorkle, in Non-Equilibrium Effects in Ion and Electron Transport, J. W. Gallagher, D. F. Hudson, E. E. Kunhardt, and R. J. Van Brunt (Eds.), Plenum, New York, 1990, pp.

116. A. Zlatkis and C. F. Poole (Eds.), Electron Capture: Theory and Practice in Chromatography; Journal of Chromatography Library, Vol. 20, Elsevier Scientific Publishing Company, Armsterdam, 1981; L. G. Christophorou, D. L. McCorkle, and I. Sauers, Tagging Materials for Detection of Explosives, Analytical Chimica Acta 135:179-192 (1982).

117. L. G. Christophorou and D. W. Bouldin (Eds.), Gaseous Dielectrics V, Peryamon, New York, 1987; L. G. Christophorou and M. O. Pace (Eds.), Gaseous Dielectrics IV, Pergamon, New York, 1984; L. G. Christophorou and L. Pinnaduwage, Basic Physics of Gaseous Dielectrics, IEEE Trans. Electr. Insul. 25:55-74 (1990).

118. A. Guenther, M. Kristiansen, and T. Martin (Eds.), Opening Switches, Plenum, New York, 1987; L. G. Christophorou, Electron Collisions in Gas Switches, in Non-Equilibrium Processes in Partially Ionized Gases, M. Capitelli and J. N. Bardsley (Eds.), Plenum, New York, 1990; S. R. Hunter, J. G. Carter and L. G. Christophorou, Electron Transport Studies of Gas Mixtures for Use in e-Beam Controlled Diffuse Discharge Switches, J. Appl. Phys. 58:3001-3015 (1985).

119. G. E. Caledonia, A Survey of the Gas-Phase Negative Ion Kinetics of Inorganic Molecules. Electron Attachment Reactions, Chem. Rev. 75:333-351 (1975). 
120. L. G. Christophorou, Interactions of $\mathrm{O}_{2}$ With Slow Electrons, Radiat. Phys. Chem. 12:19-34 (1978).

1.21. Y. Hatano and H. Shimamori, in Electron and Ion Swarms, L. G. Christophorou (Ed.), Pergamon Press, New York, pp. 103-116, 1981.

122. H. Shimamori and Y. Hatano, Mechanism of Thermal Electron Attachment in $\mathrm{O}_{2}-\mathrm{N}_{2}$ Mixtures, Chem. Phys. 12:439-445 (1976); H. Shimamori and R. W. Fessenden, Thermal Electron Attachment to Oxygen and Van der Waals Molecules Containing Oxygen, J. Chem. Phys. 74:453-466 (1981).

123. S. R. IIunter, L. G. Christophorou, D. L. McCorkle, I. Sauers, H. W. Ellis, and D. R. James, Anorialous Electron Attachment Properties of Perfluoropropylene $\left(1-\mathrm{C}_{3} \mathrm{~F}_{6}\right)$ and Their Effect on the Breakdown Strength of This Gas, J. Phys. $D$ 16:573-580 (1982).

124. G. Bakale, U. Sowada, and W. F. Schmidt, Effect of an Electric Field on Electron Attachment to $\mathrm{SF}_{6}, \mathrm{~N}_{2} \mathrm{O}$, and $\mathrm{O}_{2}$ in Liquid Argon and Xenon, J. Phys. Chem. 80:2556-2559 (1976).

125. G. Bakale and W. F. Schmidt, Effect of an Electric Field on Electron Attachment to $\mathrm{SF}_{6}$ in Liquid Ethane and Propane, Z. Naturforsch. 36a:802-806 (1981).

126. S. R. Hunter and L. G. Christophorou, Basic Studies of Gases for Fast Switches, Oak Ridge National Laboratory Report ORNL/TM-10844, August 1988.

127. T. F. O'Malley, Calculation of Dissociative Attachment in Hot $\mathrm{O}_{2}$, Phys. Rev. 155:59-63 (1967); J. N. Bardsley and J. M. Wadehra, Dissociative Attachment and Vibrational Excitation in Low-Energy Collisions of Electrons With $\mathrm{H}_{2}$ and $\mathrm{D}_{2}$, Phys. Rev. 20:1398-1405 (1979); Dissociation Attachment in HCl, DCl, and $\mathrm{F}_{2}, J$. Chem. Phys. 78:7227-7234 (1983).

128. S. M. Spyrou and L. G. Christophorou, Effect of Temperature on the Dissociative Electron Attachment to $\mathrm{CClF}_{3}$ and $\mathrm{C}_{2} \mathrm{~F}_{6}, J$. Chem. Phys. 82:2620-2629 (1985). 
129. E. Alge, N. G. Adams, and D. Smith, Rate Coefficients for the Attachment

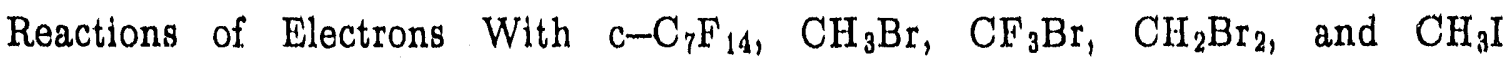
Determined Between 200 and $600 \mathrm{~K}$ Using the FALP Technique, J. Phys. $B$ $17: 3827-3833$ (1984).

130. S. M. Spyrou and L. G. Christophorou, Effect of Temperature of the Dissociative and Nondissociative Electron Attachment to $\mathrm{C}_{3} \mathrm{~F}_{8}, J$. Chem. Phys. 83:2829-2835 (1985); P. G. Datskos and L. G. Christophorou, Variation With Temperature of the Electron Attachment to $\mathrm{SO}_{2} \mathrm{~F}_{2}, \quad J$. Chem. Phys. 90:2626-2630 (1989); P. G. Datskos, L. G. Christophorou, and J. G. Carter, Temperature-Enhanced Electron Attachment to $\mathrm{CH}_{3} \mathrm{Cl}$, Chem. Phys. Lett. 168:324-329 (1990); P. J. Chantry and C. L. Chen, Ionization and Temperature Dependent Attachment Cross Section Measurements in $\mathrm{C}_{3} \mathrm{~F}_{8}$ and $\mathrm{C}_{2} \mathrm{H}_{3} \mathrm{Cl}$, J. Chem. Phys. 90:2585-2592 (1989).

131. P. G. Datskos and L. G. Christophorou, Variation of Electron Attachment to n- $\mathrm{C}_{4} \mathrm{~F}_{10}$ With Temperature, J. Chem. Phys. 86:1982-1990 (1987).

132. S. M. Spyrou and L. G. Christophorou, Effect of Temperature on Nondissociative Electron Attachment to Perfluorobenzene, J. Chem. Phys. 82:1048-1049 (1985).

133. A. A. Christodoulides, L. G. Christophorou, and D. L. McCorkle, Effect of Temperature on Low-Energy $(<1 \mathrm{eV})$ Electron Attachment to Perfluorocyclobutane $\left(\mathrm{c}-\mathrm{C}_{4} \mathrm{~F}_{8}\right)$, Chem. Phys. Lett. 139:350-356 (1987).

134. C. L. Chen and P. J. Chantry, Photon-Enhanced Dissociative Electron Attachment in $\mathrm{SF}_{6}$ and Its Isotopic Selectivity, J. Chem. Phys. 71:3897-3907 (1979); I. M. Beterov and N. V. Fateyev, Laser Optogalvanic Effects Caused by Formation of Negative Ions, J. de Phys. (Paris), Collog, C7:447 (1983); M. W. McGeoch and R. E. Schlier, Dissociative Attachment in Optically Pumped Lithium Molecules, Phys. Rev. A 33:1708-1717 (1986).

135. R. I. Hall and S. Trajmar, Scattering of $4.5 \mathrm{eV}$ Electrons by Ground (X ${ }^{3}$ gg) State and Metastable $\left(\mathrm{a}^{1} \Delta_{\mathrm{g}}\right)$ Oxygen Molecules, J. Phys. B 8:L293--L296 (1975). 
136. P. D. Burrow, Dissociative Attachment to $\mathrm{O}_{2}\left(\mathrm{a}^{1} \Delta_{\mathrm{g}}\right)$ State, J. Chem. Phys. 59:4922-4.931 (1973); D. S. Belic and R. I. Hall, Dissociative Electron Attachment to Metastable Oxygen $\left(a^{1} \Delta_{g}\right)$, J. Phys, B 14:365-373 (1981).

137. L. G. Chrigtophorou, S. R. Hunter, L. A. Pinnaduwage, J. G. Carter, A. A. Christodoulides, and S. M. Spyrou, Optically-Enhanced Electron Attachment, Phys, Rev. Lett. 58:1316-1319 (1987).

138. I. A. Pinnaduwage and L. G. Christophorou, Measurement of Electron Attachment to Superexcited States of Saturated Tertiary Amines, Phys. Rev. Lett. (submitted).

139. L. A. Pinnaduwage, L. G. Christophorou, and A. P. Bitouni, A Novel Technique for the Measurement of Electron Attachment to Short-Lived, Laser-Excited Species, J. Chem. Phys. (submitted).

140. R. S. Mock and E. P. Grimsrud, Optically-Enhanced Electron Capture by p-Benzoquinone and Its Methylated Derivatives, J. Phys. Chem. 94:3550-3553 (1990). 


\section{FIGURE CAPTIONS}

Fig. 1: Density-normalized electron impact ionization coefficients $\alpha / \mathrm{N}$ versus $\mathrm{E} / \mathrm{N}$ for $\mathrm{CF}_{4}, \mathrm{CH}_{4}, \mathrm{C}_{2} \mathrm{~F}_{6}, \mathrm{C}_{3} \mathrm{~F}_{8}$, and $\mathrm{n}-\mathrm{C}_{4} \mathrm{~F}_{10}[13,14]$. Note that the $\alpha / \mathrm{N}(\mathrm{E} / \mathrm{N})$ curves shift to higher $E / N$ values as the molecular size is increased. This is because $\alpha / \mathrm{N}$ is related to $\sigma_{1}(\epsilon)$ and $f(\epsilon, \mathrm{E} / \mathrm{N})$ by $\alpha / \mathrm{N}(\mathrm{E} / \mathrm{N})=(2 / \mathrm{m})^{\frac{1}{2}}$ $\int_{0}^{\infty} \sigma_{j}(\epsilon) \epsilon^{\frac{1}{2}} \mathrm{f}(\epsilon, \mathrm{E} / \mathrm{N}) \mathrm{d} \epsilon$ and as the molecule becomes mo-e complex, $\mathrm{f}(\epsilon, \mathrm{E} / \mathrm{N})$ shifts to lower energies for a fixed $\mathrm{E} / \mathrm{N}$ due to the increase in the energy loss processes.

Fig. 2: (a) The slope (order of multiphoton ionization) as a function of laser excitation wavelength for the azulene molecule in liquid 2,2,4,4-tetramethylpentane (TMP). Regions I, III, and II, correspond respectively to wavelength ranges where two-photon, three-photon and both two- and three-photon ionization occurs. The arrow points to the laser wavelength where the two-photon ionization onset energy is located [33]. (b) Schematic illustration of the energetics and mechanisms involved (see the text).

Fig. 3: Measured ionization threshold energy $I_{F}$ of tho TMPD molecule in ethane as a function of ethane density $\rho$ at various temperatures $T$, The solid lines represent the predicted values of $\mathrm{I}_{\mathrm{F}}$ based on the SJC model [46] for hard core radil $\langle\vec{a}\rangle=1.30,1.40$, and $1.50 \AA$; the best fit to the experimental data is for $\langle\bar{a}\rangle$ values between 1.45 and $1.50 \AA$. Densities $\rho>10 \mathrm{M} \ell^{-1}$ are for liquid ethane [34].

Fig. 4: $\quad \mathrm{V}_{0}$ of $\mathrm{C}_{2} \mathrm{H}_{6}$ and $\mathrm{P}^{+}$of TMPD ${ }^{+}$in $\mathrm{C}_{2} \mathrm{H}_{6}$ as a function of the ethane density p. The $\mathrm{P}^{+}$was determined using $\mathrm{Eq}$. (4) and the $\mathrm{V}_{\mathrm{o}}$ using either the SJC model (_ $)$ or as modifled in Ref. 34 (_ - - The experimental points (4) are from Ref. 48. 
Fig. 5: $\quad \mathrm{V}_{0}$ vorsus $\mathrm{N}$ for $\mathrm{Ar}, \mathrm{Kr}$, and $\mathrm{Xe}[12,40]$.

Fig. 6: $\quad G_{f e}^{0}$ and b $\rho$ versus fluid density $\rho$ for $n$-pentane and neo-pentane. Also shown are the $G_{t e}(p)$ for $n-$ pentane $(\Delta)$ and neopentane $(\Delta)$. The critical densities and temperatures are, respectively, $0.232 \mathrm{~g} \mathrm{~cm}^{-3}$ and $434 \mathrm{~K}$ for neo-pentane and $0.237 \mathrm{~g} \mathrm{~cm}^{-3}$ and $470 \mathrm{~K}$ for $\mathrm{n}$-pentane [16] (see the text).

Fig. 7: Density dependence of $\mathrm{k}_{\mathrm{r}}$ (Fig. 7a) and $\mu$ (Fig. 7b) in methane [58]. Solld, a; liquid, $;$ gas, $0(295 \mathrm{~K}),+(254 \mathrm{~K}), \mathrm{x}(222 \mathrm{~K}), \mathrm{a}(193 \mathrm{~K}), \mathrm{n}_{\mathrm{c}} \equiv$ critical density $\left(6.11 \times 1.021\right.$ molecules $\left.\mathrm{cm}^{-3}\right), \quad \Delta(104 \mathrm{~K})[59]_{i}-$ - (205 $\mathrm{K}),-(273 \mathrm{~K}),--(206 \mathrm{~K}), \ldots(196 \mathrm{~K})[60]$.

Fig. 8: $\quad<\epsilon>$ versus $\mathrm{E} / \mathrm{N}$ for $\mathrm{Ar}, \mathrm{CH}_{4}, \mathrm{CF}_{4}, \mathrm{~N}_{2}, \mathrm{C}_{2} \mathrm{H}_{2}, \mathrm{CO}_{2}$, and $\mathrm{NH}_{3}$. The data for Ar and $\mathrm{N}_{2}$ are from [61]; those for $\mathrm{CH}_{4}, \mathrm{CF}_{4}$, and $\mathrm{CO}_{2}$ are computed values [62] using published cross section data for elastic and inelastic scattering and Ionization $[2,63]$; the data for $\mathrm{C}_{2} \mathrm{H}_{2}$ and $\mathrm{NH}_{3}$ are characteristic energles $[1,2]$.

Fig. 9: Normalized electron energy distribution functions $f(\epsilon, E / N) \equiv f^{\prime}(\epsilon) \epsilon^{\frac{1}{2}}$ for several $\mathrm{E} / \mathrm{N}$ values in $\mathrm{Ar}$ and $\mathrm{N}_{2}$ obtained using a two-term Boltzmann solution and the cross sections shown in the figure [61].

Fig. 10: Calculated [65] $\left[\frac{3}{2} \mathrm{e} \frac{\mathrm{D}_{\mathrm{T}}}{\mu}\right]_{\mathrm{G}}$ versus $\mathrm{E} / \mathrm{N}$ for gaseous $\mathrm{Ar}$ at $\mathrm{T}=300 \mathrm{~K}(0)$ and $\mathrm{T}=87 \mathrm{~K}(\mathrm{a})$ and gaseous $\mathrm{Xe}$ at $\mathrm{T}=300 \mathrm{~K}(\Delta)$ and $165 \mathrm{~K}(\nabla)$. The experimental $\left[\frac{3}{2} \in \frac{\mathrm{D}_{\mathrm{T}}}{\mu}\right] \mathrm{L}$ versus $\mathrm{E} / \mathrm{N}$ for liquid $\operatorname{Ar}$ (口: [66]) and for liquid Xe ( $\mathbf{v}:[67])$ respectively at 87 and $165 \mathrm{~K}$. Inset: Ratio $\left[\frac{\mathrm{D}_{\mathrm{T}}}{\mu}\right]_{\mathrm{G}}<\left[\frac{\mathrm{D}_{\mathrm{T}}}{\mu}\right]_{\mathrm{L}}$ versus $\mathrm{E} / \mathrm{N}$ for $\mathrm{Ar}(\mathbf{c})$ and $\mathrm{Xe}(\Delta)$ (from [65]).

Fig. 11: Calculated $\langle\varepsilon\rangle_{L}$ versus $\mathrm{E} / \mathrm{N}$ for liquid Ar: $\nabla[68] ; \quad$ [69]; $\Delta$ [70]; $\bullet$ [71], in comparison with the calculated values of [65] for liquid Ar at $\mathrm{T}=87 \mathrm{~K}(\Delta)$ and gaseous Ar at $\mathrm{T}=87 \mathrm{~K}(0)$ and $300 \mathrm{~K}(\mathrm{a})$ [from [65]). 
Fig. 12: $\quad$ Calculated $\langle\epsilon\rangle_{L}$ versus $\mathrm{E} / \mathrm{N}$ for liquid $\mathrm{Xe}(\mathrm{T} \simeq 105 \mathrm{~K}): \Delta[70]_{;}$o $[\theta 5]$, For comparison $\langle\epsilon\rangle_{G}$ versus $\mathrm{E} / \mathrm{N}$ is shown for gaseous $\mathrm{Xe:}$ a $(165 \mathrm{~K}) ; \square(300 \mathrm{~K})$ (from [65]).

Fig. 13: Cross sections for momentum transfer and inelastic electron scattering in $\mathrm{CO}_{2}$ calculated $[80,81]$ from an analysis of electron transport data. The Ionization cross sections are from [82] (from [83]).

Fig. 14: (a) wersus $\mathrm{E} / \mathrm{N}$ for $\mathrm{NH}_{3}$ at vastous values of $\mathrm{N}$ at $\mathrm{T}=300 \mathrm{~K}$. $\mu \mathrm{N} /(\mu \mathrm{N})_{0}$ versus $\mathrm{P}$ (or $\mathrm{N}$ ) for $\mathrm{NH}_{3}$ at a number of T, For a given value of $\mathrm{E} / \mathrm{N}$, the $\mathrm{w}$ and $\mu \mathrm{N}$ data were plotted as a function of $\mathrm{N}$ and extrapolated to $\mathrm{N} \longrightarrow 0$. These values are designated in $(a)$ by the solid circles $(\mathrm{N}=0)$ and in (b) by $(\mu \mathrm{N})_{0}$ (from $\left.[92]\right)$.

Fig. 15: $\quad \mu$ versus $\mathrm{N}$ in subcritical and supercritical $\mathrm{NH}_{3}$ vapor at various $\mathrm{T}: 300(0)$, $320(\square), 340(\nabla), 360(\Theta), 380(\Delta), 400(\Delta), 410(\nabla), 420(\diamond), 440(+)$, and $460(\bullet)$. The arrow indicates the critical density of $\mathrm{NH}_{3}$ and the dashed line represents the averaged mobility of unidentified impurity lons $(\mathrm{T}<4.00 \mathrm{~K})$ (from [93]).

Fig. 16: $\quad$ w versus $\mathrm{E} / \mathrm{N}$ for $\mathrm{Xe}(\mathrm{T}=298 \mathrm{~K})$ at various values of $\mathrm{N}$. Curves 1 through 14 correspond to $\mathrm{N}$ (in units of 1.021 atoms $\mathrm{cm}^{-3}$ ) of: $4.24,4.97,5.38,6.3$, $6.97,7.34,7.75,0.1,0.438,0.91,1.92,2.74,3.54$, and 3.92 , respectively, (from [94]).

Fig. 17: $\quad \mu \mathrm{N}$ versus $\mathrm{N}$ for $\mathrm{Xe}$ (from [95].

Fig. 18: $\quad$ wersus $E / N$ for gaseous $\operatorname{Ar}(\square, \square ;[1,96])$ and gaseous $X e(\bullet, 0[1,97])$ and liquid $\operatorname{Ar}(\square:[98])$ and liquid $X e(\mathbf{\Delta}:[98])$. Inset: Ratio $w_{G} / w_{L}$, versus $\mathrm{E} / \mathrm{N}$ for Ar and Xe (from [65]).

Fig. 19: w versus $\mathrm{E} / \mathrm{N}(\mathrm{T} \simeq 295 \mathrm{~K})$ for gaseous and liquid TMS, TMC, and TMP (see the text) (from [73]). 
Filg, 20: Cross sections $\sigma_{0}(\epsilon), \sigma_{1}(\epsilon)$, and $\sigma_{\text {in }}(\varepsilon)$ for licluefied Ar and Xe (seo the text); $\sigma_{m}$ ls the low density gaseous momentum transfer cross section (from [00]).

Filg. 21: Schematic lllustration of the relative value of EA and VAE in a gas and a llquid.

Fig. 22: Electron attachment rate constant for $\mathrm{N}_{2} \mathrm{O}$ in gaseous, $\left(\mathrm{k}_{\mathrm{a}}\right)_{G}$, and liquid, $\left(k_{n}\right)_{L}$, argon plotted versus $\mathbb{E} / \mathrm{N}$ and $\langle\epsilon\rangle_{G}$ or $\langle\epsilon\rangle_{L}[60]$. The attachment is due to the reaction (21). Note the shift of the resonance to lower energles- - and the increase in the rate constant- - in the liquid.

Fig. 23: (a) Total electron-attachnent rate constant $\mathrm{k}_{a}$ as a function of the mean electron energy $\langle e\rangle$ for the perfluoroalkanes $n-\mathrm{C}_{\mathrm{N}} \mathrm{F}_{2 \mathrm{~N}+2}(\mathrm{~N}=1$ to $\theta)$. (b) Corresponding cross sections [61].

Fig. 24: Electron attachment rate constant for $\mathrm{O}_{2}$ in $\mathrm{N}_{2}(0), \mathrm{C}_{2} \mathrm{H}_{4}(\bullet)$ and $\mathrm{C}_{2} \mathrm{H}_{0}(\Delta)$ as a function of the pressure (corrected for compressibility) of these buffer gases. These rate constants correspond to a value of $\langle c\rangle \simeq 0.05 \mathrm{oV}$ (from [107]).

Fig. 25: Electron attachment rate constant $\mathrm{k}_{\mathrm{a}}$ as a function of mear electron energy $\langle\epsilon\rangle$ and total gas pressure for $\mathrm{C}_{3} \mathrm{~F}_{8}$ (Fig. 25a) and $\mathrm{n}-\mathrm{C}_{4} \mathrm{~F}_{10}$ (Fig. 25b) in Ar buffer gas [61].

Fig. 26: $\quad\left(k_{a}\right)_{G}$ versus $\langle\epsilon\rangle_{G}$ or $E / N$ for $S F_{\theta}$ in gaseous $A r$ and $\left(k_{a}\right)_{L}$ versus $E / N$ for $\mathrm{SF}_{0}$ in liquid $\mathrm{Ar}_{;} \Delta$, thermal value of $\left(\mathrm{k}_{\mathrm{a}}\right)_{\mathrm{G}}$ at $298 \mathrm{~K} ; \Delta$, thermal value of $\left(\mathrm{k}_{\mathrm{a}}\right)_{\mathrm{G}}$ extrapolated to $87 \mathrm{~K}$ (from [69]).

Fig. 27: Rate constant, $\left(\mathrm{k}_{a}\right)_{\mathrm{L}}$ for electron attachment to $\mathrm{SF}_{6}, \mathrm{~N}_{2} \mathrm{O}$ and $\mathrm{O}_{2}$ measured in liquid Ar [124] plotted versus $\langle\epsilon\rangle_{L_{1}}[65]$.

Fig. 28: Total electron attachment rate constant as a function of the mean electron energy $\langle\epsilon\rangle$ and $T, k_{a}(\langle\epsilon\rangle, T)$ for (a) freon $\mathrm{CClF}_{3}$ which attaches show electrons dissociatively [128] and (b) $\mathrm{C}_{6} \mathrm{~F}_{6}$ which attaches show electrons nondissociatively [132]. 
Fig. 20: Electron attachment coeffctent $\eta / \mathrm{N}_{\mathrm{A}}$ versus $\mathrm{E} / \mathrm{N}$ for thiophenol $\left(\mathrm{C}_{0} \mathrm{H}_{0} \mathrm{SH}\right.$ ) In $\mathrm{N}_{2}$ buffer gas. Curve 1 was obtained without laser irradiation and depicts electron attachment to the ground state. Curves 2 and 3 wore obtained with $\mathrm{X}_{\theta \mathrm{Cl}}$ and $\mathrm{KrF}$ laser lines respectively. The photon energy of the XeCl line is not suffictent to excite electronically the molecule monophotondcally and therefore only the ground state attachment is observed; however, electronic excitation and enhanced electron attachment occurs at the KrF line. [Note that $\eta / \mathrm{N}_{\mathrm{A}}^{*}$ is $~ 100$ times larger than $\eta / \mathrm{N}_{\mathrm{A}}$ since the excited molecule number density $\mathrm{N}_{\mathrm{A}}^{*}$ is about one percent of $\mathrm{N}_{\mathrm{A}}$ ]. The photoenhanced electron attachment (Curve 3) was attributed to electronically-axcited first triplet states populated indirectly via laser irradiation $[10,137]$. 


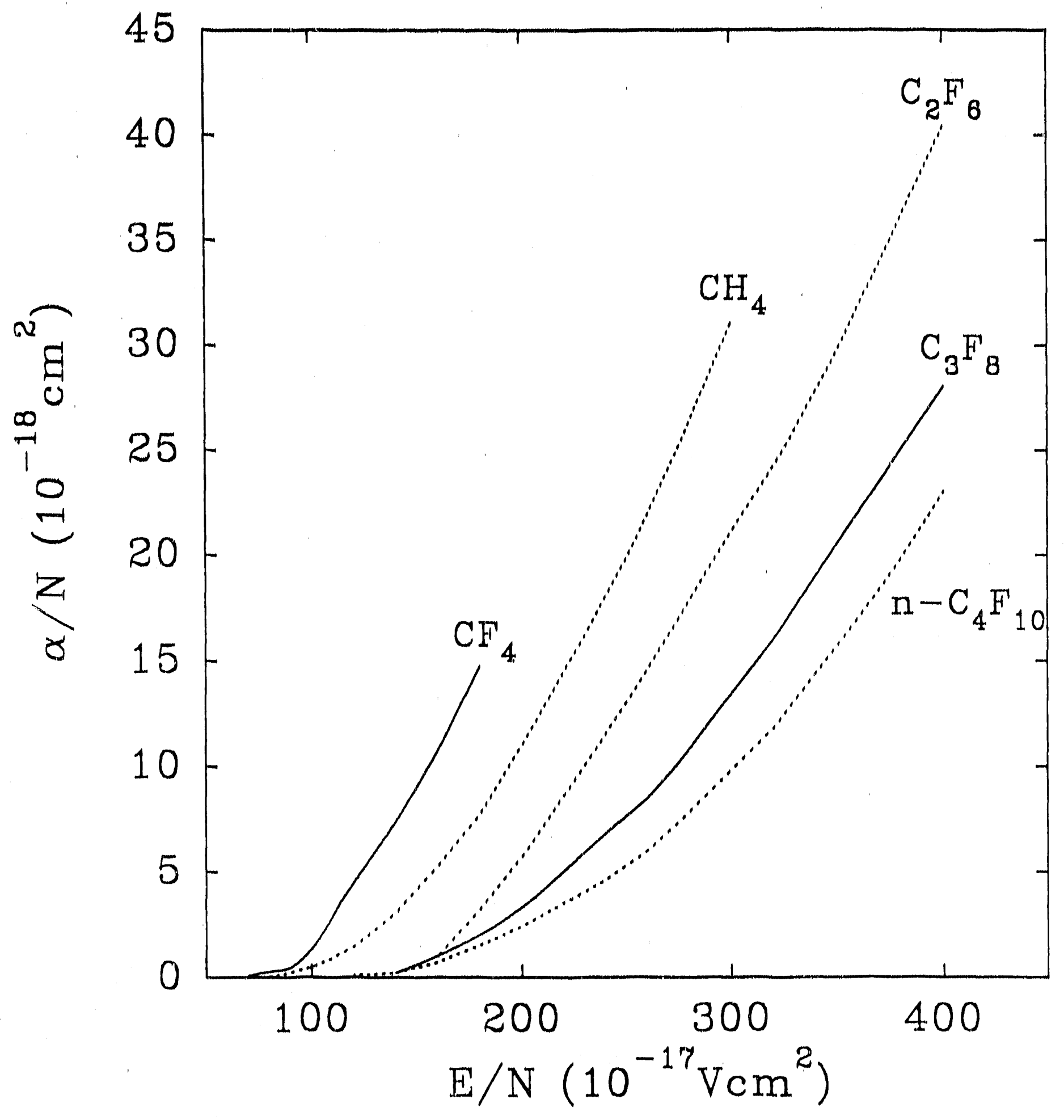

Fig. 1 

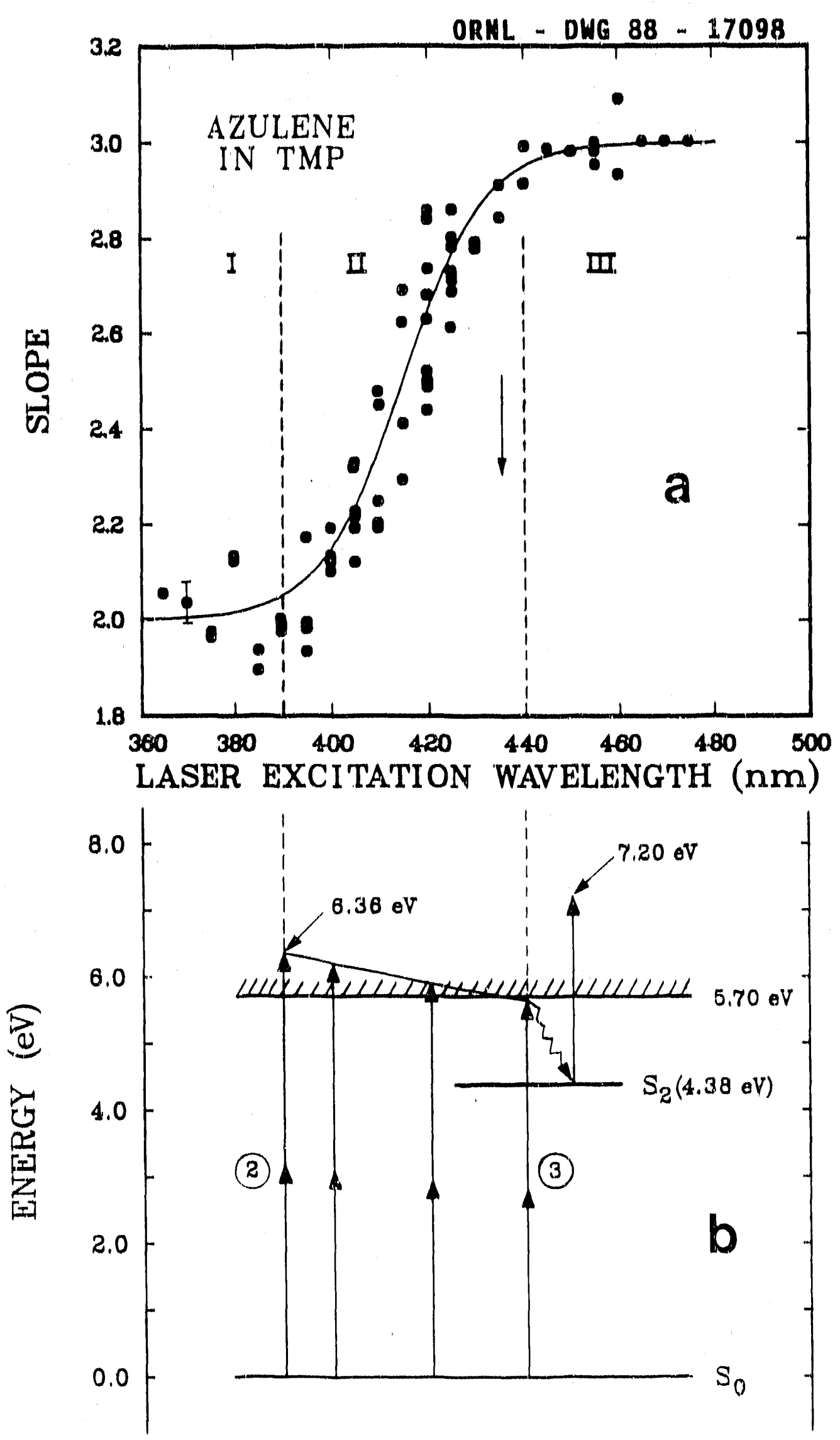

Fig. 2. 


\section{IONIZATION THRESHOLD, IF (eV)}

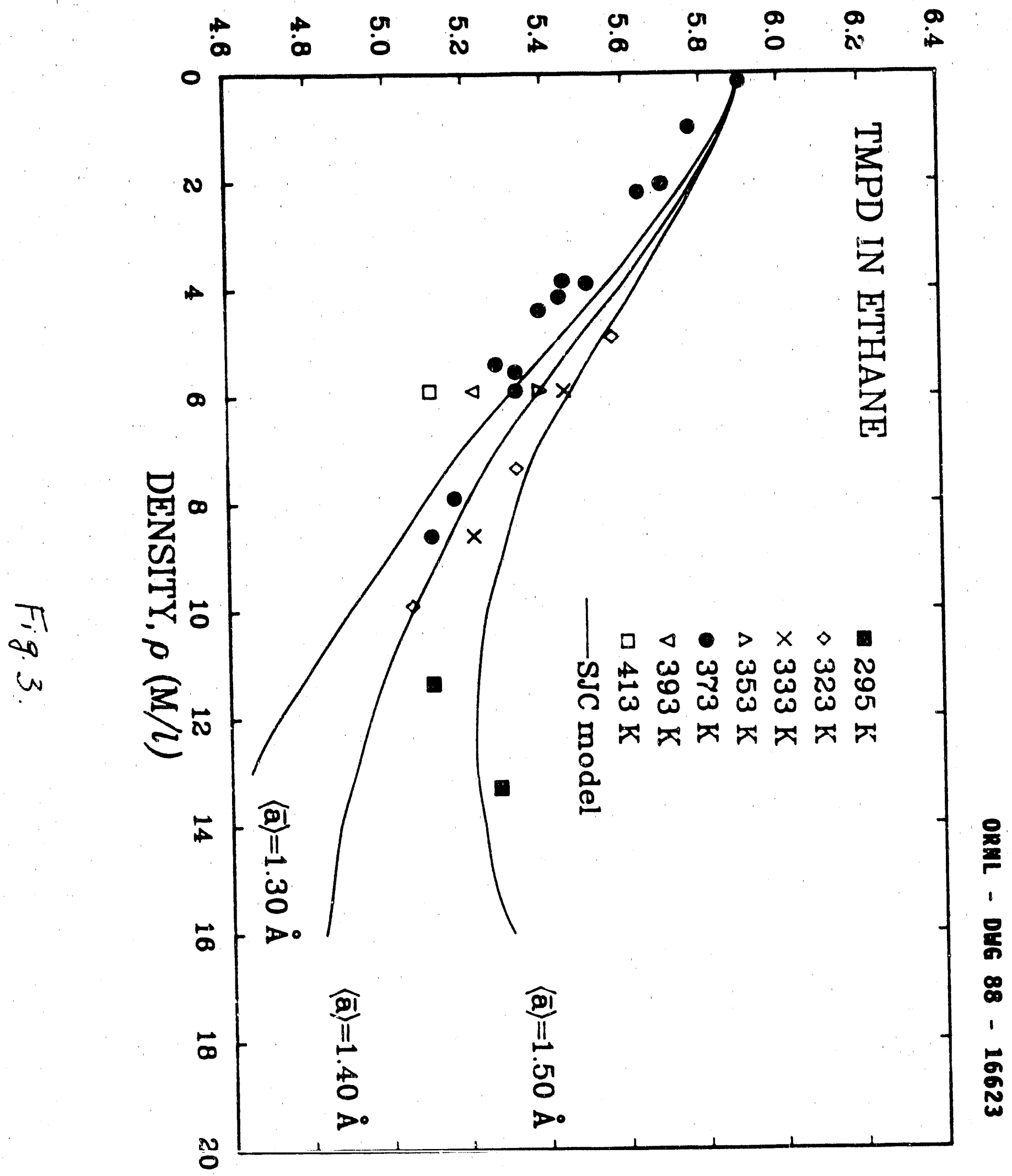




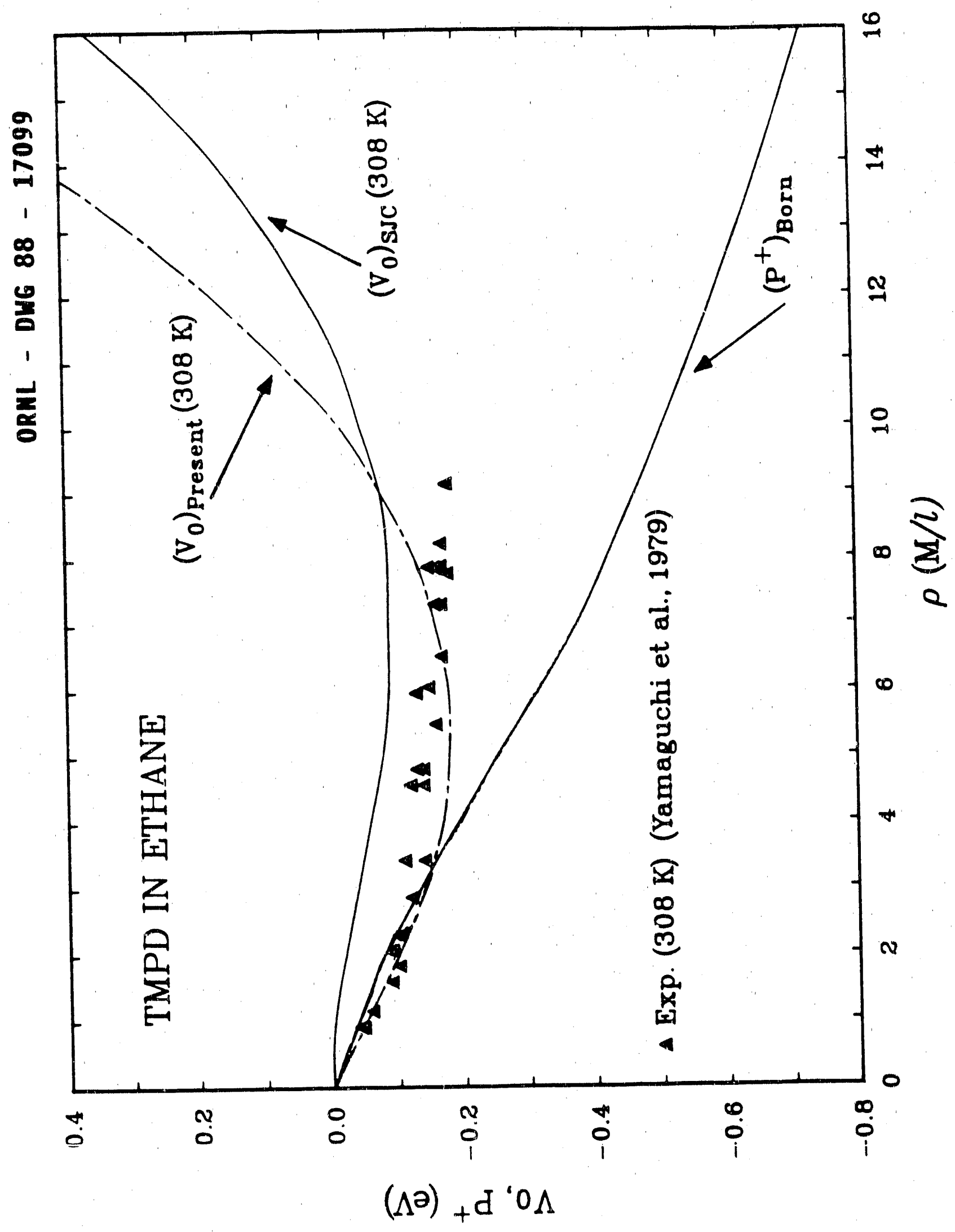




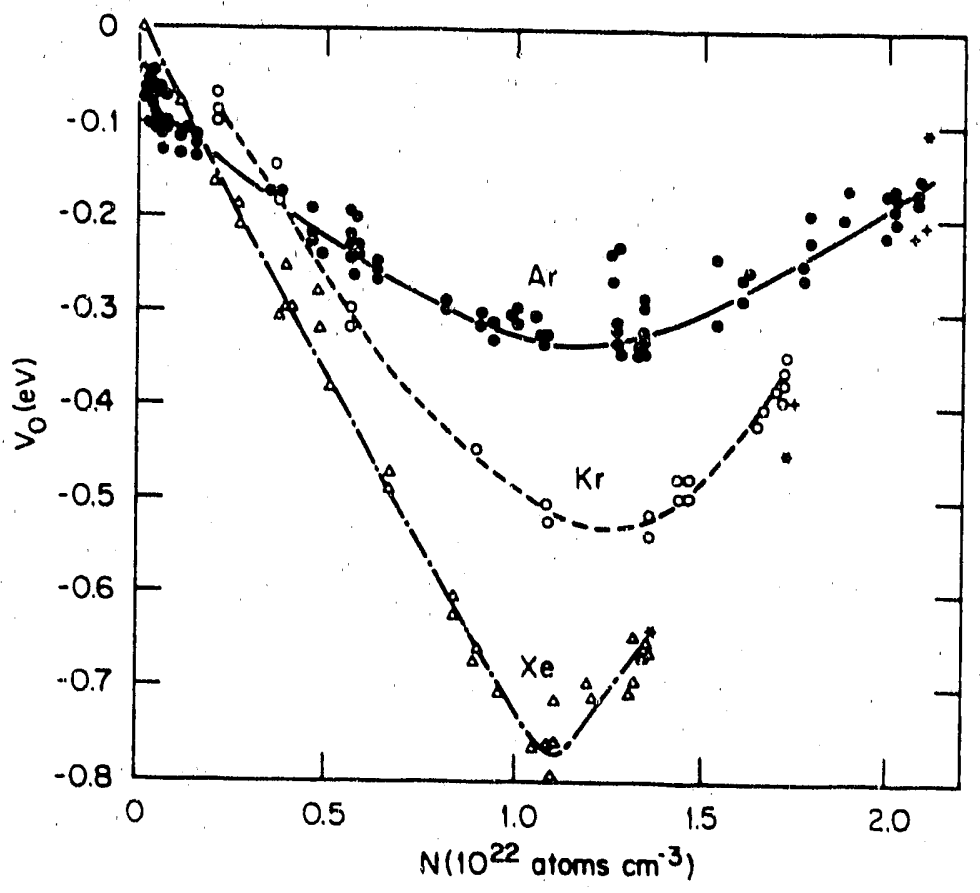

Fig. 5. 


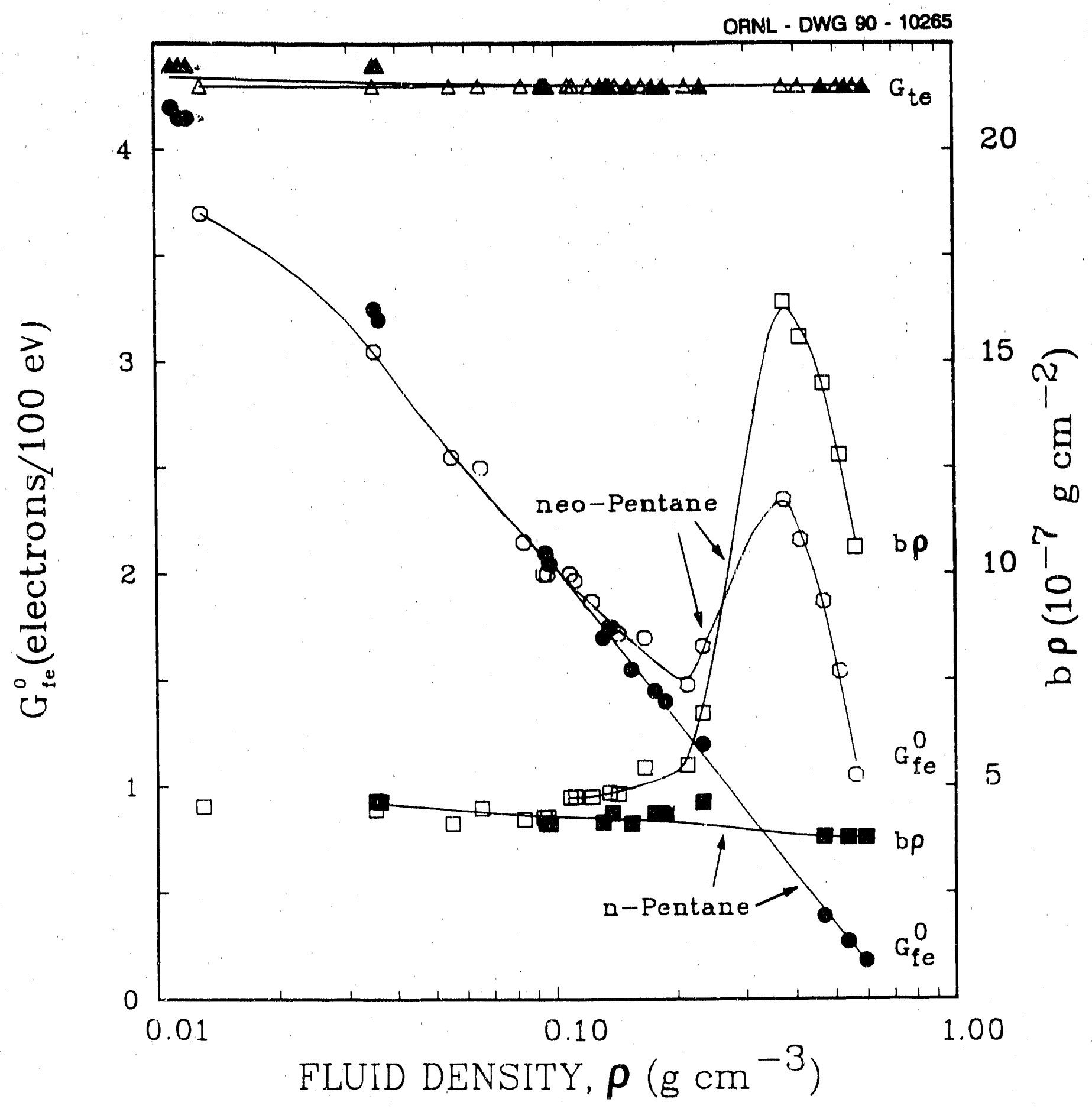

Fig. 6 

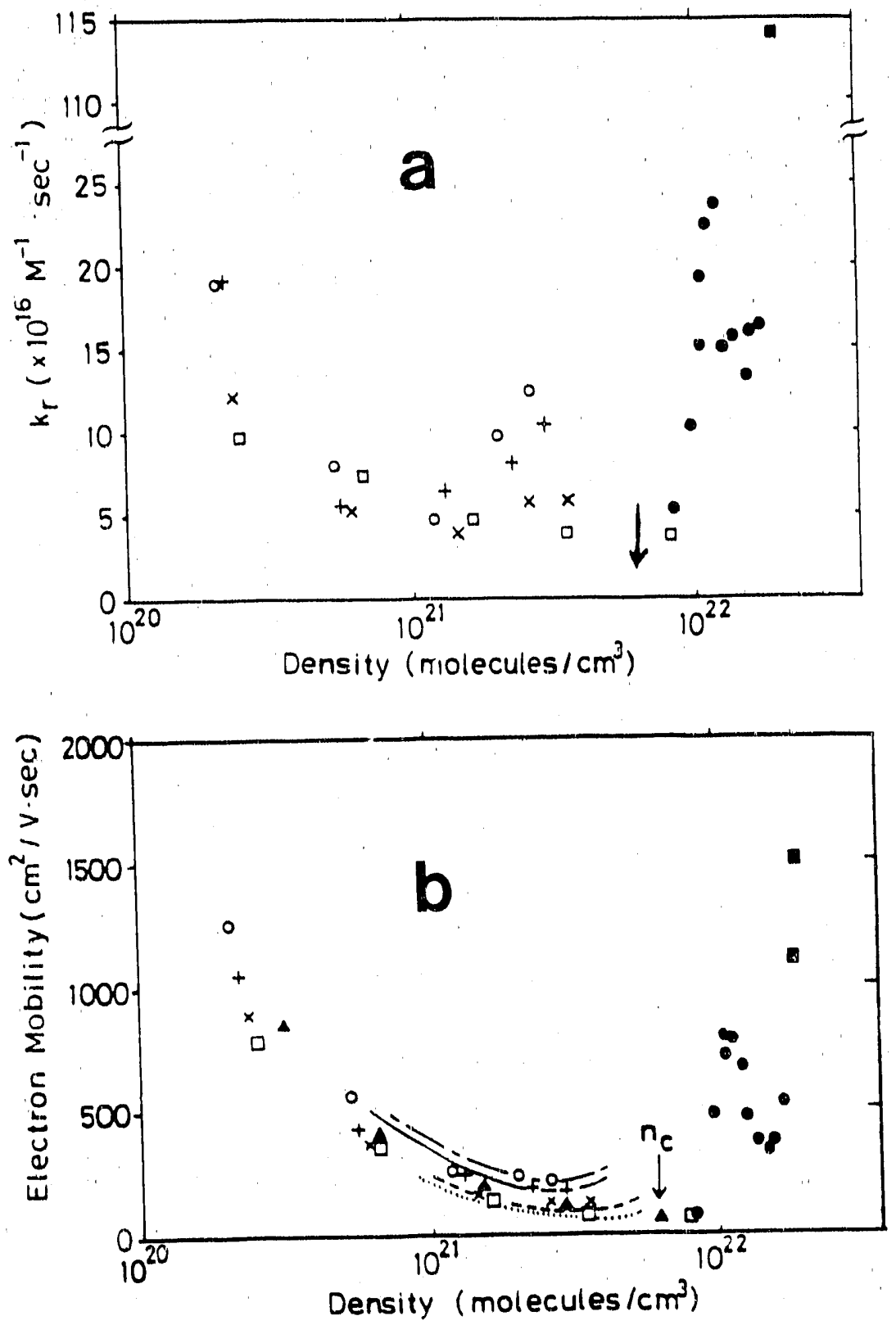

Fig. 7 


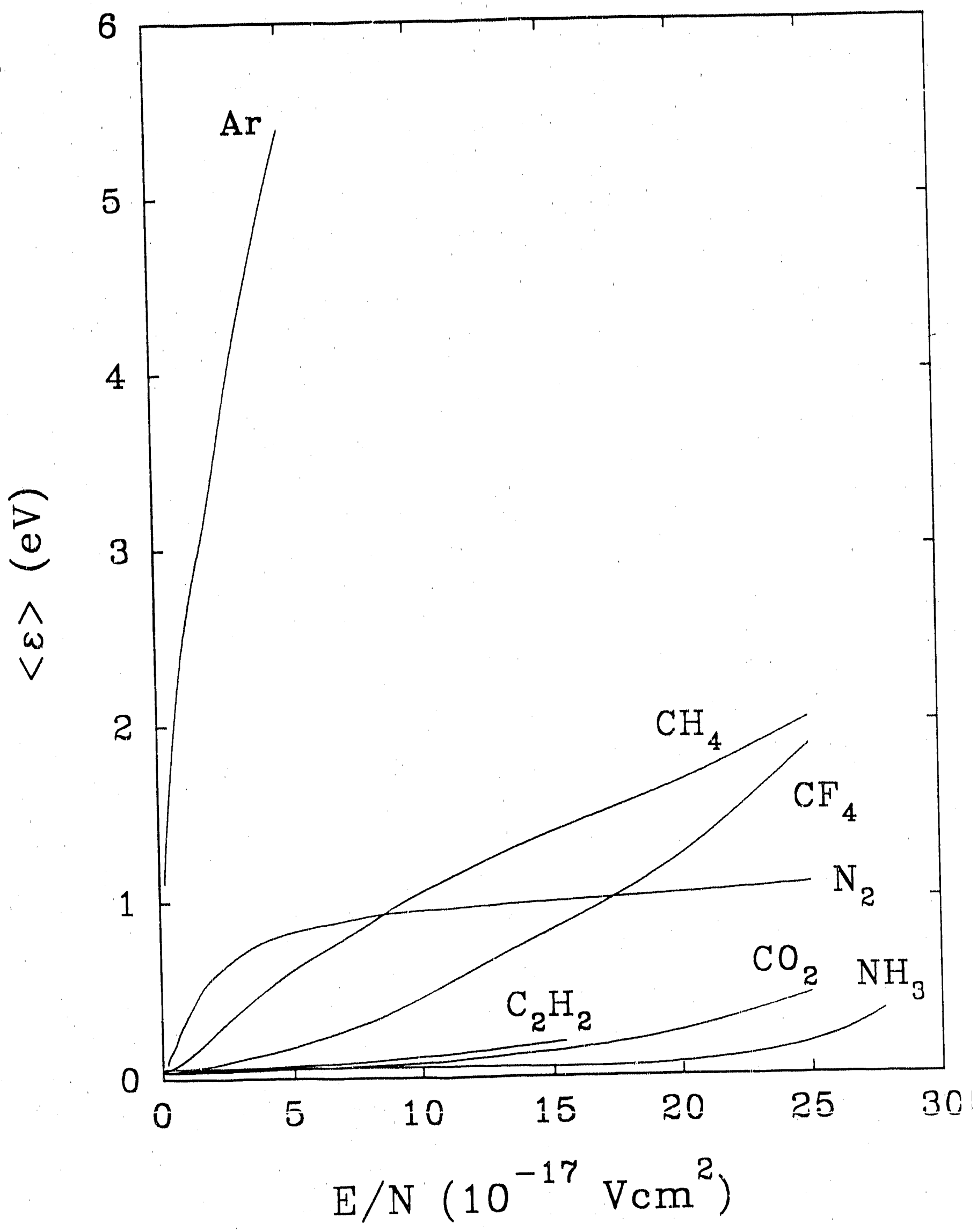

Fig. 8 

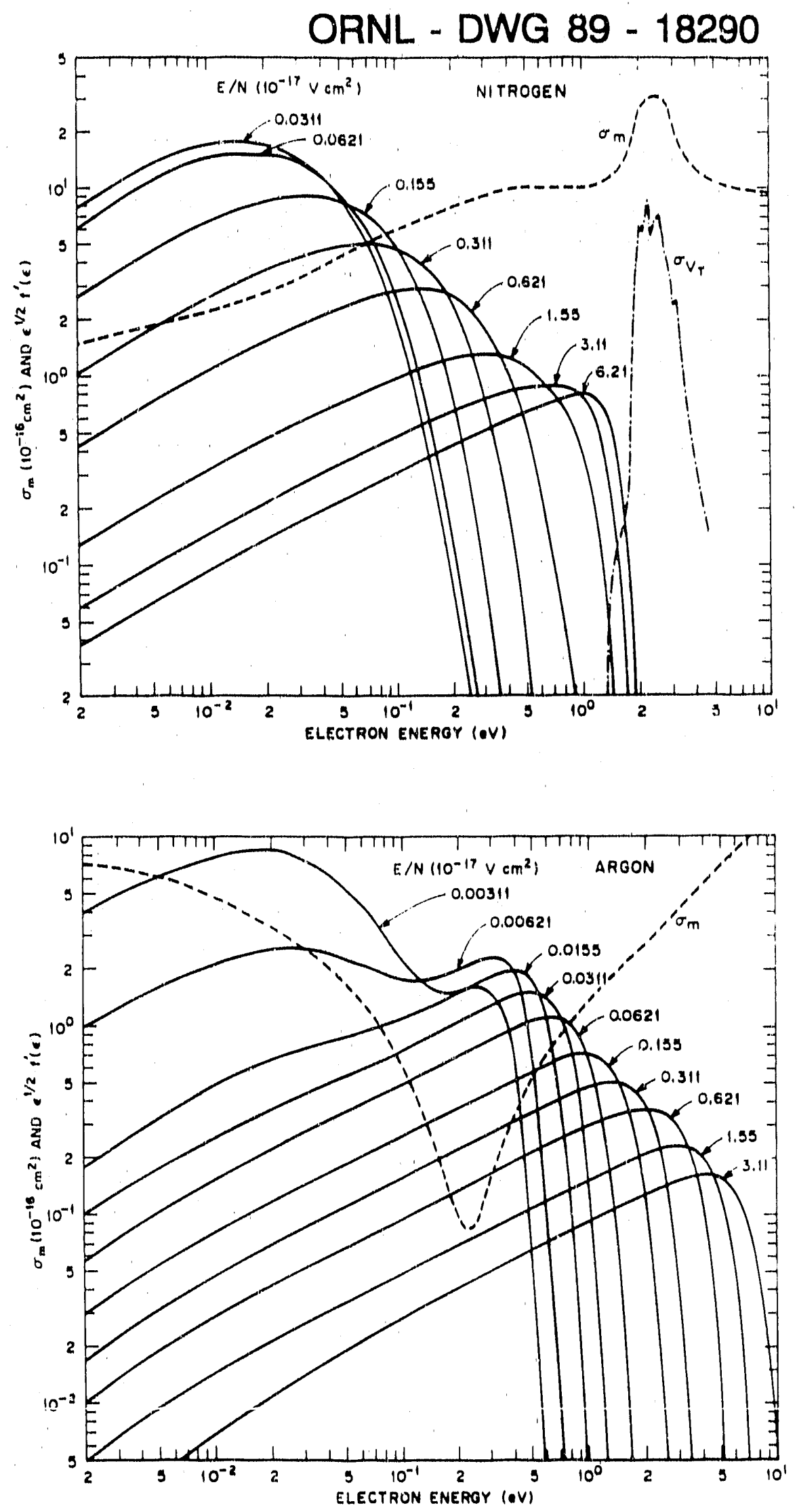

Fig. 9 


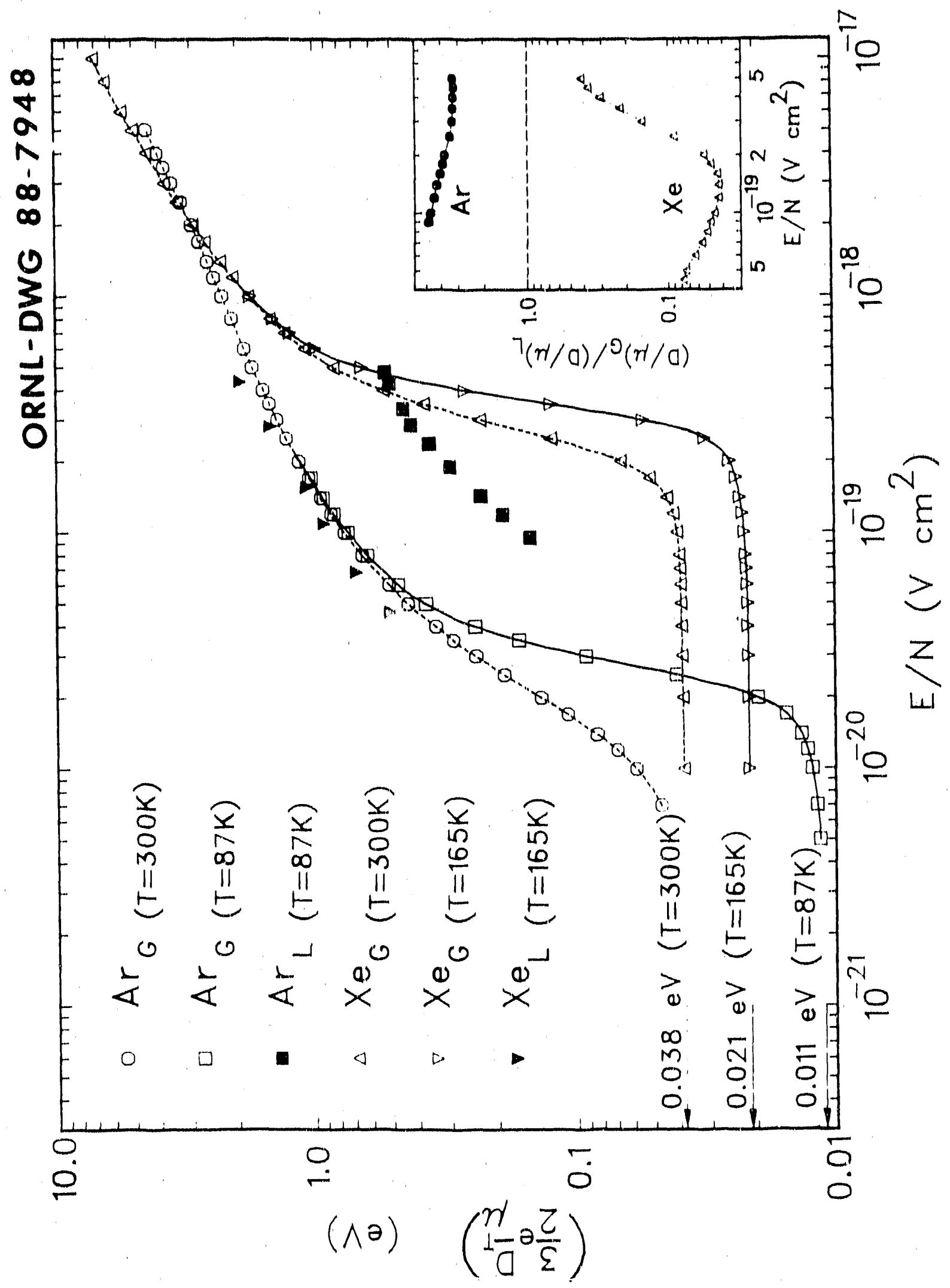


ORNL-DWG 88-7954

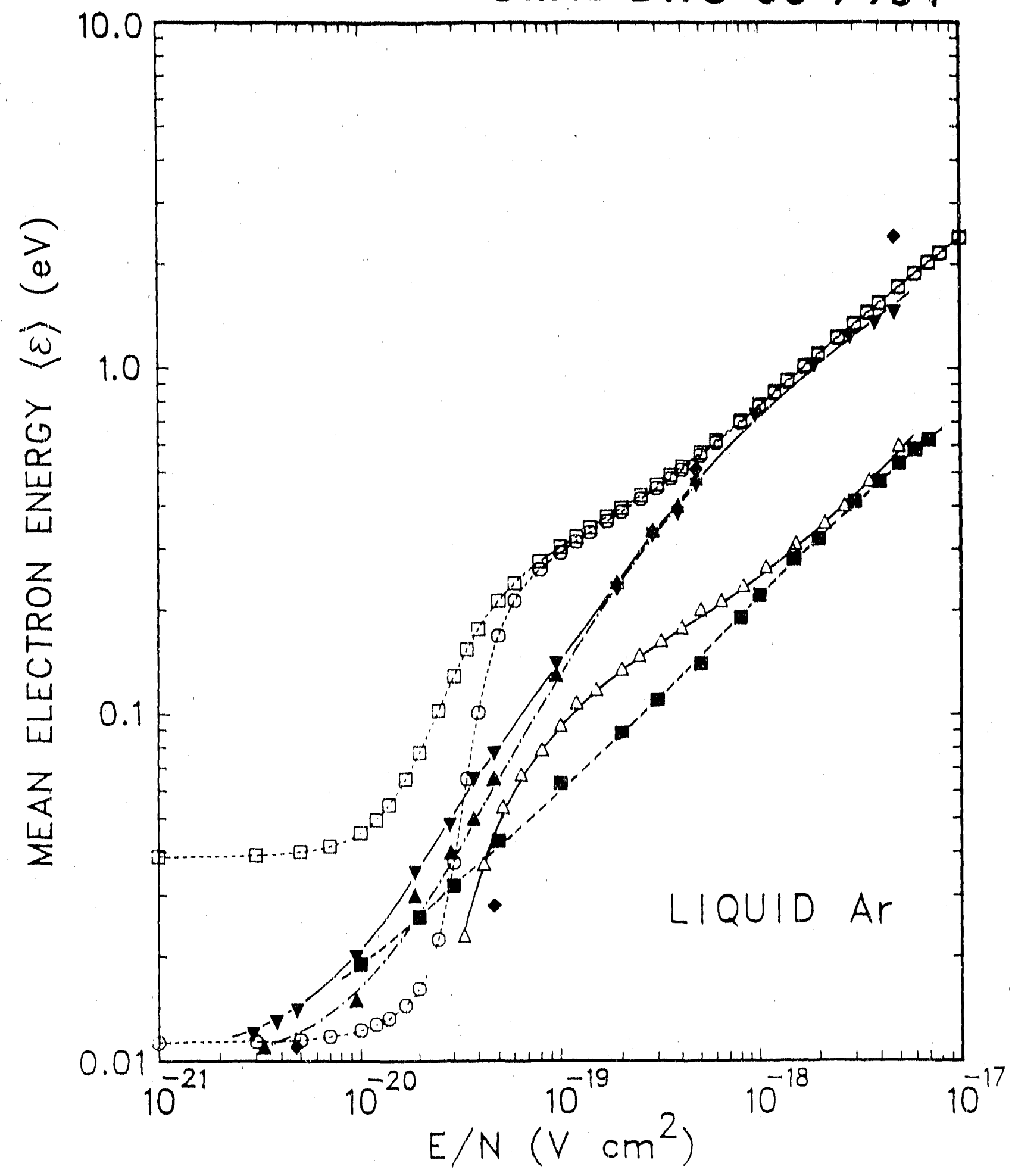

Fig. II 


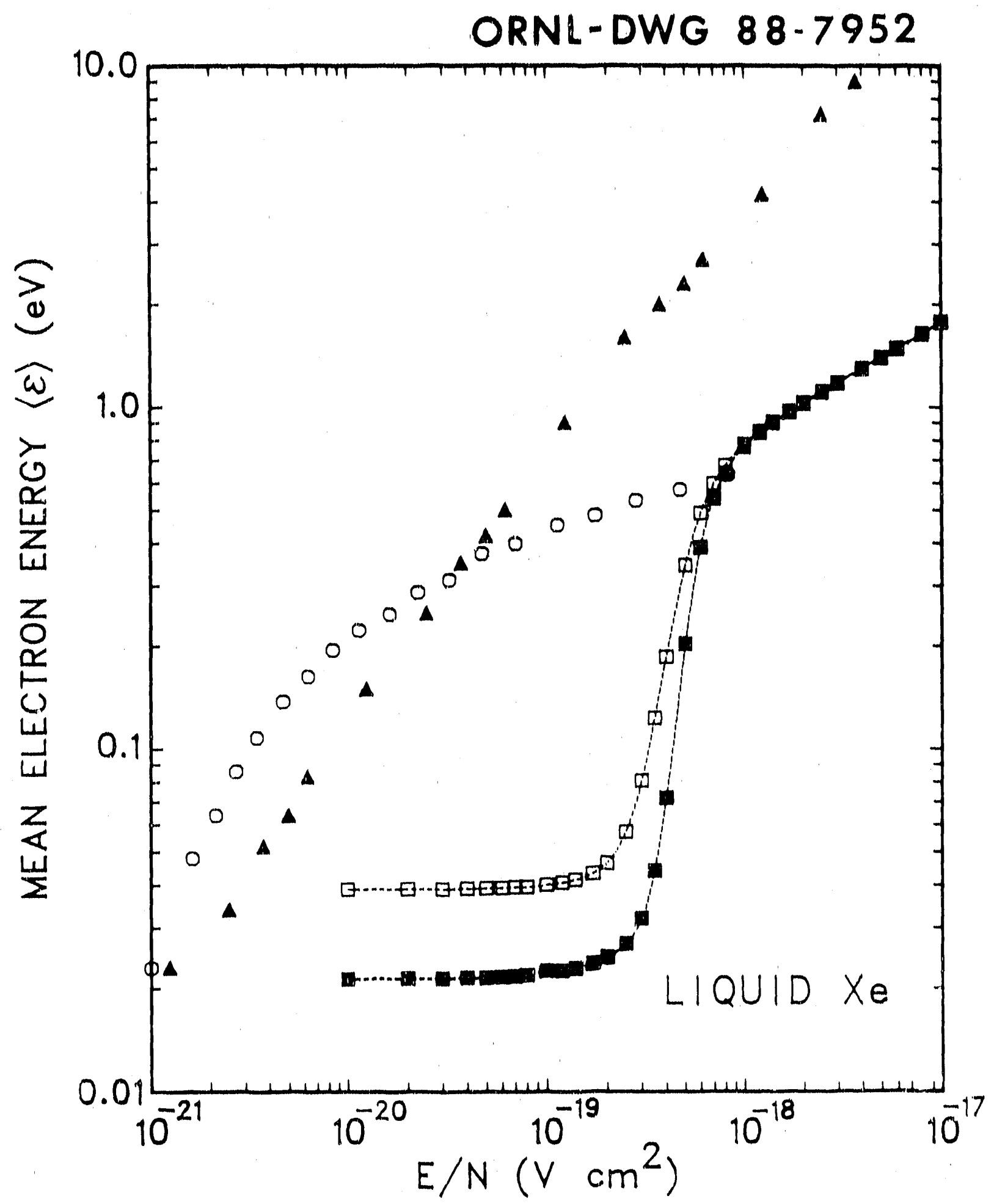

Fig. 12 


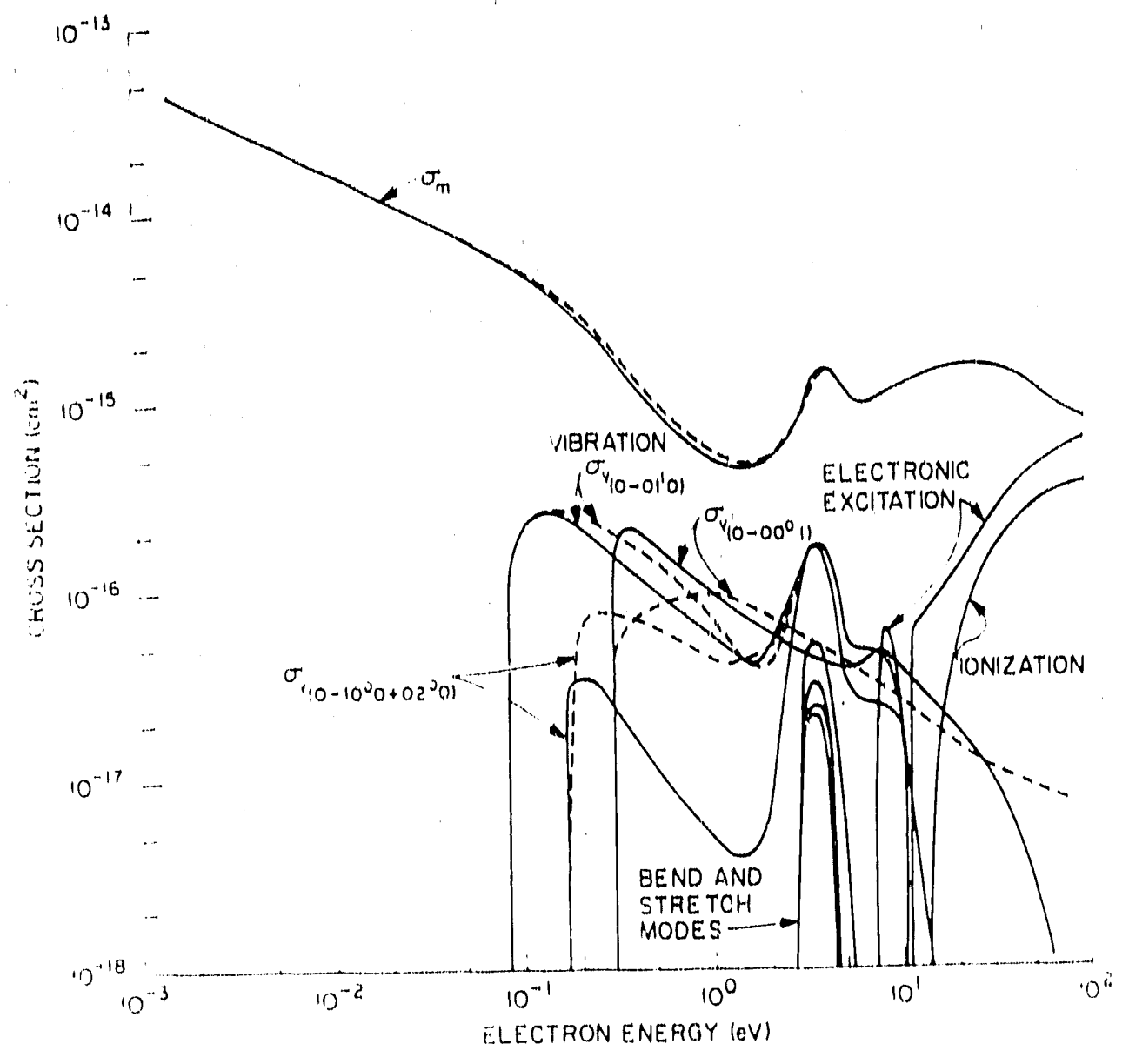

Fig. 13 

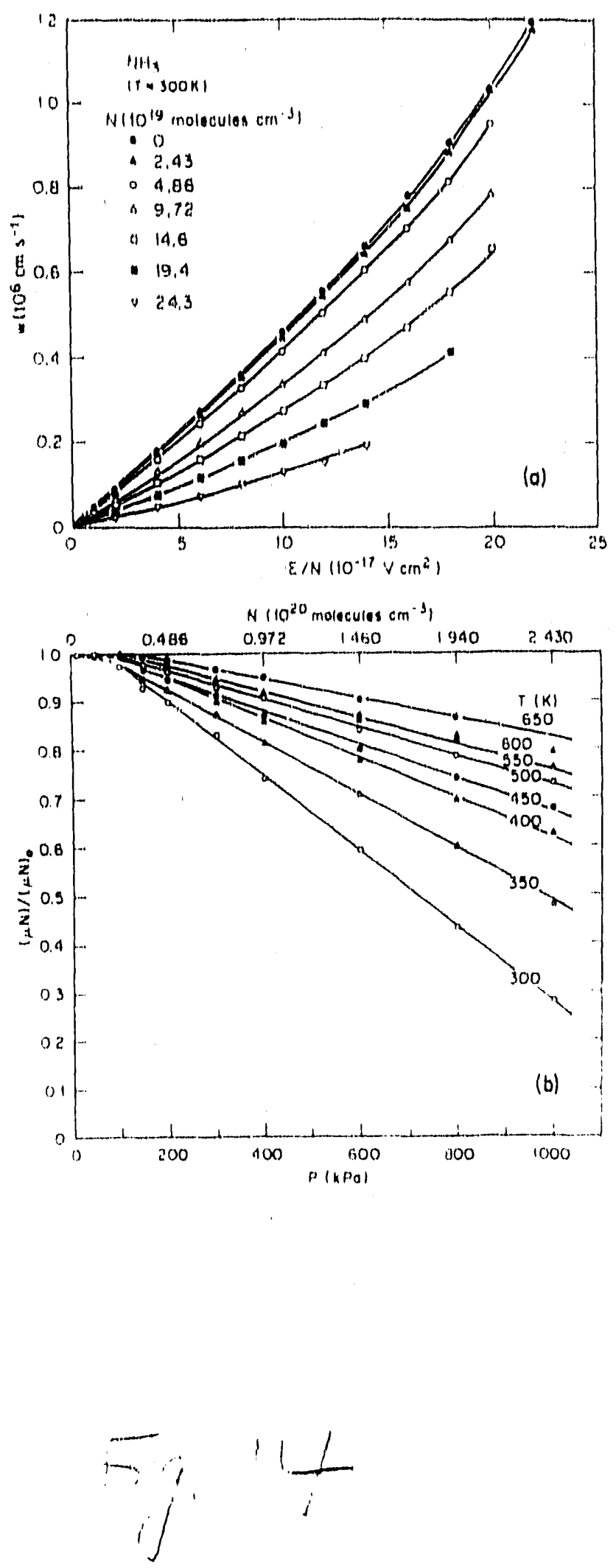


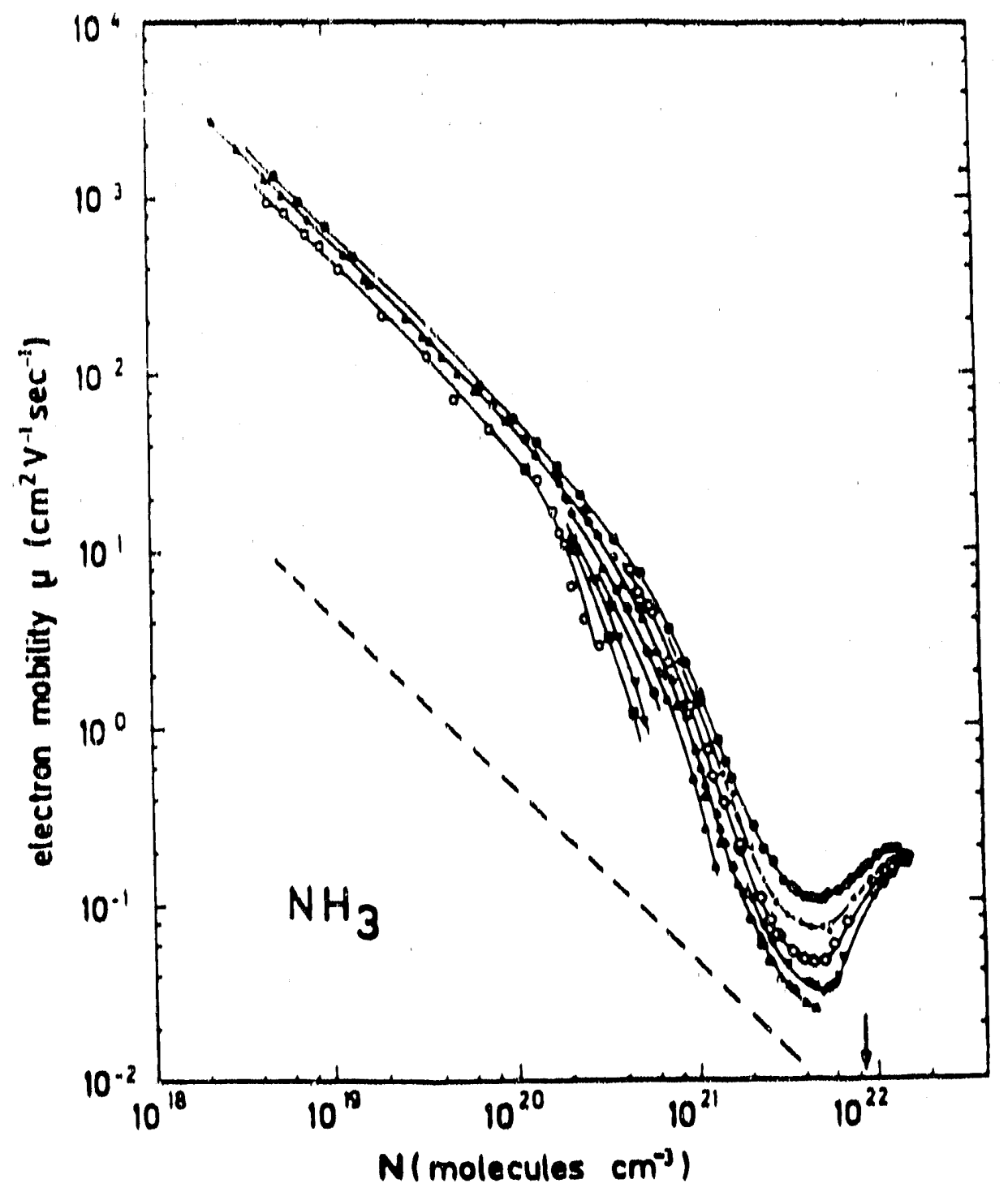

Fig. 15 

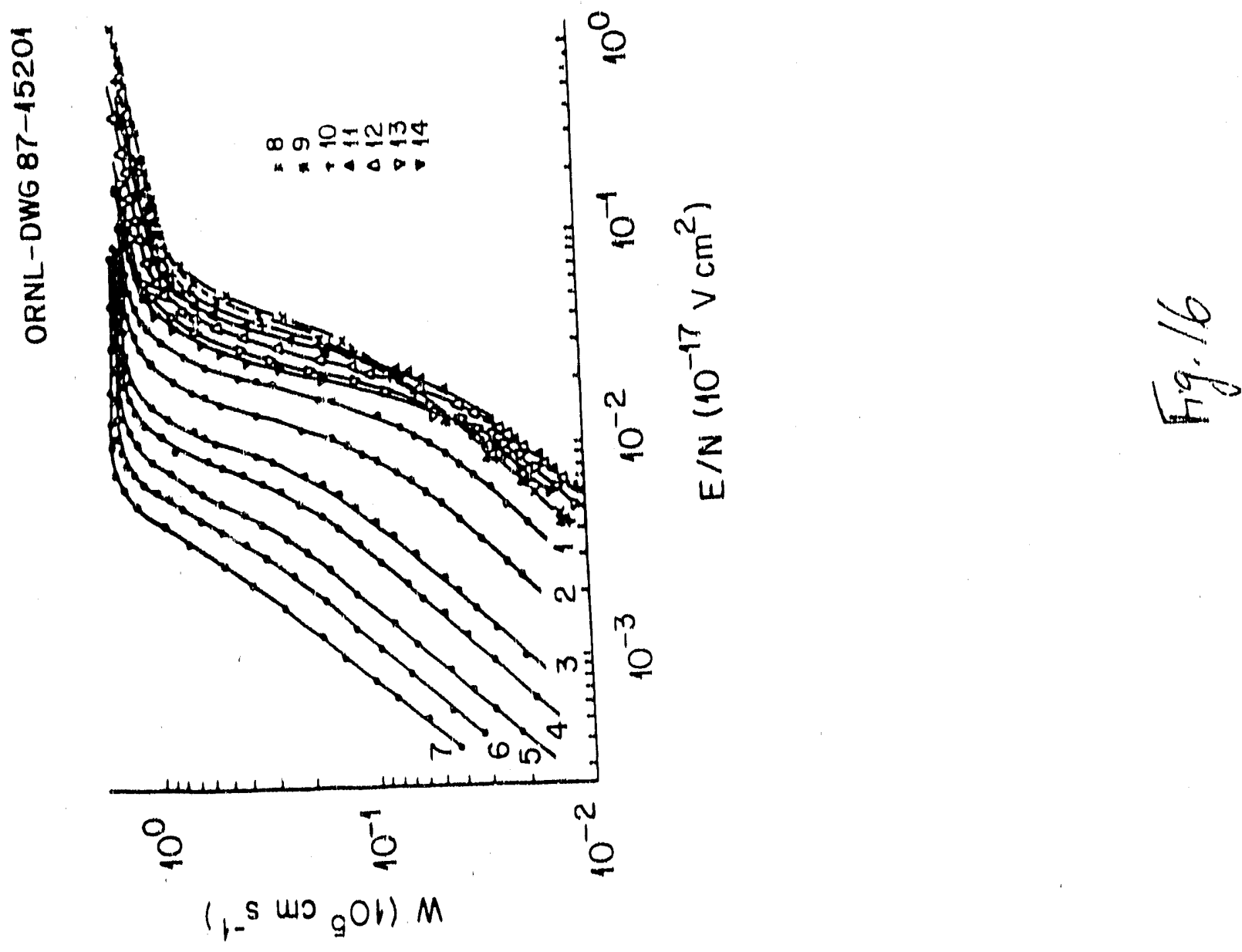


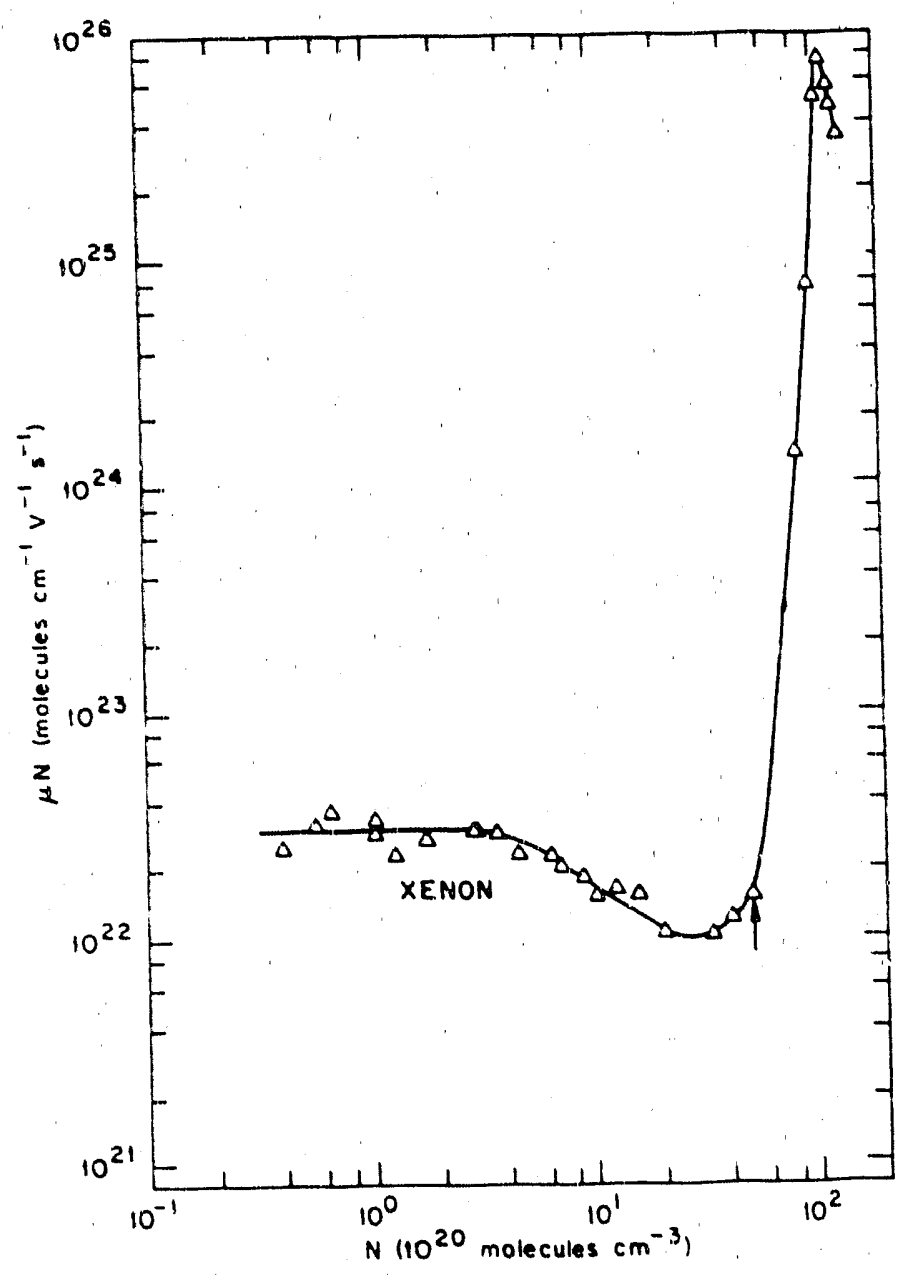

Fig $/ 7$ 


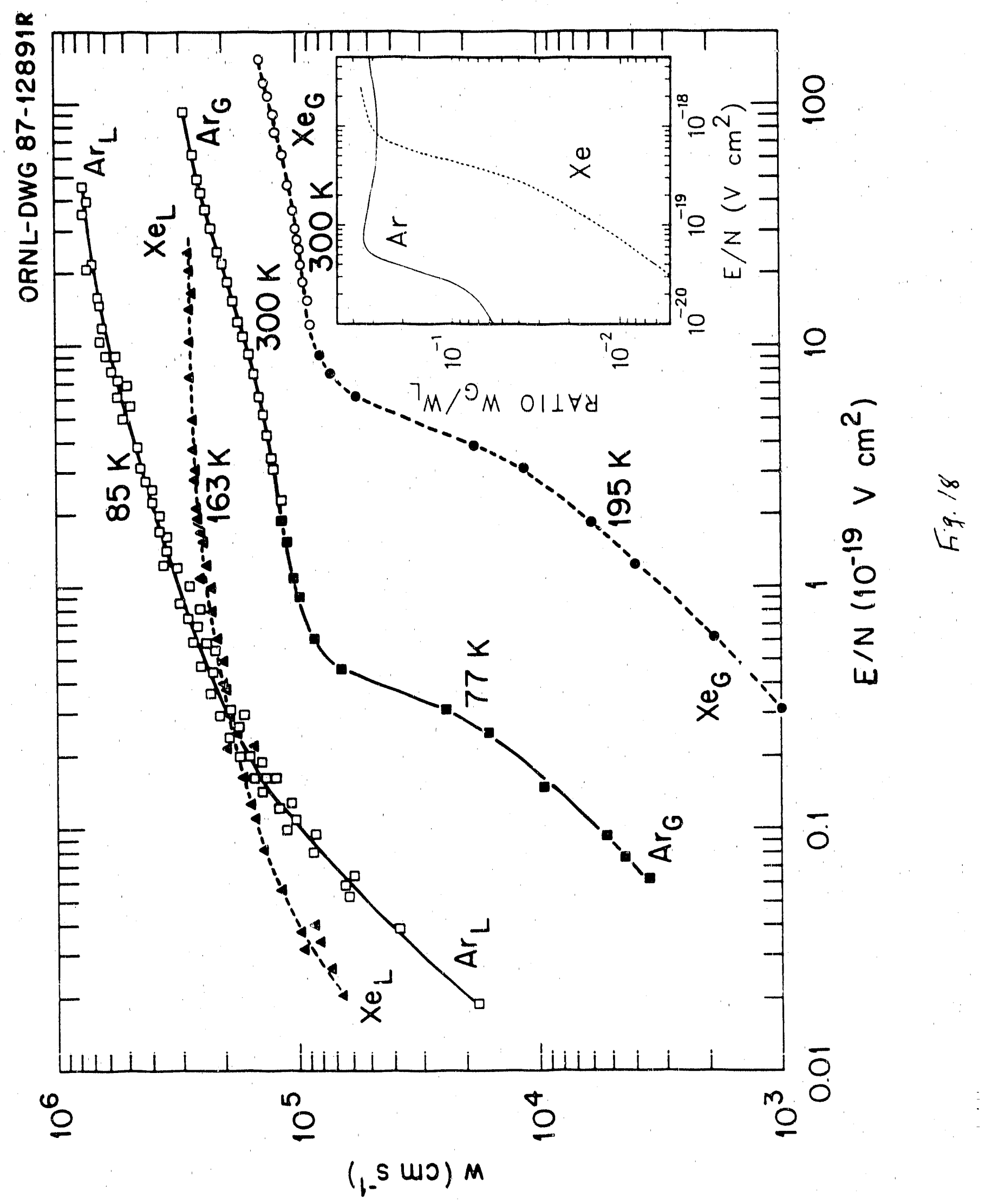




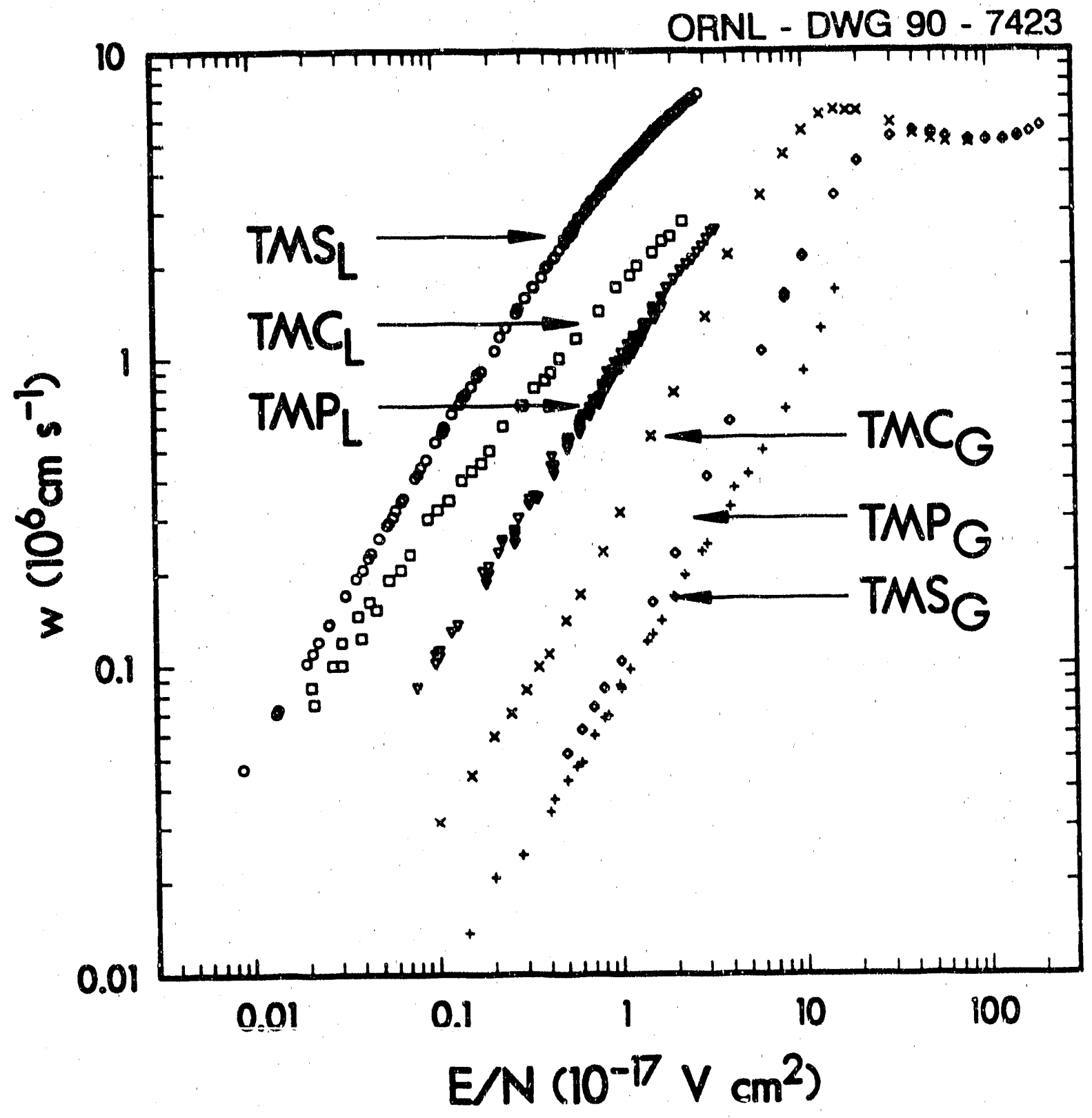

F. 19 


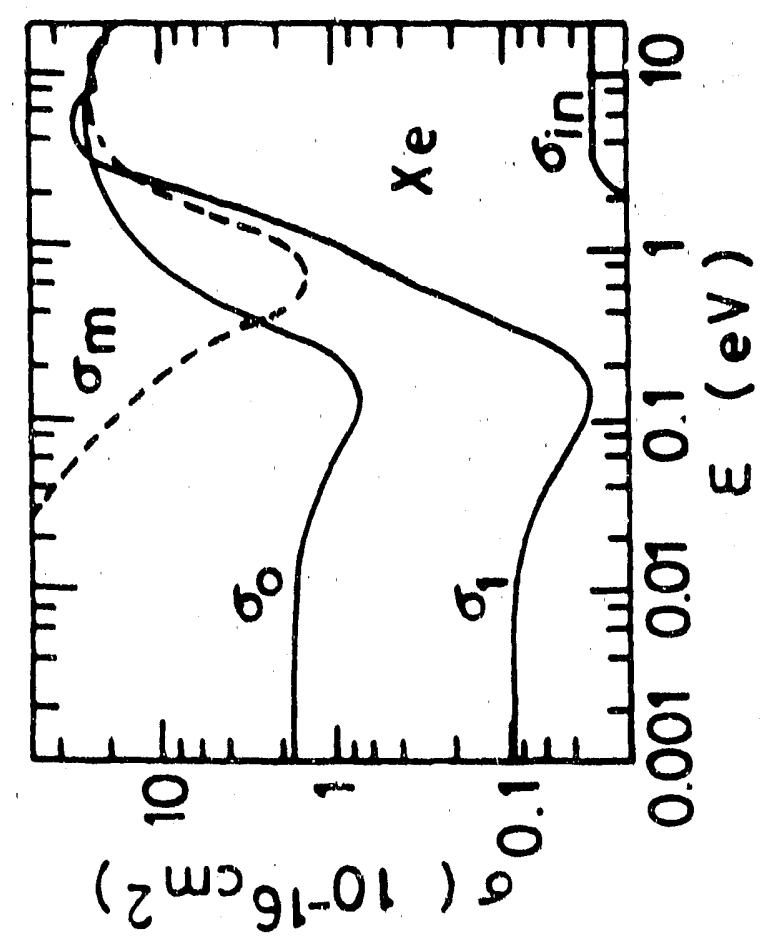

$\stackrel{0}{N}$
$\dot{\sigma}$

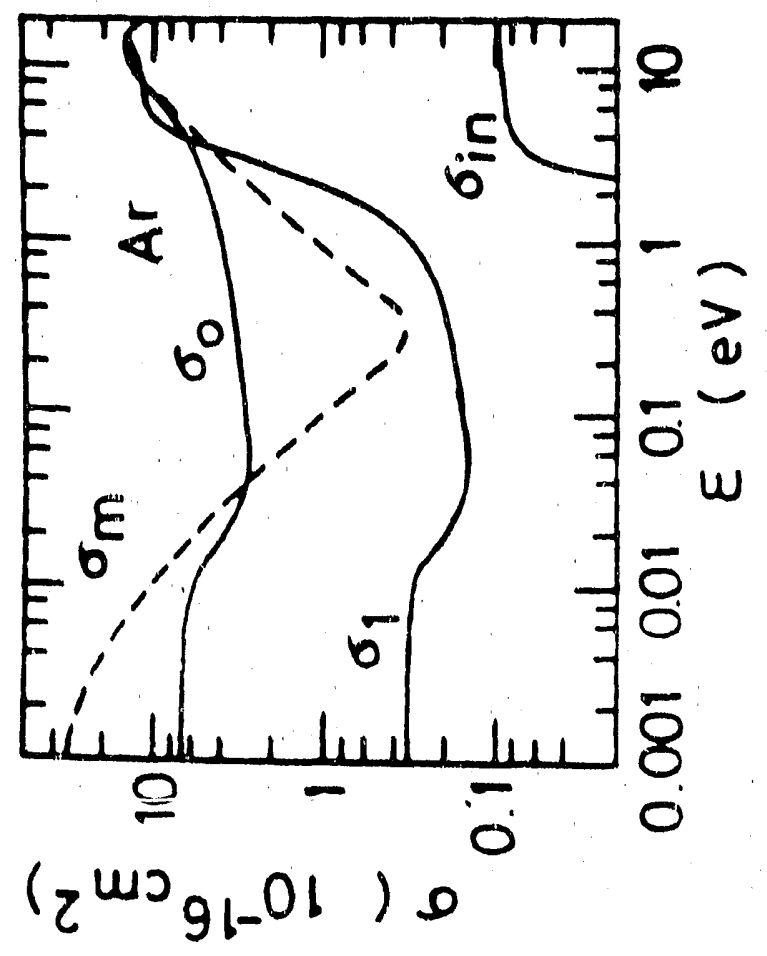


GAS

- NIS: ENERGIES

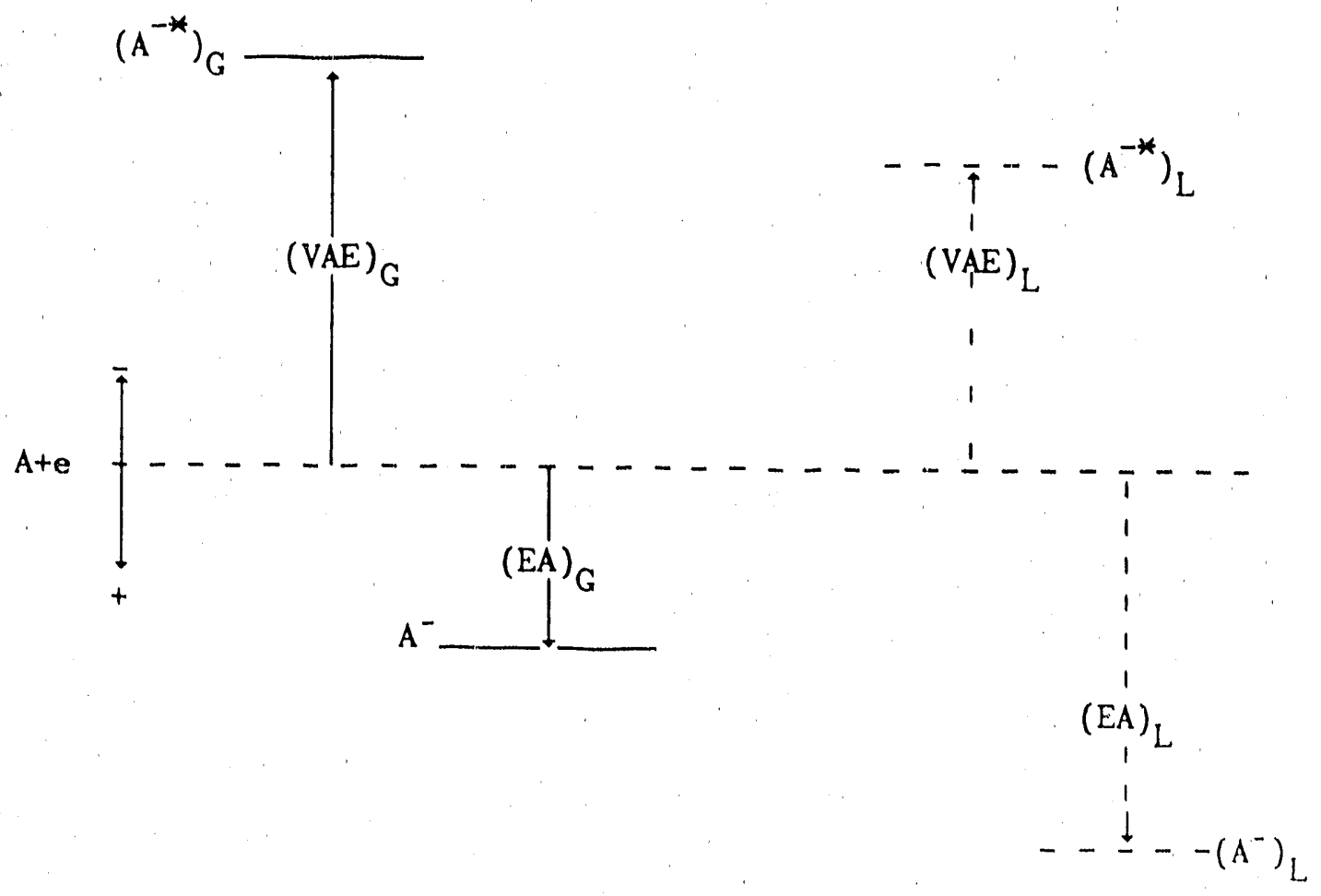

Fig.21 


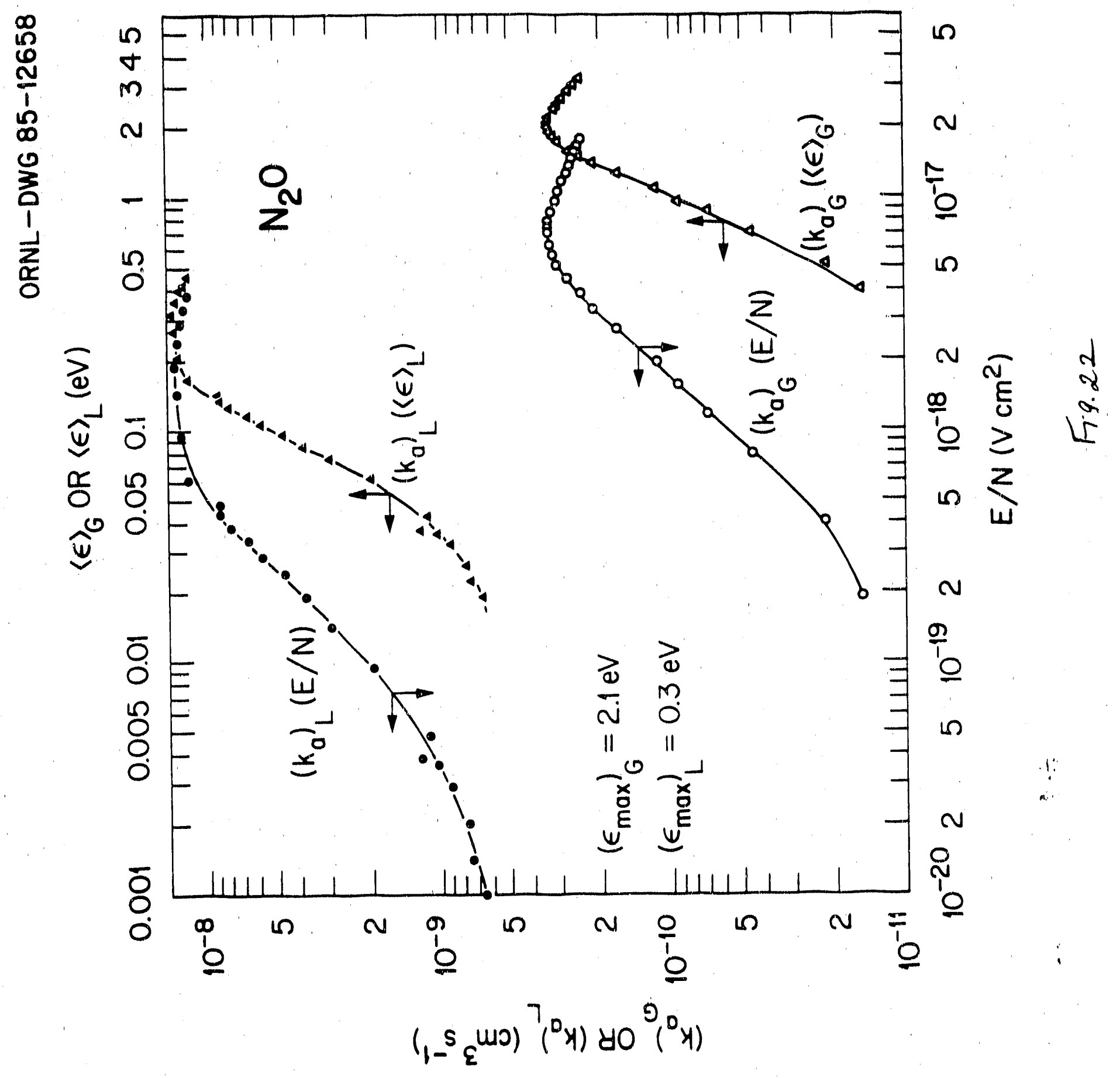



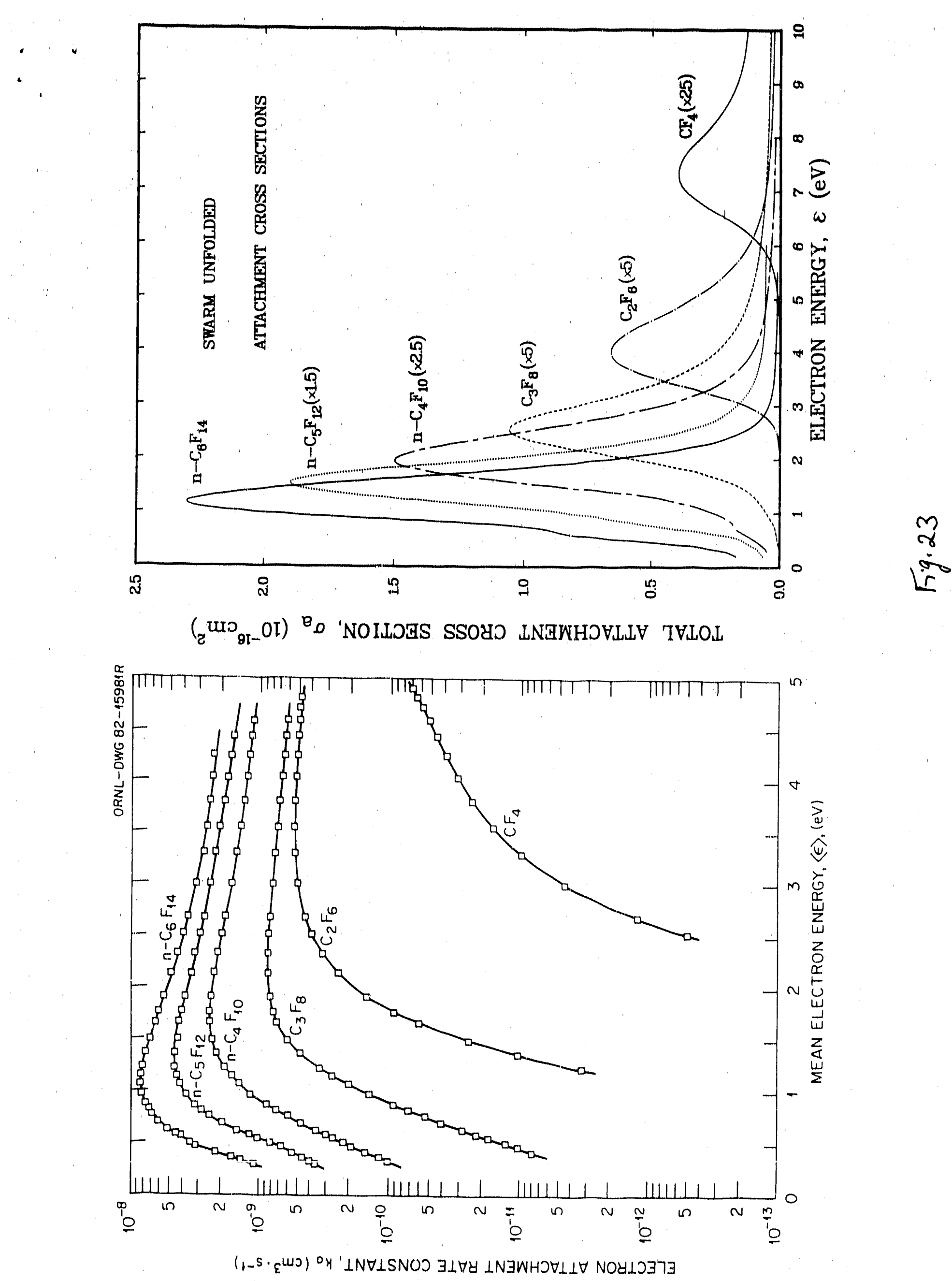


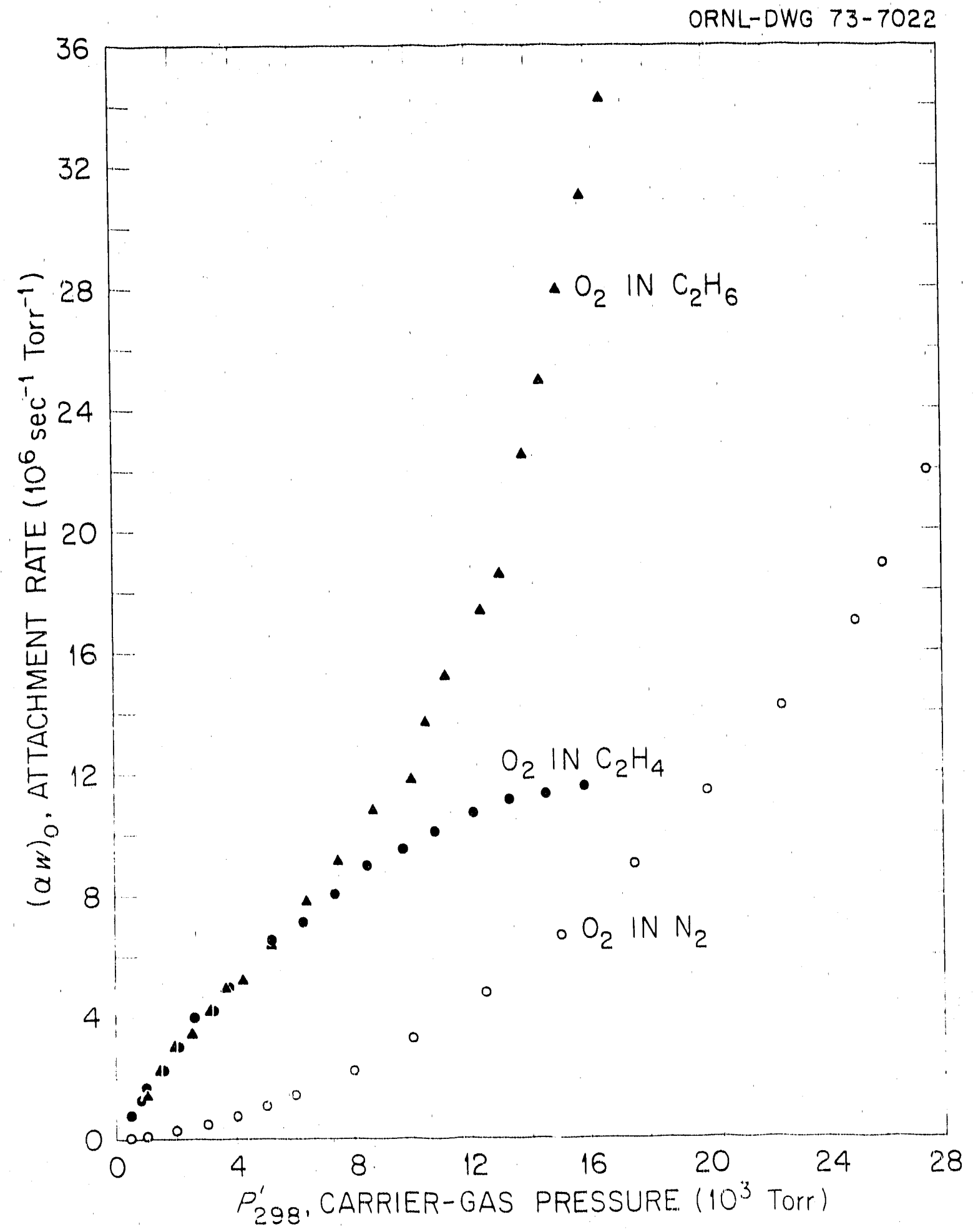

Fig. 24 . 


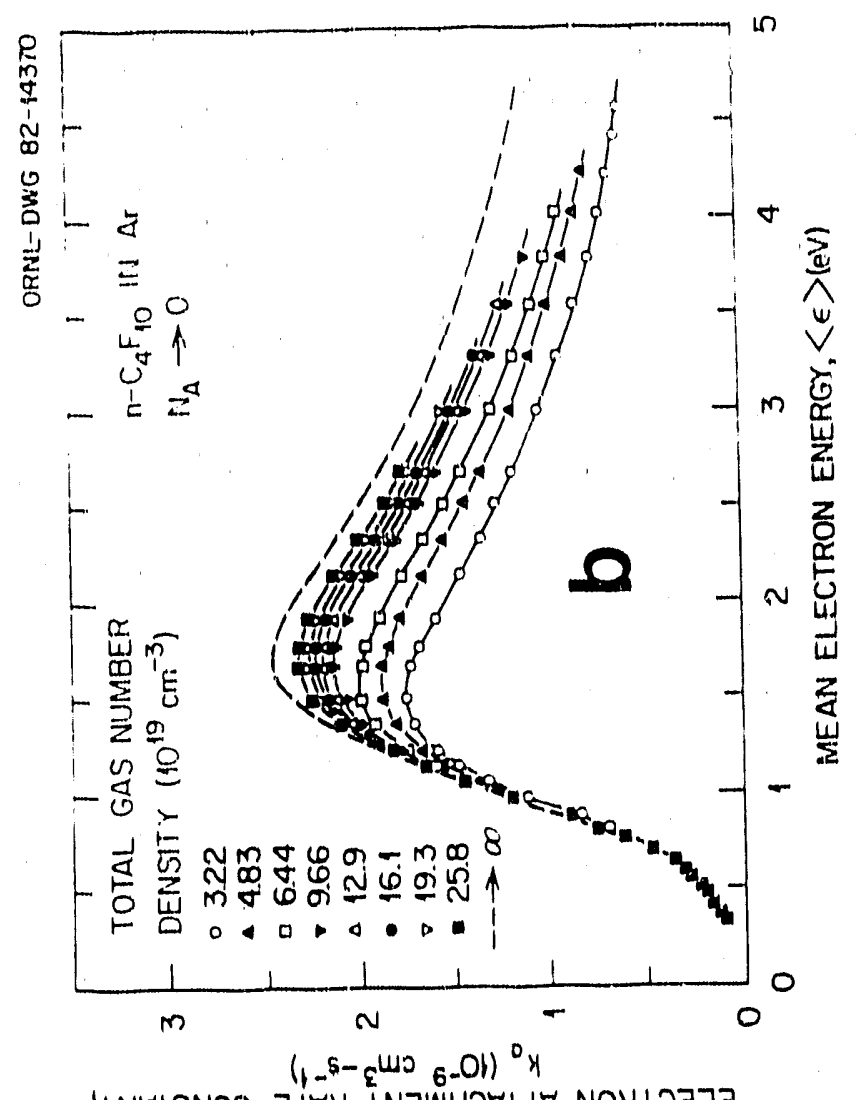

'LNV.LSNOS $\exists \perp \forall Y ~ \perp N 3 W H O \forall \perp \perp \forall$ NOY $\perp 0 \exists 7 \exists$

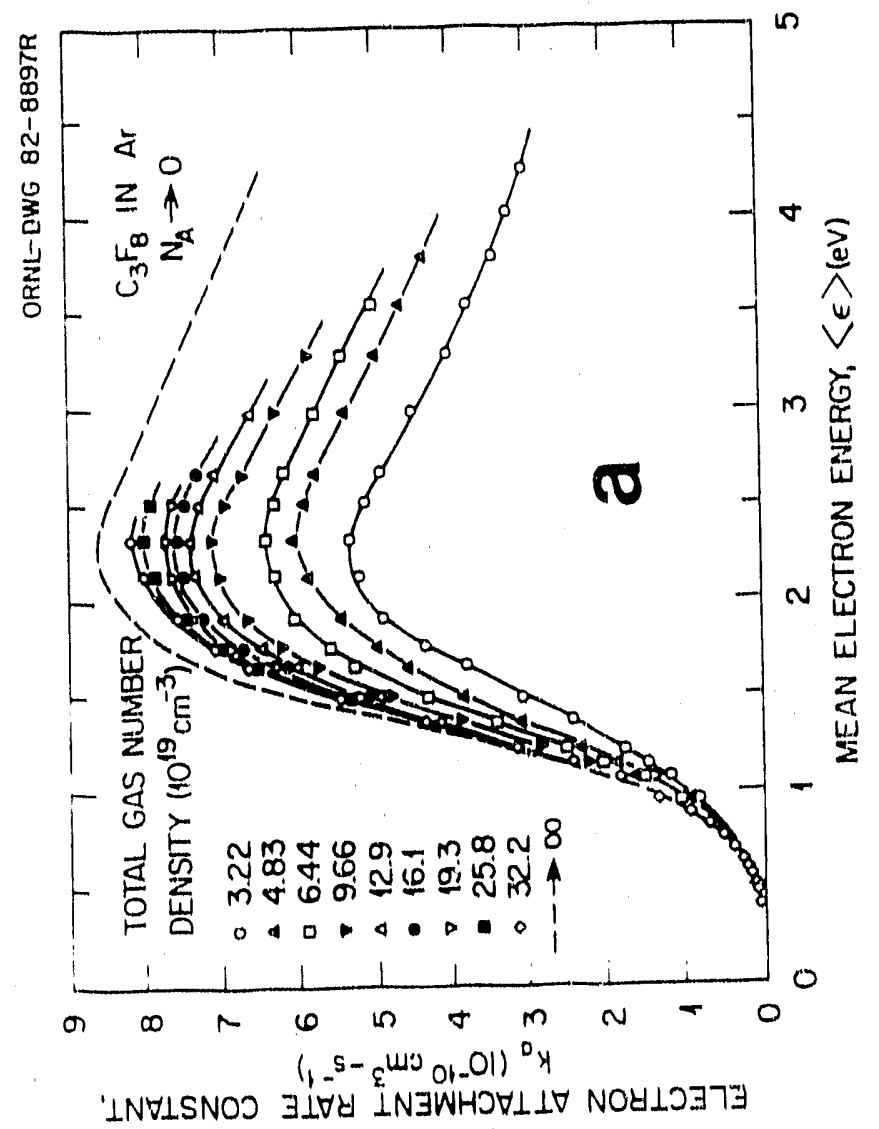




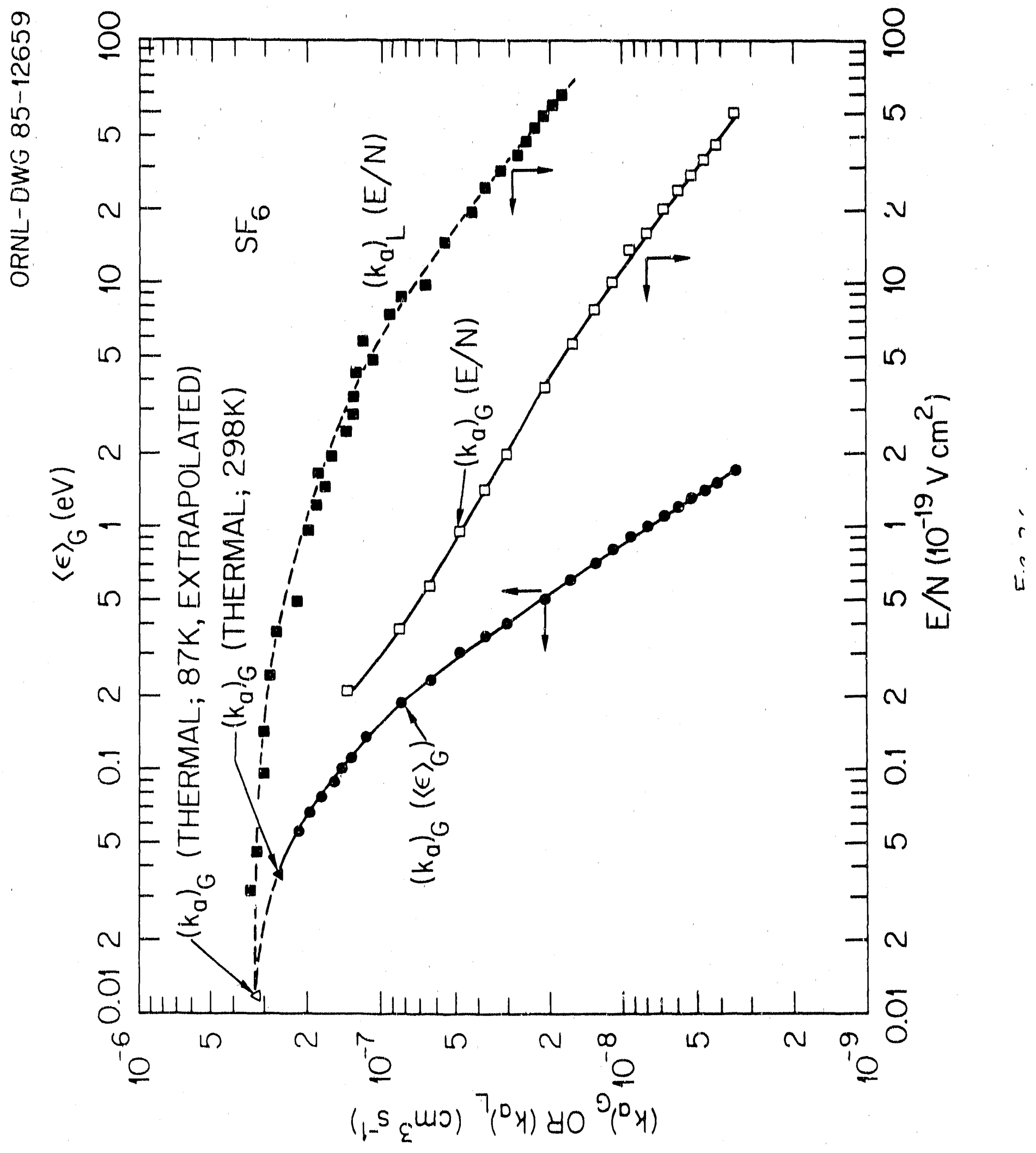


ORHL - DHG 88 - 13100

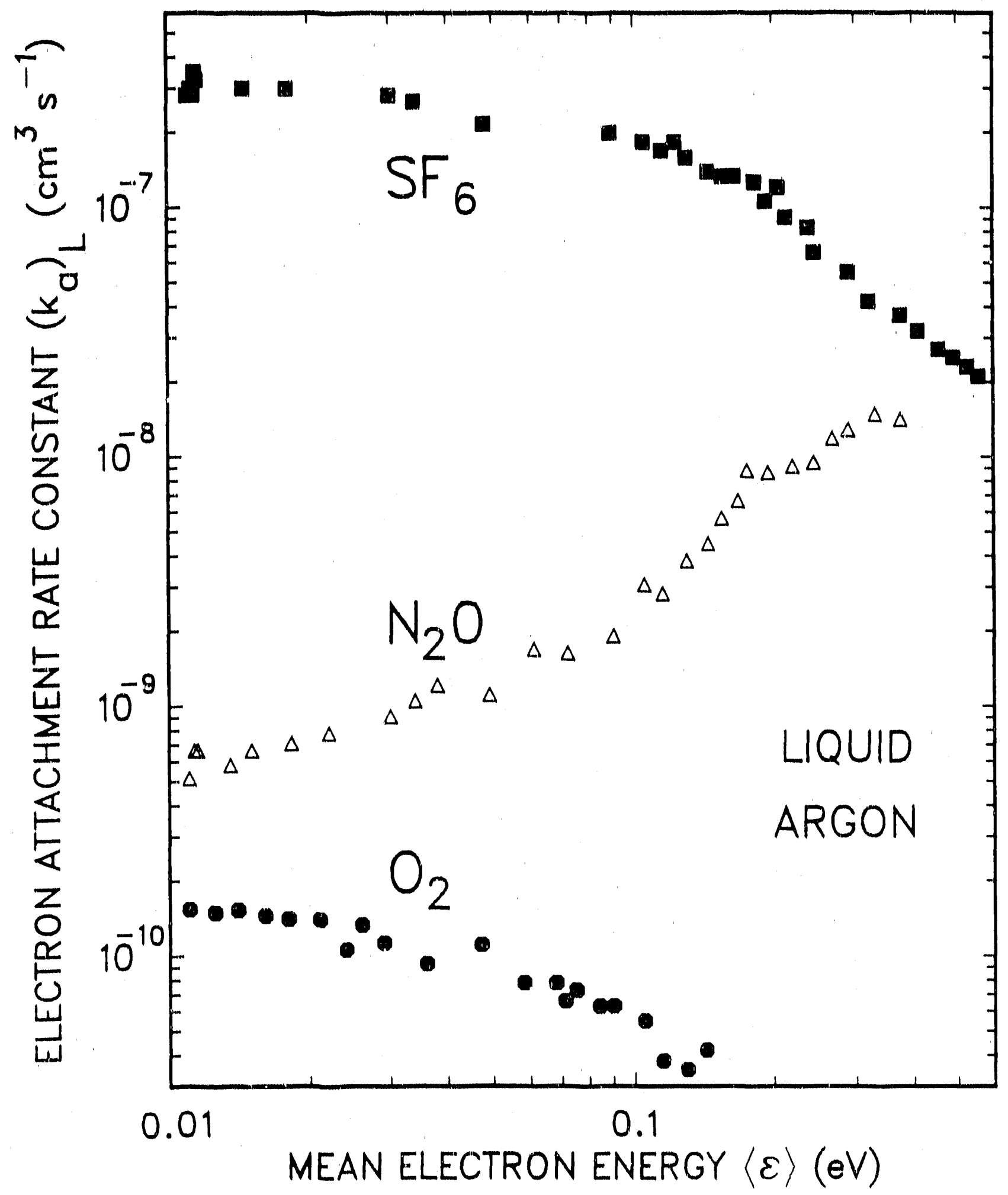

Fig. 27 


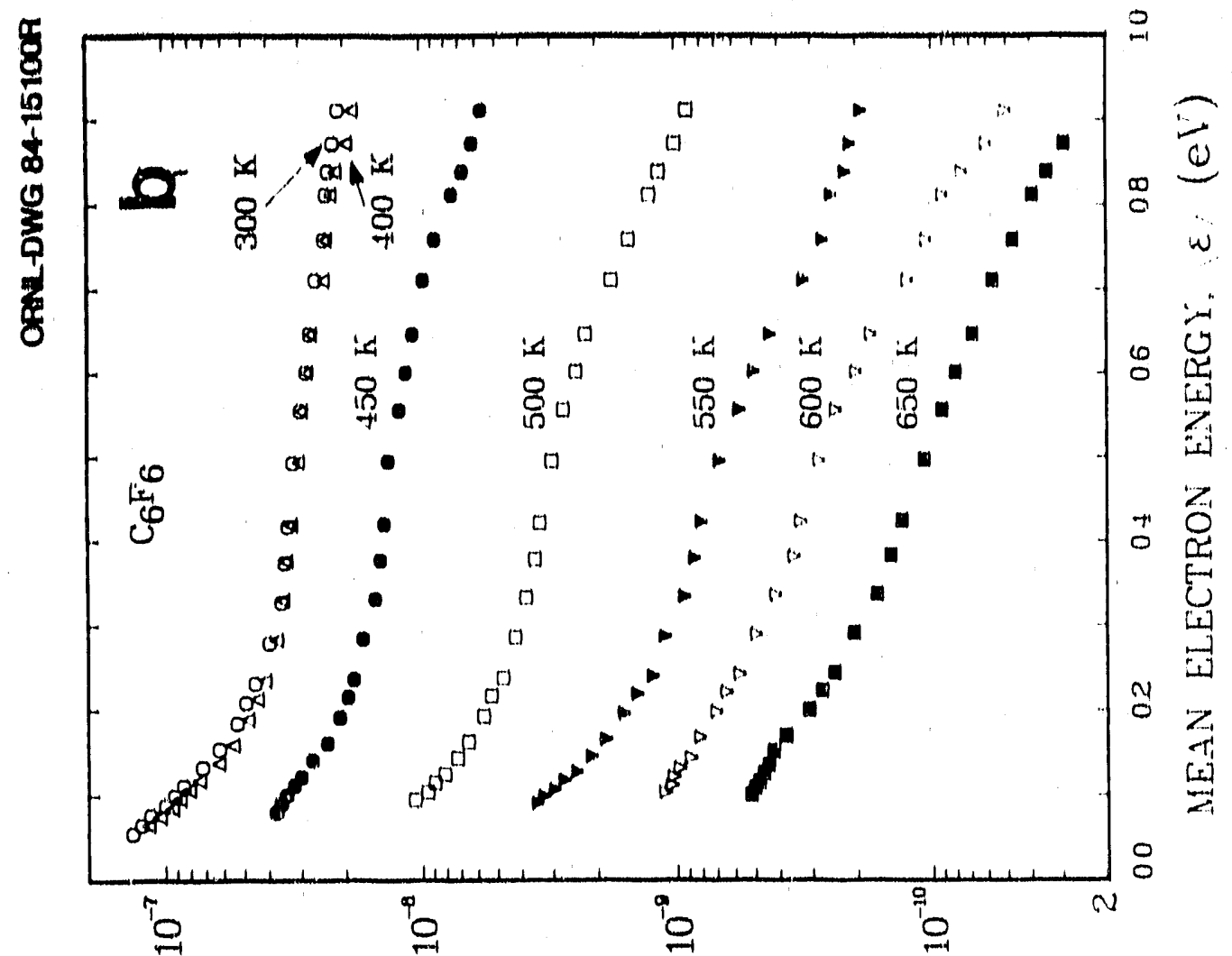

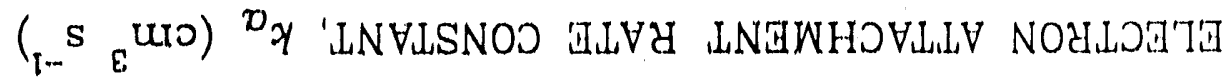

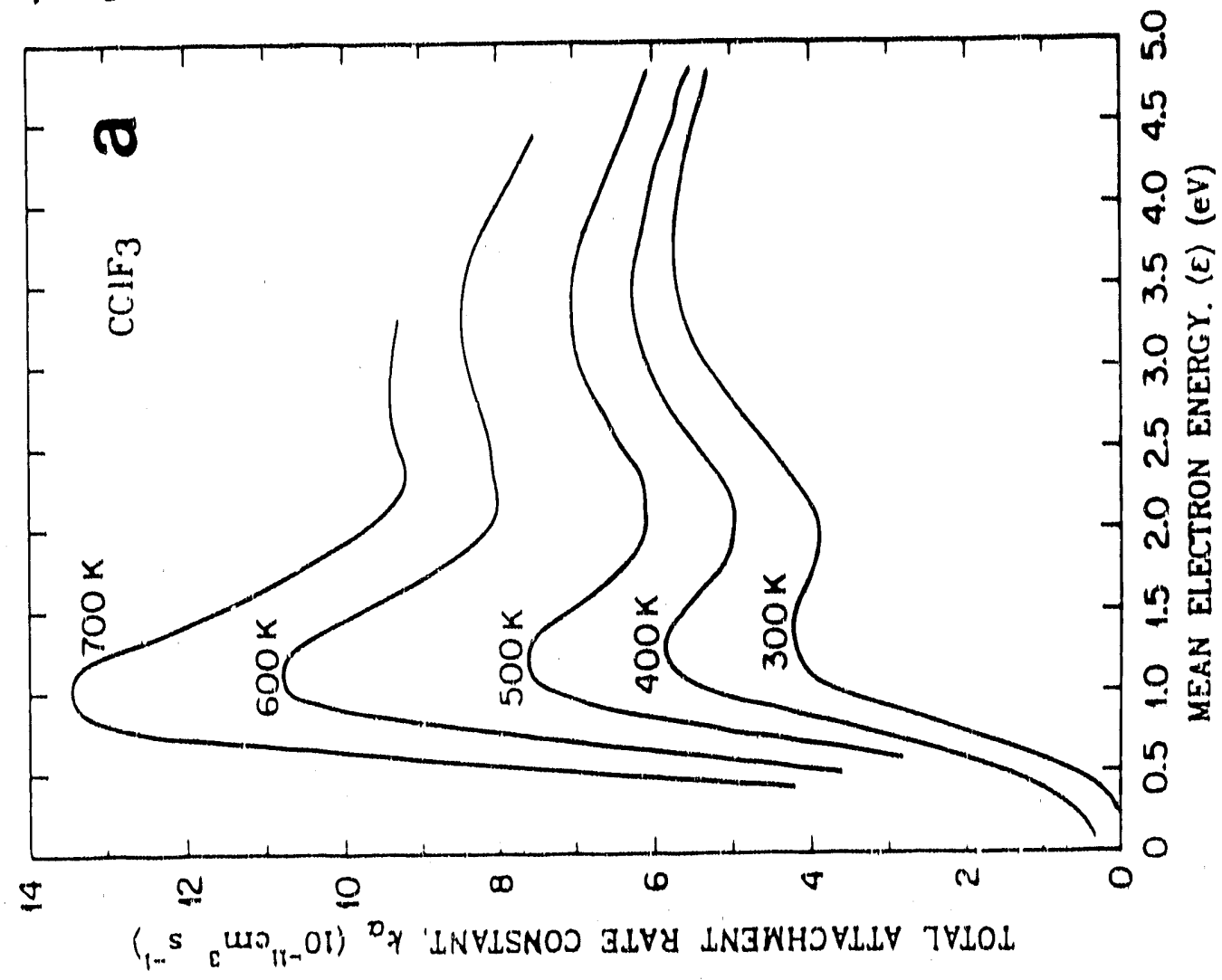




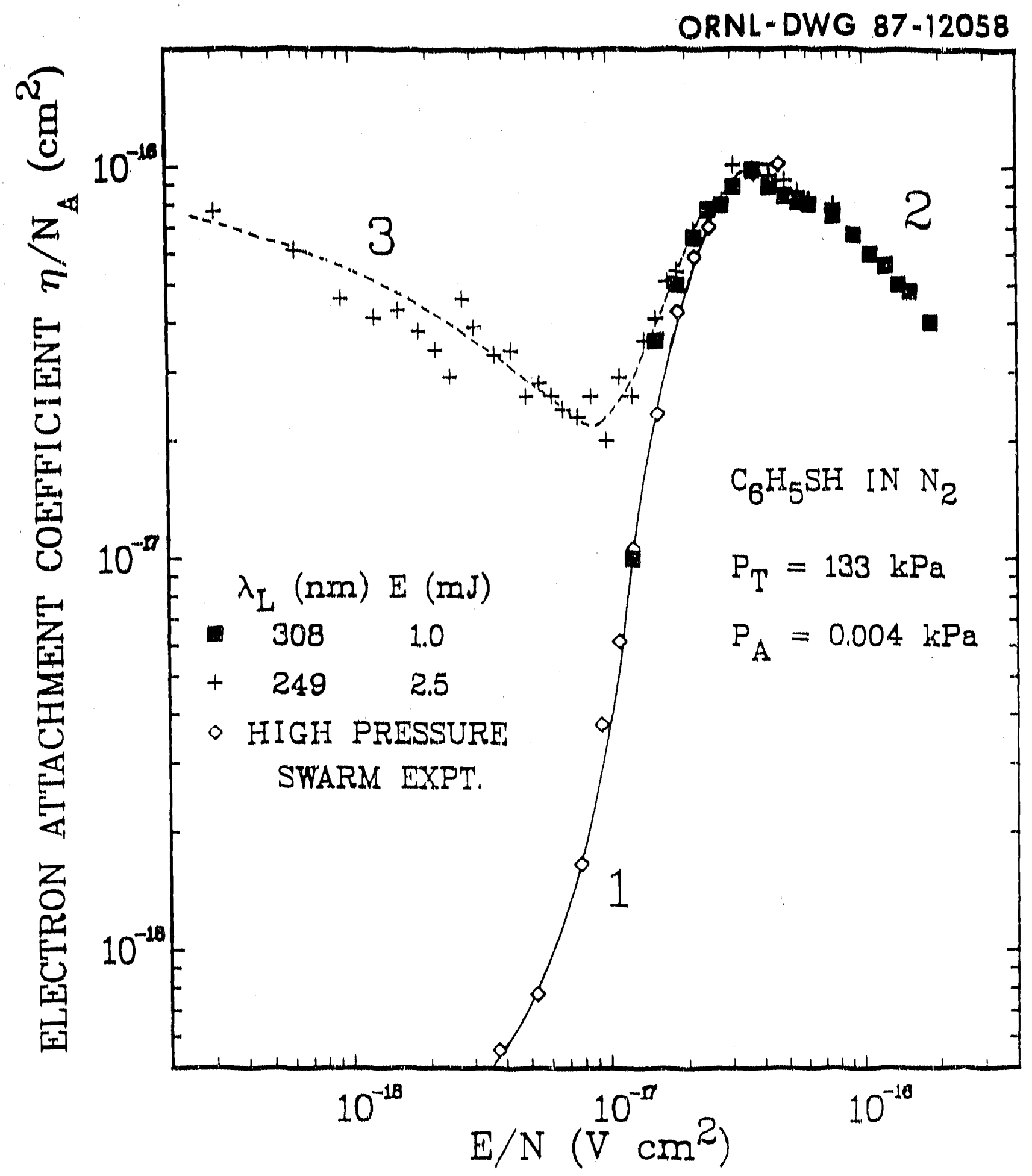

Fig. 29 

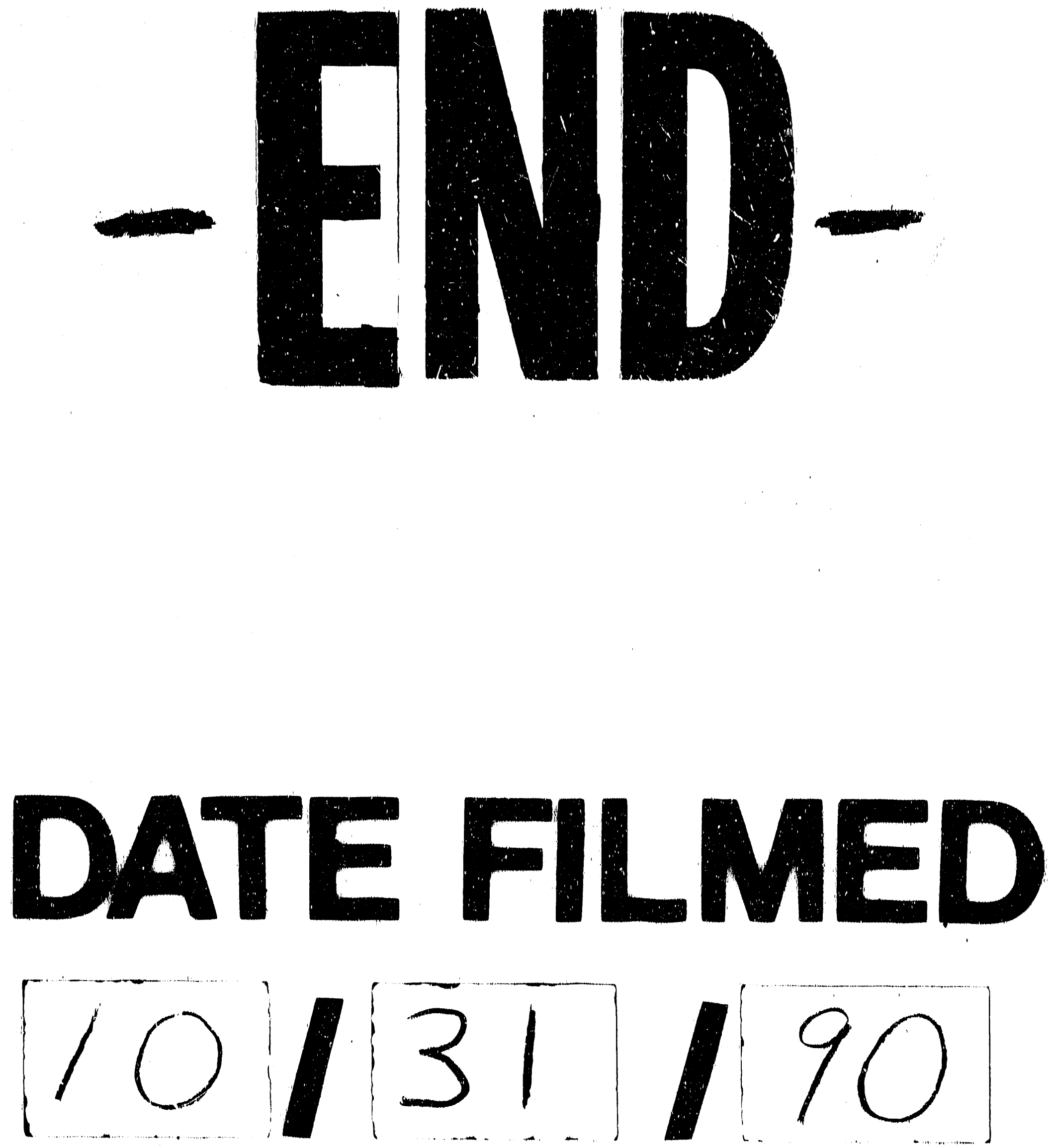